THE ROLE OF INTUITION IN ETHICAL DECISION MAKING

by

\author{
JAMES R. GUZAK \\ Presented to the Faculty of the Graduate School of \\ The University of Texas at Arlington in Partial Fulfillment \\ of the Requirements \\ for the Degree of
}

DOCTOR OF PHILOSOPHY

THE UNIVERSITY OF TEXAS AT ARLINGTON

August 2009 
Copyright @ $@$ by James R. Guzak 2009

All Rights Reserved 


\section{ACKNOWLEDGEMENTS}

I wish to thank Dr. Kenneth H. Price and Dr. Yongmei Liu for their tireless efforts in my behalf during the writing of this paper. It has been a privilege to be able to work with them and have the benefit of their insight. Additional thanks go out to members of my committee including Dr. Marcus Butts, Dr. Jim Lavelle, and a special thanks to Dr. Dan Levine for his inspiration and guidance. I also would like to thank my wife, Terressa, and my daughter, Jamey, for their understanding and patience during my time as a student. I would be remiss if I also did not extend a thank you to Dr. Jeff McGee for his personal interest in me, Dr. Gary McMahan for his guidance while in the doctoral program, and Rita Delmar for her kind assistance in all things administrative. While in the doctoral program at UTA I have been fortunate to be around a group of people who have taken a personal interest in my success. Finally, thanks to my Mom and Dad, without their support I could not have returned to college.

May 29, 2009 


\title{
ABSTRACT \\ THE ROLE OF INTUITION IN ETHICAL DECISION MAKING
}

\author{
James R. Guzak, PhD
}

The University of Texas at Arlington, 2009

Supervising Professors: Kenneth H. Price \& Yongmei Liu

The literature regarding ethical decision making has focused almost exclusively on examination of variables that test relationships between individual or situational differences and ethicality. These examinations, on the whole, have not been fruitful. Little attention has been given to the actual process of ethical decision making to try to explain how ethical decisions are made, not just under what circumstances they might occur. Recently, some authors have begun to suggest that intuition and affect might play an important role in our ethical decision making processes. This paper examines evidence as to whether the ethical decision making process uses both rationality and intuition working conjointly, and under what conditions might one or the other more strongly influence the ethical decision process.. 


\section{TABLE OF CONTENTS}

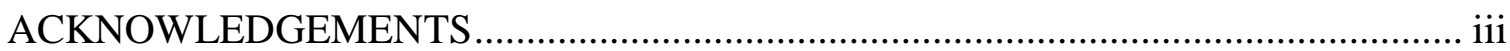

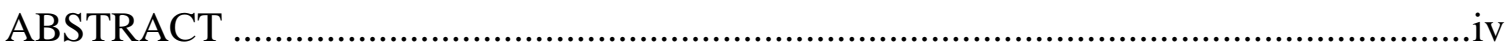

LIST OF ILLISTRATIONS ............................................................................. ix

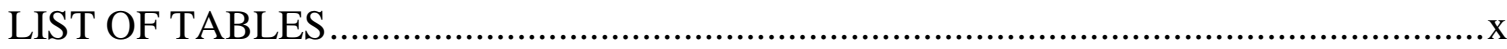

Chapter Page

1. INTRODUCTION ............................................................

2. LITERATURE REVIEW ...................................................................... 4

2.1 Ethical Business Decision Making Research ...................................4

2.1.1 Ethical Decision-Making in Business.................................4

2.1.2 Ethical Dilemmas and Ethical Decisions...........................5

2.1.3 How Ethical Decisions Differ from Other Decisions ............7

2.1.4 Theoretical Foundations For and a

Review of Ethical Decision-Making Research..................8

2.1.5 Empirical Studies........................................................ 10

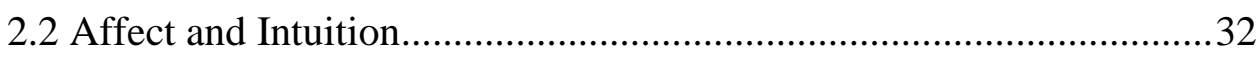

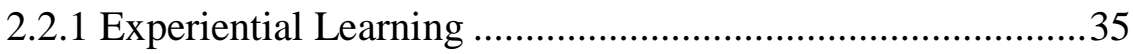

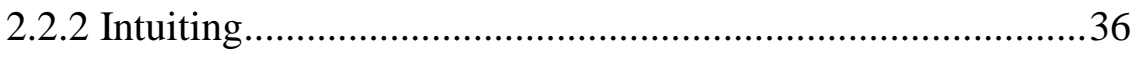

2.2.3 Intuitive Judgments and Affective Outcomes.....................38

2.2.4 Summary of Intuition..................................................41 
2.2.6 The Value of the Experiential System in Ethical Decision-Making

2.3 Conjoint Intuition and Rationality

Frameworks for Decision-Making

2.3.1 Different Types of Decisions

2.3.2 The Nature of Ethical Decisions Within

The Context of Conjoint Frameworks .............................52

2.3.3 Theoretical Models of Ethical Decision-Making that

Conjointly Incorporate Rationality and Intuition .55

2.3.4 Summary of Theoretical Dual Processing Models 57

2.4 Gaps and Inconsistencies in the Literature .58

3. HYPOTHESES AND RESEARCH METHODOLOGY ..............................60

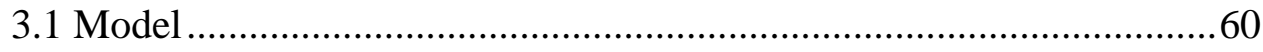

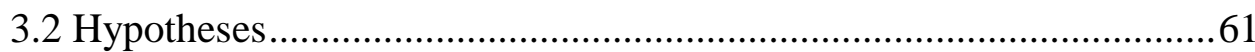

3.2.1 Intuition and Information Modality ...................................61

3.2.2 Intuition, Affect and Vivid Mental Imagery .......................66

3.2.3 Affective Priming and Decision Processing.......................72

3.2.4 Decision Making Style and Decision Outcome...................76

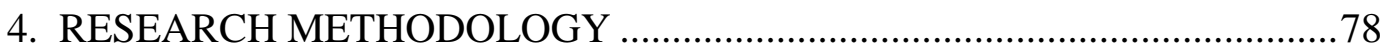

4.1 Participants and Recruitment .................................................. 78

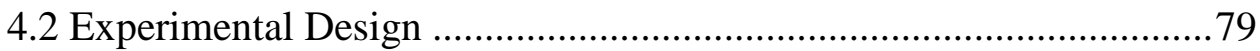

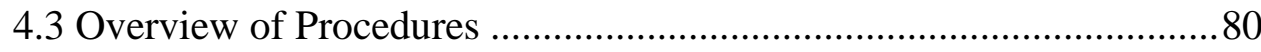

4.4 Manipulation of Independent Variables ..........................................8 81 
4.4.1 Manipulation of Initial Affective State.............................8 81

4.4.2 Manipulation of Vividness ............................................ 83

4.5 Strategy for Scale Reduction .................................................. 86

4.6 Measured by Dependent Variables ................................................ 88

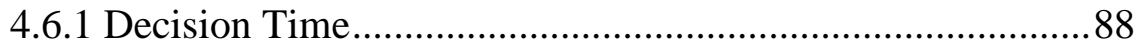

4.6.2 Decision Outcome Confidence ........................................ 88

4.6.3 Decision Approach Confidence .........................................89

4.6.4 Decision Recall Confidence ...........................................90

4.6.5 Intuitive Processing Self-Report .................................... 90

4.6.6 Rational Processing Self-Report ...................................91

4.6.7 Decision Outcome and Dilemma Information...................92

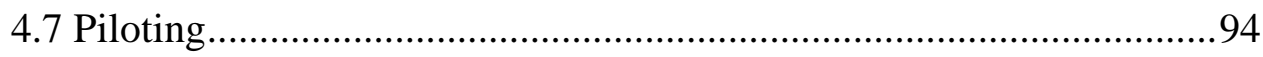

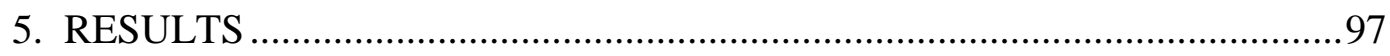

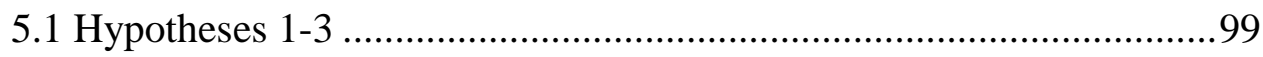

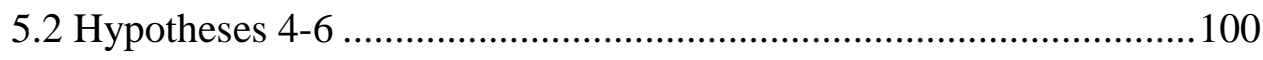

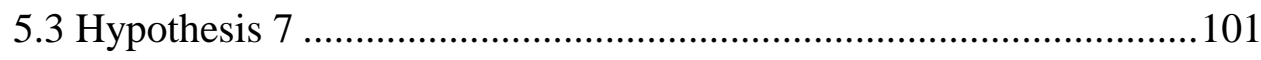

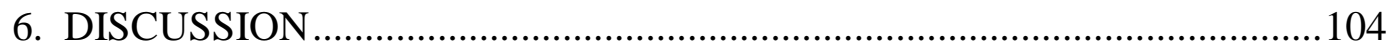

6.1 The Impact of Vividness..................................................... 106

6.2 The Impact of Affect …...................................................... 108

6.3 Decision Outcomes ............................................................ 111

6.4 Limitations: Measurement Issues and Non-Findings ....................112 


\section{APPENDIX}

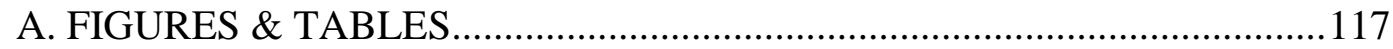

B. CASES \& MANIPULATION MATERIALS ........................................... 130

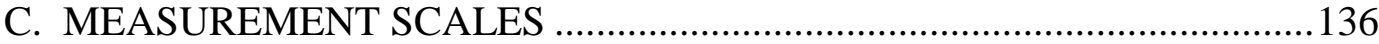

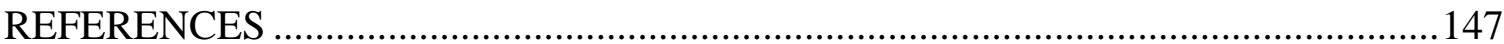

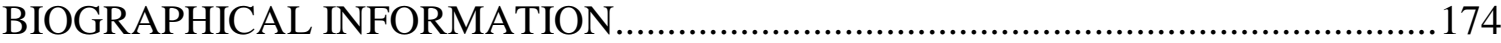




\section{LIST OF ILLUSTRATIONS}

Figure $\quad$ Page

A.1 Characteristics of Processing Strategies in

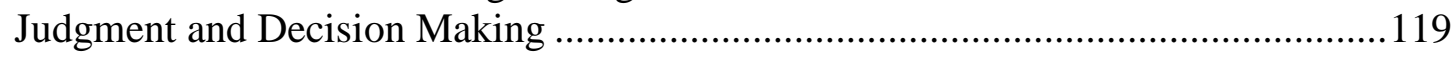

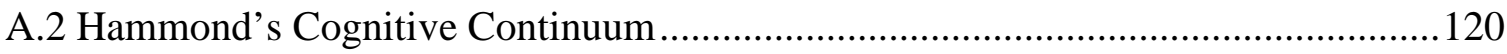

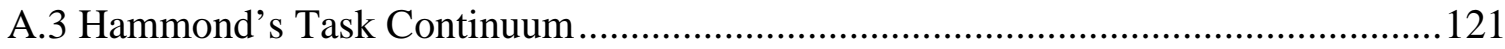

A.4 Proposed Model ............................................................................................. 122

A.5 A Structural Model of Dual Coding Theory ......................................................123

A.6 ANOVA Cell Design for the Present Study ...................................................124

A.7 Revised Model ......................................................................................... 129 


\section{LIST OF TABLES}

Table

A.1 Comparison of Experiential and

Rational System Characteristics

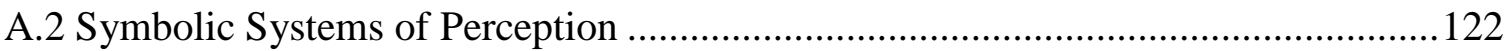

A.3 ANOVA Results for Affective State and Vividness..........................................125

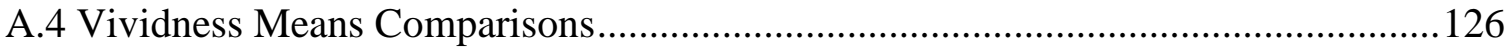

A.5 Affective State Means Comparisons........................................................................ 126

A.6 Higher Levels of Dependent Measures and

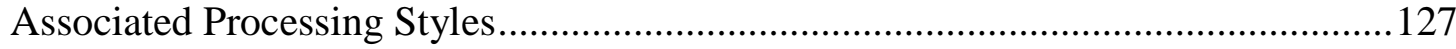

A.7 Correlations Between Dependent Measures ....................................................... 127

A.8 Decision Outcome Means Comparisons ................................................................. 128

A.9 Support for Hypotheses by Response Variable .................................................128 


\section{CHAPTER 1}

\section{INTRODUCTION}

"I think, therefore I am."

Rene Descartes

In his treatise Discourse on the Method and Principles of Philosophy, Rene Descartes (1637) distilled reason to a single immutable law from which scientific knowledge could be based. For Descartes reasoning represented the universal constant that demonstrated our existence, and thus his work highlights the importance of rational thought in the philosophy of science, the scientific method, and in the advancement of human kind.

The preeminent position of rational thought has influenced perspectives in the decision-making literature as well. Up until the last few years, scholars and practitioners alike have agreed that sound decision-making was understood to occur under only the most rational conditions (e.g. March, 1978; Simon, 1957). Important to the rationalist conception is that, to obtain optimal results, emotions and intuition should be kept out of the process of decision-making and the ideal decision-maker was understood to be cool, reasoned, and analytic (Sayegha, Anthony, \& Perrewe, 2004).

The literature on ethical decision-making in the business arena has likewise been dominated by the assumption that ethical decision-making is and should be rational and 
analytic (Sonensheim, 2007). Along with a prevailing assumption that ethical decisions are the result of reasoning, the preponderance of the literature on ethical decisionmaking has been focused on individual and situational variables that may associate with ethical awareness, judgment, intent or behavior. Yet our ability to explain ethical awareness, judgment, intent or behavior within this research stream has met with limited success (McDevitt, Giapponi, and Tromley, 2007).

We have only to turn to the many recent examples of ethical lapses in the early $21^{\text {st }}$ century to acknowledge the importance of sound ethical decision-making to our society and to the business community. Our failure to establish an understanding of why people make good and bad ethical choices highlights a critical gap in research literature that needs attention.

Against this backdrop, research is beginning to suggest that intuition and emotions play a key role in our everyday lives and in the decisions we commonly make. Intuitions are acquired through experience and good feedback from a unique area of competence, and are intimately tied to affect (Dane \& Pratt, 2007). Research on firefighters, pilots, military personnel, police officers and others has clearly demonstrated that under certain conditions rapid, intuitive decision-making can be very effective (Klein, 2003). The importance of intuition, and how intuition and emotion work with rationality in decision-making, is just starting to be understood (Epstein, 2008).

Research in ethical decision-making has only recently begun to explore intuition in decision-making processes. This paper will address this gap in the ethical decision- 
making literature by exploring the current literary stream on ethical decision-making, the role that intuition and emotion might conjointly play in the ethical decision-making process, and what factors might influence the use of intuition in ethical decision making.

In his book Descartes' Error, Anotino Damasio (1994) discusses the relationship between rational and emotional behavior. Particularly fascinating is his description of neurologically damaged patients who suffered lesions to certain cortical areas of the brain, through surgery or accident, resulting in a "disconnect" between an individual's rationality and emotion. Typically these patients retain their capacity to reason, but lacking an emotional side they remain incapable of making effective personal or social decisions. If in our ethical decision making we fail to take into consideration our intuitions and emotions, then questions might arise about our ability to make good ethical decisions as well.

The following chapter covers the state of current literature on ethical decision making and reports on recent calls for considering intuition's role in ethical decision making. Subsequent chapters suggest how intuition might be influenced by possible antecedents, and these factors are tested in research. The research questions in this paper are: What role does intuition play in ethical decision making and what could influence a person to be more intuitive in ethical decision making? 


\section{CHAPTER 2}

\section{LITERATURE REVIEW}

\subsection{Ethical Business Decision Making Research}

\subsubsection{Ethical Decision-Making in Business}

This research will focus on the specific area of ethical decision-making that occurs within the context of business. Business decisions commonly involve work related ethical dilemmas and work related ethical judgments (Guy, 1990). Business ethics is commonly divided into two areas consisting of normative and descriptive ethics (O'Fallon and Butterfield, 2005). The former resides largely in the realm of moral philosophy and theology and serves to guide individuals as to how they should behave. The latter, descriptive (or empirical) ethics, resides primarily in the sphere of management and business decision-making and is concerned with explaining and predicting individuals' actual ethical behavior. This paper addresses descriptive ethics.

Ethical decisions in the business arena are important because they can have significant implications for business as well as society. For instance, as Vice President of Corporate Development at Enron Corporation in early 2002 Sherron Watkins made an ethical decision to blow the whistle to the Securities Exchange Commission (SEC) on Enron's illegal accounting practices. The result contributed to the demise of a company once worth $\$ 63$ billion representing the second largest bankruptcy in U.S. 
history (BankruptcyData.com, 2008), the loss of 4,000 jobs, prosecution of former Enron executives and major new legislation in the form of the Sarbanes-Oxley Act (SOX) (Miceli, Near, and Dworkin, 2008). Another example with more positive consequences is the decision by Johnson \& Johnson executives to react aggressively in the wake of outside tampering of Tylenol bottles that caused seven deaths from cyanide poisoning in 1982. Johnson \& Johnson executives made a decision to recall and destroy large quantities of Tylenol inventory resulting in significant scrap losses, and they incurred additional expenses by introducing tamper evident packaging for future production. Though Johnson \& Johnson absorbed large financial charges, advocates for consumers praised Johnson \& Johnson's response that today remains a textbook case for the positive impact of good ethical decision-making (Sonenshein, 2005).

\subsubsection{Ethical Dilemmas and Ethical Decisions}

Ethical decision-making has been a topic of philosophical thought since the dawn of recorded history; certainly the classical Greek philosophers such as Socrates, Plato and Aristotle remain influential in this area of study even today as our society continues to grapple with the same elemental philosophical questions regarding morality and ethics (e.g. Hartman, 2008). Making decisions has always been one of the most crucial activities of human beings; ethical decisions are among the most intricate and vexing and historically have involved both philosophy and research in their study (Brans, 2000). Moral or ethical decisions are distinct from other kinds of decisions because they stem from a specific type of dilemma in which the decision-maker's 
options lead to material and psychological consequences to others, and the violation of rights and conflicts between opposing claims (Garcia and Ostrosky-Solis, 2006).

According to Loewenberg and Dolgoff (1996), a dilemma is a problem, situation, or predicament which seems to defy a satisfactory solution. The word dilemma comes from two Greek roots: di (double) and lemma (propositions). A dilemma is therefore a predicament in which the decision-maker must choose between two options of near or equal value. An ethical or moral dilemma is therefore encountered in a situation where a decision-maker must choose the right moral course of action in a predicament from which there are two competing and seemingly equal choices that are in conflict with one another. An ethical dilemma might also be encountered when the decision-maker must choose the right moral course of action without knowing in advance the actual outcome of the decision and with the possibility that the course of action could not be beneficial for all parties involved or might even harm a party. In other instances, ethical dilemmas that confront individuals could result from decision options that are not well defined, or from solutions that create additional known or unknown problems and harm for the decision maker or for others (Tallant and Ryberg, 2008).

Rest (1986) offers that an ethical decision is a considered opinion of what should be done when confronted with an ethical dilemma. Guy (1990) proposes that ethical decisions involve a moral dilemma that touches on two or more personal core values and involves uncertainty and possibly unknown consequences. Trevino and Youngblood (1990) advise that ethical decisions have a normative-affective component, 
and that individuals often struggle with their feelings as to whether they are making a good decision. Jones (1991) suggests that an ethical decision is one that is acceptable both legally and morally to the larger community.

\subsubsection{How Ethical Decisions Differ From Other Decisions}

Mathieson (2007) provides a framework perspective for understanding how ethical decisions compare to other decisions using a two dimensional continuum. She borrows from Campbell (1988) who writes that decisions can be classified along the dimension of task complexity from simple to fuzzy. On one end of this continuum are simple tasks, which have a single solution and no conflicts, and at the other end are fuzzy tasks which are those that have multiple solutions and conflicting situations. Mathieson (2007) suggests ethical decisions commonly involve uncertainty and confliction and therefore can be classified as fuzzy tasks. As a second dimension, Mathieson (2007) also contends that tasks can be classified as either intellective or judgmental following Langhlin (1980). Intellective tasks have a correct solution, but judgmental tasks have no discernibly correct answer, therefore ethical decisions can be also be viewed as judgmental. Ethical decisions are therefore different from other decisions because they can be classified within this framework as both fuzzy and judgmental, and thus are among the most difficult to make.

Given this background on the characteristics of ethical decisions the following section reviews the empirical and theoretical literature on ethical decisions with an emphasis on decisions as they unfold in a business context. This literature has focused primarily on associations between constructs that might contribute to making ethical 
decisions, and the present paper goes on to identify the relatively few constructs have been reliable predictors of ethical business decisions. Significantly, ethical business decision-making literature rests upon an underlying assumption regarding how people make ethical decisions, an assumption that has recently been called into question.

\subsubsection{Theoretical Foundations For and a Review of Ethical Decision-Making Research}

The theoretical underpinning for modern ethical decision-making research in the business context stems from Rest's (1986) foundational work that suggests that people move sequentially along a four-step process of decision-making. These steps include 1) moral awareness-being able to interpret the situation as being moral; 2) moral judgment-deciding which course of action is morally right; 3) moral intentprioritizing moral values over other values; and 4) moral behavior-executing and implementing the moral intention. Traditionally these four steps (awareness, judgment, intent, and behavior) have been treated as outcome variables while researchers have looked at individual and organizational factors as predictor variables (O'Fallon and Butterfield, 2005). In this way researchers have attempted to determine what characteristics of individuals or situations are associated with higher levels of ethical awareness, ethical judgment, ethical intent or ethical behavior.

Jones (1991) made significant theoretical contributions in the area of ethical decision-making by organizing a number of disparate theoretical perspectives and recasting them within Rest's (1986) four-step ethical decision-making framework. Importantly he also introduces the construct of moral intensity as the "extent of issuerelated moral imperative in a situation" (Jones, 1991, p. 372). Moral intensity is a 
multi-dimensional construct that contains a number of facets. These include the magnitude of consequences of an immoral act (the sum of the harm or benefit to victims or beneficiaries in a moral act), social consensus (the degree of social acceptance that a given act is good or evil), probability of effect (the probability that a given act might actually take place and the probability of its potential for harm or good), temporal immediacy (the length of time between the present and the onset of consequences of the moral act in question, proximity (feeling of nearness that the moral agent has for victims) and concentration of effect (an inverse function of the number of people affected by an act of given magnitude). In essence the Jones model suggests that Rest's (1986) framework is contingent upon the nature of the ethical dilemma that is being decided upon. This implies that the greater the moral intensity of any given ethical situation the higher the level of an individual's ethical awareness, the more likely for that person to render an ethical judgment, the greater the level of the individual's ethical intent, and the more likely the individual is to exhibit ethical behavior.

Following the theoretical contributions of Rest (1986) and Jones (1991), subsequent empirical research in ethical decision making has primarily focused on testing constructs that might explain Rest's (1986) outcomes of ethical awareness, ethical judgment, ethical intent or ethical behavior that commonly are used by researchers as dependent measures. Explanatory, independent variables that have been emphasized can be categorized into individual constructs and organizational constructs, and Jones' (1991) moral intensity construct (Ford and Richardson, 1994; Loe, Ferrell, and Mansfield, 2000; McDevitt, Giapponi, and Tromley, 2007; O'Fallon and 
Butterfield, 2005). For instance, individual constructs, such as the decision maker's gender, age, job experience, etc., have to do with individual traits or the things a decision maker brings to the decision situation. Organizational constructs, for example organization size, industry, or whether the company has an explicit code of ethics, have to do with the circumstances that decision makers find themselves in (O'Fallon and Butterfield, 2005). The orientations of these studies explore under what conditions a person might be more ethically aware, make more ethical judgments, and intend to or actually behave more ethically. As findings are dispersed across these multiple dependent measures, for simplicity, and to be able to draw general conclusions, this paper makes use of the term aspects of ethicality as a way to group these commonly used dependent measures of ethical awareness, judgment, intent and behavior into a single category.

\subsubsection{Empirical Studies}

There are three comprehensive literature reviews on ethical decision making that have summarized the literature. Ford and Richardson (1994) document research up to and including 1992. Loe, Ferrell and Mansfield (2000) examine studies reported on by Ford and Richardson (1994) as well as additional work up through 1997. O'Fallon and Butterfield (2005) report studies included in Ford and Richardson (1994) and Loe et al. (2000) as well as new work through 2003. The present paper relies on the work of these three groups of researchers to summarize findings, particularly O'Fallon and Butterfield (2005) who provide a more recent and encompassing viewpoint of the three literary reviews. Additionally more current studies are also considered and contrasted with 
prior research for the purpose of examining the consistency of findings within this literature stream.

\subsubsection{Individual Difference Variables}

Research studying individual difference variables seeks possible associations between unique characteristics or traits of decision makers and aspects of ethicality. For instance, gender is the most frequently studied individual difference characteristic. In their review of the literature O'Fallon and Butterfield (2005) concluded that there are no consistent associations between sex and aspects of ethicality, a conclusion shared more recently by Valentine \& Rittenburg (2007).

Nationality, another frequently researched individual difference variable, also appears to be inconsistently associated with aspects of ethicality. O'Fallon and Butterfield (2005) struggled to draw conclusions from studies of this variable because the majority of these studies were not directly comparable. Of the studies that could be directly compared, those that contrast U.S. citizens to other nations, inconsistencies in findings cause O'Fallon and Butterfield (2005) to note that no firm conclusions can be drawn regarding the association of nationality with aspects of ethicality.

Age of the decision maker has also been considered. Generally researchers hypothesize that increasing age may be related to aspects of ethicality. Reviewing pre1996 findings, Loe and his colleagues (2000) suggest that age-related research does demonstrate a positive relationship between age and aspects of ethicality. However examination of more recent literature by O'Fallon and Butterfield (2005) calls this 
conclusion into question. O'Fallon and Butterfield (2005) conclude, "research on age has produced only mixed and inconsistent results."

Cognitive moral development (CMD) refers to Kohlberg's (1969) stage model of moral reasoning development. Kohlberg (1969) proposed that individuals, as they grow to adulthood, move through the CMD stages sequentially from a self-centered interpretation as to what is proper moral behavior through to a socially conscious and morally responsible perspective. While acknowledging "notable exceptions" O'Fallon and Butterfield (2005) conclude that research generally suggests a positive relationship between CMD and one or more aspects of ethicality.

However, O'Fallon and Butterfield (2005) did not consider results in the whistle blowing literature. Whistle blowing is defined as "the disclosure by organization members (former or current) of illegal, immoral, or illegitimate practices under the control of their employers to persons or organizations that may be able to effect action." (Near and Miceli, 1985, p. 4). Whistle blowing can be considered a type of ethical decision because it involves a dilemma, either to remain silent and thus maintain the stability of the status quo or call attention to unethical situations, and involving the trade-off of potential harm and benefit to different parties (Miceli, Near, and Dworkin, 2008). Brabeck (1984) found a positive relationship between CMD levels and whistle blowing, but a replication by Miceli and her colleagues (1991) documented that lower levels of CMD were associated with higher levels of whistle blowing.

A more recent study by Monga (2007) found that respondents scored higher on CMD when subjects considered vignettes placed outside of a business context than 
when considering vignettes having to do with a business setting. The implications are that CMD might not be a reliable metric of ethical reasoning maturity for individuals in a work context. Additionally Tsui and Windsor (2001) found evidence that higher CMD scores are not consistent with aspects of ethicality in collectivist societies, such as those found in the Far East, thus casting doubt on CMD's generalizablity. These types of inconsistencies are illustrated in research reported by Ge and Thomas (2008). They document that Canadian decision makers displayed higher levels of ethical intentions than Chinese decision makers in only two of four scenarios despite Canadians having higher levels of CMD than their Chinese counterparts. Considering O'Fallon and Butterfield's (2005) acknowledgment of notable exceptions as well as evidence not taken into account in their review, the relationship between CMD and aspects of ethicality might be more complex than first thought.

Individual dimensions of education, experience, and job tenure are routinely examined within the same study but are also scrutinized separately on occasion. Generally researchers hypothesize that more education, experience or tenure is related positively to aspects of ethicality. Twenty-three studies reviewed by Ford and Richardson (1994), Loe et al., (2000) and O'Fallon and Butterfield (2005) examine years of education and a possible relationship to aspects of ethicality. Of these only eight suggest a positive association between education and aspects of ethicality, while two other studies reported a reverse relationship (e.g. Kaynama, King and Smith, 1996). Loe and his colleagues (2000, p. 187) conclude, "we do not clearly understand the role of experience and education in ethical decision making in organizations." Ford and 
Richardson (1994, p. 211), Loe et al. (2000), and O'Fallon and Butterfield (2005) all conclude that results documenting a relationship between age, work experience, and tenure are at best inconclusive.

A number of value orientation constructs have been examined in the literature on ethical decision-making including the construct of idealism/relativism. Forsyth (1980) defines idealism as the degree to which individuals "assume that desirable consequences can, with the 'right' action, always be obtained', (p. 176). According to Forsyth, idealistic individuals adhere to moral absolutes when making ethical judgments. He explained that "Highly idealistic individuals feel that harming others is always avoidable" while the less idealistic individuals "assume that harm will sometimes be necessary to produce good" (Forsyth, 1992, p. 462). On the other hand, Forsyth (1980, p. 175) defines relativism as "the extent to which an individual rejects universal moral rules", when making ethical judgments. Relativists generally feel that moral actions depend upon the nature of the situation and when judging situations they weigh the circumstances more than ethical principles (Forsyth, 1992, p. 462).

Together Loe et al. (2000) and O'Fallon and Butterfield (2005) identify sixteen studies dealing with idealism's relationship to aspects of ethicality. While fifteen of these studies do provide supporting evidence, this evidence is demonstrable only for two (of four) of Rest's (1986) commonly accepted dependent measures of ethical awareness and ethical judgment. Interestingly, three of the same studies that found support for idealism's positive relationship with ethical judgment also found no support for a relationship with ethical intent (Bass, Barnett and Brown, 1998; Bass, Barnett and 
Brown, 1999; Sivadas, Kleiser, Kellaris and Dahlstrom, 2003). In their literature review O'Fallon and Butterfield (2005) suggest that past literature provides supporting evidence that higher levels of idealism are generally positively related to ethicality, while higher levels of relativism are negatively related.

More recently Singhapakdi, Gopinath, Marta, and Carter (2008) found idealism positively associated with awareness but idealism did not have a significant relationship with ethical intent or behavior. On the other hand relativism did not associate with awareness but did negatively influence ethical intent and ethical behavior through the mediator of "perceived ethical problem". In yet another study Singhapakdi and Marta (2005) found evidence that associated relativism negatively to ethical intent but idealism had no relationship to ethical intent. This suggests there might be a more complex relationship between idealism, relativism and aspects of ethicality than previous literature has suggested.

The construct of personal values has also been examined in the form of deontic or teleological orientation. Deontic orientation is the extent to which a person believes an action is consistent with an individual's duties or unwritten obligations while a teleological orientation is one that is centered on a pragmatic cost benefit analysis (Cohen, Pant, and Sharp, 2001). O'Fallon and Butterfield conclude that, overall, studies demonstrate higher levels of deontology are generally positively related to aspects of ethicality while higher levels of teleology reveal a negative relationship.

However, Ladkin (2006) and Micewski and Troy (2007) cast doubt on deontic orientation's reliability as a predictor because of the possibility that deontic orientation 
fails to account for the relational and contextual nature of ethical decisions. These researchers suggest that the framing of any situation may alter the individual's application of deontic duty, such that decision makers may respond differently in similar situations given different framing references of the situation context.

Past research on the construct of Machiavellianism also seems to support an association with aspects of ethicality (O'Fallon and Butterfield, 2005). People with high levels of machiavellianism employ aggressive and devious methods to achieve goals without regard for the feelings, rights, and needs of other people (Wilson, Near, and Miller, 1996) suggesting a negative relationship with aspects of ethicality. Of the twelve studies in literature reviews completed by Ford and Richardson (1994), Loe et al., (2000) and O'Fallon and Butterfield (2005), ten provide supporting evidence linking hypothesized lower levels of Machiavellianism with aspects of ethicality.

In more recent research Tang and Chen (2008) found support for past findings, but reached a different conclusion regarding Machiavellianism. They reported Machiavellianism mediates the relationship between love of money and unethical behavior, but these researchers suggest love of money is the more important construct in this relationship. Tang, Chen, and Sutarso (2008) provide evidence that suggests love of money is correlated to Machiavellianism and correlates highly with risk tolerance as well. These recent findings provide evidence that suggests Machiavellianism may be a less important construct than love of money for predicting aspects of ethicality, but to date love of money has received only limited research attention. 
The degree of religiousness or spirituality a person holds has also been an objective of research efforts with researchers testing whether higher levels of religiousness are associated with aspects of ethicality. Religions, through the values they embody, often build the basis for what is considered right and wrong (Turner, 1997). Loe et al. (2000) and O'Fallon and Butterfield (2005) conclude that past research demonstrates support for a positive association between religiousness and aspects of ethicality. However, more recent work by Pabroteeah, Hoegl, and Cullen (2008) reached a different conclusion regarding the association between religiousness and aspects of ethicality when examining studies in both management and marketing literatures. Using data from forty-four different nations, provided by the international World Values Survey (World Values Study Group, 2000), these researchers tested a model incorporating a cognitive knowledge dimension of religion, an affective-feelings dimension toward religion, and a behavioral or performance manifestation dimension of being religious, finding negative relationships to ethical awareness in all three components.

The influence on the individual by significant others has also been targeted by researchers who hypothesize that peers, supervisors, or other significant people inside or outside of the workplace are the source of social norms that might have either a positive or even a negative association with aspects of ethicality. Solomon Asch (1955), in his notable work on line length observations, demonstrated that social influence could regularly cause individuals to make incorrect statements that align themselves with peer influence. Both Trevino (1986) and Jones (1991) identify social 
influence from significant others as a determinant of individuals' moral intentions. In their respective reviews Loe et al. (2000) and O'Fallon and Butterfield (2005) conclude that past research provides strong support for the importance of the influence of significant others on aspects of ethicality, although the direction can vary according to the type of social support.

In summary, while a few individual difference variables, such as idealism, relativism and the influence of significant others, do seem to be useful in predicting aspects of ethicality the larger body of literature in this area does not consistently demonstrate how characteristics of individuals matter in ethical decision making. Additionally more recent research casts doubt on the efficacy of some variables that were previously assumed to be associated with aspects of ethicality.

\subsubsection{Organizational Variables}

Organizational variables attempt to explain ethicality by looking outside the individual for factors in the work situation that relate to aspects of ethicality. Organizational variables that have attracted the most research attention include whether a code of ethics has been formally adopted by an organization, whether a code of ethics is actually used or attended to by the organization, ethical climate or culture, type of industry, enforcement of rewards and sanctions, and organizational size (O'Fallon and Butterfield, 2005).

As the use of codes of ethics by listed companies is now legislatively mandated under the Sarbanes Oxley Act (SOX), research into the use of codes of ethics in organizations has recently gained more attention (Myers, 2003). Researchers 
hypothesize that organizational use of codes of ethics is associated with aspects of ethicality (O'Fallon and Butterfield, 2005). In their review O'Fallon and Butterfield (2005) conclude that the formal adoption of a code of ethics within the organization is positively associated with aspects of ethicality.

However, O'Fallon and Butterfield (2005) do not review Matthews' (1987) examination of 202 Fortune 500 firms with codes of ethics, nor his conclusion that there was little evidence to suggest a link between ethical codes and ethical behavior. Similarly McKendall, DeMarr and Jones-Rikkers' (2002) study of 108 large U.S. corporations also went unnoticed by O'Fallon and Butterfield (2005). Their report concludes that codes are ineffective in predicting ethical behavior.

More recent evidence also suggests a more complicated relationship might exist between use of codes of ethics and aspects of ethicality than was taken into account in the review by O'Fallon and Butterfield (2005). For instance, Stevens and his associates (2005) point out that codes of ethics are used for decision making only when there is pressure from stakeholders, if decision makers perceive codes add to internal ethical culture and external reputation, and if there is supporting ethical training integrating the code with daily activities. Pucetaite and Lamsa (2008) theorize and provide empirical support to suggest that organizational trust must precede the use of codes of ethics for codes to be effective in predicting ethical behavior. Stevens (2008) reviews studies of ethical codes published since 2000, providing evidence that codes of ethics are not effective unless integrated into corporate culture and embraced by leaders. Finally a more recent review of the effectiveness of business codes, conducted by Kaptein and 
Schwartz (2008) concludes that research on codes of ethics has produced only divergent findings due to varying definitions of key terms, deficiencies in empirical data and methodologies, and a general lack of theory.

The level of ethical climate or culture within an organization represents another organizational construct focus for researchers that has generated frequent interest. Culture and climate research postulates that principled culture might be positively associated with aspects of ethicality. This expectation is also supported by literature that is outside of the scope of ethical decision making literature where there is evidence to suggest that organization culture can affect an individual's actions and attitudes (e.g. O'Reilly and Chatman, 1996). This might be particularly true in situations not governed by formal control systems (Trevino and Weaver, 2001), and culture might affect individual behavior through a variety of mechanisms including goal alignment and norm enforcement (Caldwell and Moberg, 2007). The preponderance of evidence regarding climate and culture prompts O'Fallon and Butterfield (2005) to suggest that research generally supports the existence of this relationship.

What is not considered in the studies reviewed by these researchers is the extent to which individuals with a strong self-identity are less influenced by cultural cues. For instance, Chatman and Barsade (1995) demonstrate that individuals who have a strong individualistic disposition are less likely to be influenced by organizational cultures. Tett and Burnett (2003) provide support to the position that if a particular characteristic is central to one's identity then situational cues, such as those provided by culture, will have less impact on behavior if that cue is not an important part of the individual's 
sense of self (Caldwell and Moberg, 2007). Yet another concern in this stream of research is whether conflicting goals can overcome cultural influence, for example the pressure to perform can increase unethical behavior (Robertson and Rymon, 2001). Additionally research has yet to fully explore the influence of ethical microclimates that might exist within the firm (Mathieson, 2007).

Organizational size is another variable frequently of interest to ethical decision making researchers, who hypothesize that larger firms are less ethically oriented and might be negatively related with aspects of ethicality. Ford and Richardson (1994) and O'Fallon and Butterfield (2005) together identify nine studies of which five provide supporting evidence linking smaller organization size positively with aspects of ethicality. O'Fallon and Butterfield (2005) offer a qualified conclusion regarding this research, suggesting that organizational size has a detrimental effect on aspects of ethicality while proposing that, given the mixed results, more research be conducted in this area.

Some researchers have considered the conjoint effects of the influence of significant others, organizational size, and organizational culture on aspects of ethicality (e.g. Weber, 1990; Weber and Seger, 2002). These researchers have suggested that size and culture interact, with culture playing a more important role in small organizations and significant of others playing a more important role in larger organizations in determining aspects of ethicality. Consequently, the relationship between culture, organization size and aspects of ethicality may be more complex than first thought thus 
accounting for inconsistent relationships across studies when these variables are examined.

Research has been conducted to determine if a relationship can be found between aspects of ethicality and type of industry a firm resides in. For instance, $\mathrm{Oz}$ (2001) compared professionals in high tech companies with professionals in other industries (such as accountants, lawyers, teachers, engineers and others) finding high tech professionals to exhibit less ethical behavior in 2 of 4 scenarios. Due to the wide variety of industries examined and inconsistent findings across the various aspects of ethicality, O'Fallon and Butterfield (2005) conclude that past research findings in this category cannot be aggregated, and therefore no conclusions can realistically be drawn regarding the type of industry and how this construct relates to aspects of ethicality.

Researchers have also tested whether ethicality increases with the use of supporting formal rewards and sanctions. O'Fallon and Butterfield (2005) conclude that the use of rewards and sanctions can encourage aspects of ethicality. However, Baucus and Beck-Dudley (2007) call into question the long-term effects of the use of rewards and sanctions to control aspects of ethicality. Noting that rewards and sanctions are incompatible with decentralized organizations that promote autonomous decision making at lower levels of the organization, these researchers suggest that the threat of overt orchestrated outcomes for unethical behavior actually harm the long-term ethical decision-making ability of employees because they are not free to think for themselves. These researchers go on to site the ethical success of two organizations 
that embrace decentralized ethical decision making without the use of rewards and sanctions.

Only a few organizational constructs including codes of ethics, climate and culture, and rewards and sanctions, appear to offer some ability to predict aspects of ethicality. Of these only rewards and sanctions constructs seem to offer the most robust predictive power.

\subsubsection{Moral Intensity and Ethicality}

Jones' (1991) concept of moral intensity has received recent attention as a variable that might explain aspects of ethicality. Researchers centering on moral intensity have sometimes examined this construct as a higher order latent variable but more often have split this concept into component constructs of magnitude of consequences (severity of harm), social consensus (degree of agreement), probability of effect (likelihood to cause harm), temporal immediacy (time between decision and consequences), proximity (social nearness of those affected), and concentration of effect (number of people affected) (Jones, 1991).

Of those studies examining the more general construct of moral intensity, seven studies supported a direct and positive relationship between moral intensity and aspects of ethicality (e.g. Paolillo and Vitell, 2002), one study found no significance and yet another study found the opposite effect (Fleischman and Valentine, 2003).

Of research examining the components of moral intensity, the magnitude of consequences and social consensus seem to have the most explanatory power to predict ethicality. In sixteen studies fifteen found a significant positive relationship between 
magnitude of consequences and ethicality (e.g. Barnett, 2001). Of fourteen studies eleven found a positive relationship between social consensus and ethicality (e.g. Barnett, 2001).

Notably, however, other components of moral intensity have not proven to be effective predictors. For instance two of three reported studies supported probability of effect, one of two supported concentration of effect, two of five supported proximity of effect and only one of four supported temporal immediacy as a construct associated with aspects of ethicality. Consequently, considering the multiple facets of moral intensity, the more narrow constructs of the magnitude of consequences and social consensus received the most consistent support in the literature as predictors of aspects of ethicality.

2.1.5.4 A Critique of the Underlying Assumption of Rationality In Ethical Decision Making Models

The preponderance of research examining ethical decision-making has relied upon Rest's (1986) four-step model that suggests a decision maker engages in a linear progression from recognition to action in responding to an ethical dilemma. This progression represents a rational description of the process or sub-decisions that are involved before one can plan a course of action. Rest (1986) was explicit in identifying his model as a cognitive model of ethical decision-making designed to understand what individuals think when they encounter an ethical decision (Reynolds, 2006). Consequentially, research that centers on associations between individual difference variables or organizational variables and one or more of Rest's (1986) aspects of 
ethicality must be based on an assumption that people engage in a rational decision making processes.

More specifically, to some extent individual difference variables such as age, tenure, CMD, or organizational variables like culture, use of rewards and sanctions, or facets of moral intensity, are hypothesized by researchers to be associated with steps in a rational process. For instance, the hypothesized relationship between age and awareness assumes that people engage in cognitive, effortful deliberation as a prerequisite for awareness and subsequent steps to resolve the moral issue (Sonenshein, 2007).

Recent research is now reexamining the extent to which individuals use deliberate and extensive reasoning for decision-making. Of concern for the present paper are the mental processes that decision makers might use to approach an ethical issue. By process this paper refers to the comprehensive picture of information an individual considers as they approach an ethical dilemma and go on to make an ethical business decision incorporating the individual's values and objectives (McDevitt, Giapponi, and Tromley, 2006). What then might be the process by which an individual becomes "aware" of an ethical matter, makes a "judgment", and formulates "intent" or exhibits "behavior"? Are these entirely based on logic and rational thought?

Traditional theories of human decision-making, particularly those related to the study of economics and finance, use a cognitive perspective called decision theory that features economic utility maximization. In this framework decision makers select alternatives that maximize their expected preference utility, logically assessing 
alternative probabilities and evaluating outcome contingencies mathematically (Smith, 2008). Underlying these theories is the assumption that decision makers use rationality to predict future outcomes of various options ideally utilizing logical, affect-free costbenefit analysis (Bechara, Damasio and Damasio, 2000, p. 305; Sayegha, Anthony and Perrewe, 2004). Until recently scholars and practitioners alike commonly endorsed the idea that sound decision making ideally was made with a "cool head" under the most rational of conditions without regard to emotional input (Ashton-James and Ashkanasy, 2008, p. 24; Sayegha, Anthony and Perrewe, 2004).

However, other research in human decision-making challenges the idea that purely rational decision making is either valid descriptively or that rational decisionmaking normatively results in better decisions. Indeed, human decision makers often fail to follow rational principles of utility maximization, often fail to consider all alternatives, and different individuals might vary on the relative importance given to diverse attributes under consideration (Plous, 1993). Additional criticism suggests that objective probabilities are rarely available in practical contexts, relegating the decision maker to subjective probabilities that might be biased. As well utility models assume that relatively few attributes of alternatives should determine individual preferences, these attributes being common across all alternatives. In reality decision makers often face numerous complex alternatives and asymmetrical attribute combinations. For decades managers trained in economic utility theory's analytic methods declined to consistently use them (Grayson, 1973). Increasingly, proponents of purely rational 
decision making methods are recognizing that, except in special circumstances, economic utility models are not useful (Smith, 2008).

One of the earliest alternatives to expected utility theory is provided by Herbert Simon (1956) who acknowledged boundaries to individual cognitive abilities and suggested decision makers often satisfice rather than optimize. To satisfice a decision maker chooses an option that satisfies the most important criteria without considering all possible alternatives and attributes, even though the choice may not be ideal or optimal, and satisficing can lead to valid and reasonable decisions (Plous, 1993, p. 95). Later, Tversky and Kahneman (1979) noted that decision makers routinely violate rational principles of utility maximization, leading these researchers to offer an alternative to expected utility theory called prospect theory that takes into account the irrational tendencies and emotions of most decision makers to be risk seeking to prevent losses and risk sensitive for potential gains. While accounting for some facets of irrational decision-making emotions, prospect theory still depends on decision makers to follow other rational principles that people will also invariably violate (Plous, 1993).

In recent decades decision making theorists have increasingly acknowledged the importance of affect's role in describing how people make decisions. Loomes and Sugden $(1982 ; 1986)$ and Bell $(1982 ; 1985)$ proposed models that took into account anticipated emotions of regret and disappointment for risk taking decisions (Mellers, Schwartz and Ritov, 1999). Lopes (1987) acknowledged the importance of affect and tried to include emotion as an aspect of rational decision making (Trimprop, 1994). Mellers and her colleagues (1999) proposed decision affect theory taking into account 
anticipated emotions of decision outcomes compared to the outcomes of options not taken. Decision affect theory proposed that decision choices might be made to maximize subjective pleasure rather than utility.

Grossberg and Gutowski (1987) broke new ground by developing affective balance theory utilizing a neural network model to explain cognitive-emotional interactions. In their model the extent of emotional input into decisions is controlled through neurotransmitters and directly proportional to the degree to which the decision maker can tap salient long-term memory representations of a current decision situation. These researchers suggest long-term memory representations, or schemas, contain the conditioned affective values of events created by reinforcement, with greater emotional influence for familiar events. A match of immediate stimuli with prior experiences, revealed by pattern matching of long-term memory schemas, leads to enhanced activation of the event's internal representation in short term memory (p. 306). Affective balance theory was demonstrated to explain a number of descriptive irrational and emotional decision tendencies, and is important because research attention is directed to the significance of similar events that have preceded the immediate decision.

Further research in this area was developed by Leven and Levine (1999) who expanded the Grossberg and Gutowski (1987) model to account for multiple attributes. Leven and Levine (1999) used their multiattribute model to explain the negative emotional response by consumers toward the Coca-Cola Company in 1985 to the replacement of "Old Coke" with "New Coke". Extensive taste-testing of "New Coke" by consumer focus groups supported the product change decision, but failed to take into 
account the expectations of familiarity consumers had with the existing product in everyday purchase settings. This research suggests that changes in decision context create different emotional associations for decision makers that must be taken into account (Levine, 2000).

Other research calls into question the idea that decisions should normatively be based on rationality or that rationality leads to optimal decisions. For instance, Preim, Rasheed and Kotulic (1995) suggest that under conditions of uncertainty, where it is difficult to identify, measure or predict key variables and their interrelationships, the ability to effectively employ rationality in decision-making is severely limited. Frederickson and Iaquinto (1989) and Khatri and Ng (2000) demonstrate that rational decision-making by executives is associated with organizational underperformance in unstable environments. Sayegha and her colleagues (2004) suggest that rational decision-making provides less than optimal results in crisis conditions. Still other researchers reveal that rational decision-making provides below optimal results in aesthetic or behavioral judgments where there is no objective criterion (Laughlin, 1980), in ill-structured problems (Shapiro and Spence, 1997), in problems where there are many alternatives and cues to consider, a likelihood of inaccuracy, and a lack of available organizing principles (Dunwoody, Haarbauer, Mahan, Marino, and Tang, 2000; Hammond, 1987), under conditions of time pressure with poorly defined goals and with experienced decision makers (Klein, 2003), in decisions regarding social situations (Damasio, 1994), and in decisions regarding ethical and moral situations (Anderson, Bechara, Damasio, Tranel and Damasio, 1999; Bechara, Damasio and 
Damasio, 2000; Damasio, 1994; Dane and Pratt, 2007; Garcia and Ostrosky-Solis, 2006; Haidt, 2001; Laughlin, 1980; Reynolds, 2006; Sadler-Smith and Sparrow, 2008; Sonenshein, 2007). Emiliani (2004) goes so far as to suggest that rational models of decision making are consanguineous with narrow profit maximization messages communicated to students in finance and economics courses, messages that dismiss corporate ethics and social responsibility (Smith, 2008). Making

2.1.5.5 Summary and Limitations of Research in Ethical Business Decision

The predominant research stream emphasizing the rationality of ethical decision making might be deficient in a number of ways. First, it appears only a few of the explanatory constructs reviewed above are able to offer predictive ability for aspects of ethicality. Second, while tests of associations between constructs reveal under what conditions ethical decisions might be made, they fail to reveal how those decisions are made (Haidt, 2001). Tests of association are lacking in this regard because they do not approach the actual process of ethical business decision-making, but rather are centered on the conditions that might associate with aspects of ethicality (Reynolds, 2006; Sonenshein, 2007). While identifying and defining explanatory constructs is necessary and important, it is insufficient for a complete understanding of how individuals arrive at ethical business decisions (McDevitt et al., 2006; Sonenshein, 2007). Finally, the paucity of reliably predictive explanatory variables associated with the specific steps outlined by Rest (1986) calls into question the assumption that people do and should use solely rational processes when confronted with ethical business dilemmas. Considering 
that rational models no longer are the accepted standard in decision making literature, the rationality assumption that dominates the literature in ethical decision making might provide an incomplete picture of how people make decisions when confronted with an ethical dilemma.

Instead, evidence suggests that people engage in mental processes outside of their conscious awareness and guidance when making ethical decisions (Bargh and Chartrand, 1999; Sonenshein, 2007). As an example, an fMRI investigation by Greene, Sommerville, Nystrom, Drley, and Cohen (2001) demonstrated that portions of the brain associated with emotional processes activated during ethical decisions, suggesting that emotion might play a significant role in ethical decision-making. Additionally Haidt (2001) offers evidence that moral behavior covaries with moral emotion more so than with moral reasoning.

Reynolds (2006) and Haidt (2001) criticize Rest's (1986) model by suggesting that it does not take into account the non-conscious retrospective ability people have to make decisions based on automatic processes of pattern matching and structuring of information. Reynolds (2006) provides evidence that retrospection is critical in repeated social interactions (e.g. Parks, Sanna, and Posey, 2003), which are a key component of ethical experiences.

In describing his model, Rest (1986, p 5) acknowledged the limitation that individuals will interpret situations differently. Were those differences consistently explained by individual or organizational factors, or moral intensity, a stronger argument might be made that the assumption of rationality underpinning research is 
reasonable. Given the scarcity of reliable explanatory variables in current research that base themselves on rational decision models, a potentially new and important direction for future research in ethical business decision-making is to explore the role of affect, intuition, and aspects of non-conscious pattern matching processes that occur when making ethical business decisions.

\subsection{Affect and Intuition}

While the prevailing literature stream in the realm of ethical decision making is underpinned with an assumption that ethical decisions are purely rational, the broader decision making literature stream has acknowledged the limitations of rational models of decision making and has moved beyond them to include affect as a important component in how people make decisions. Recent research has criticized the prevalent underlying assumption of rationality in the ethical business decision making literature steam for not taking into account the important role of affect and intuition in the decision making process (Garcia and Ostrosky-Solis, 2006; Haidt, 2001; Reynolds, 2006; Sayegha., et al., 2004; Sonenshein, 2007). As explained shortly, affect and intuition are inextricably linked in human decision making processes.

The term affect subsumes both emotion (feelings toward an event, object or person) and mood (feelings not linked to a specific event, object or person) (Daniels, 2008; Parkinson, 1995). It is also understood that affect has a cognitive component in addition to expressive and physiological components. Affect's cognitive component is manifested when individuals become aware of their emotional state in the conscious 
mind as affect rises to a certain level (Daniels, 2008; Epstein, 2008; Russell, 2003). Interestingly, affect's relationship with intuition could be either as an antecedent of intuitive processes or as a consequence (Dane and Pratt, 2007). Affect can trigger greater reliance on intuition (Bless, 2000), and can also be the outcome of intuition as it rises to the level of consciousness and provides the decision maker with a sense of how they feel about decision options. This latter concept of "affect as information" has been documented in research regarding the role of affect in decision-making (Schwarz, 1990; Schwarz and Clore, 2003). Emotional associations from prior experiences result in how one feels about an event, object or person, (positively or negatively) and that feeling is used directly as information in coming to a judgment (Clore, Wyer, and Dienes, 2001; Daniels, 2008).

Tilman Betsch (2008) offers this definition of intuition:

"Intuition is a process of thinking. The input to the process is mostly provided by knowledge stored in long-term memory that has been primarily acquired via associative learning. The input is processed automatically and without conscious awareness. The output of the process is a feeling which can serve for judgments and decisions."

Thus, intuition provides affective information to the decision maker that can be used in the decision-making process (Damasio, 1994; Hogarth, 2001; Sadler-Smith, Hodgkinson, and Sinclair, 2008). Intuition's role in decision-making has received more attention in recent years following advances in cognitive research suggesting human cognition utilizes a "dual-processing" arrangement (Jacoby, 1996; Sloman, 1996; 
Stanovich and West, 1998). Dual processing theory suggests humans commonly rely on two systems for information processing, intuition and rationality.

Intuition, considered more primitive in evolutionary terms (Damasio, 1994, p. 191; Dane and Pratt, 2007; Epstein, 2008), is based on rapid, automatic, relatively effortless, affect oriented, and non-conscious processing of learned experiences. This system permits individuals to learn from experiences and to reach perceptions of knowing without cognitive attention (Hogarth, 2001). Cognitions at the non-conscious, experiential level are primarily emotionally associated (Epstein, 1990; Sinclair, Ashkanasy, Chattopadhyay, and Boyle, 2002). A second cognitive system, rationality, is based on relatively slower, affect-free, deliberate, effortful and conscious learning, analysis and rationality (Epstein, 2008). These two systems of cognition have been labeled, respectively, as System 1 and System 2 (Stanovich and West, 1998), tacit and deliberate (Hogarth, 2001), X-System and C-System (Reynolds, 2006), and as experiential and rational (Epstein, 1994; 2008). Following Epstein, this paper will refer to these systems as experiential and rational. See Table A.1 for a comparison of the characteristics of these two respective systems of cognition. Intuition relies upon the experiential system and is intimately associated with affect (Damasio, 1994; Dane and Pratt, 2007).

The experiential system takes into account three aspects: non-conscious learning that is the result of deep experience within a particular domain that leads to knowledge about that domain, the non-conscious and automatic activation of learned knowledge in the face of stimuli coming from the domain, and the affective outcome or 
output of this process that can be used in decision making (Dane and Pratt, 2007). More information regarding these three aspects of the experimental system will be provided shortly.

Learning processes that lead to experiential knowledge are here called experiential learning. Some authors (e.g. Hogarth, 2001) include experiential learning as part of their concept of intuition, using the term "intuitive learning". However this paper follows Dane and Pratt (2007, p. 36) who suggest that intuition does not include experiential learning but refers to activation and outcomes of the experiential system. Dane and Pratt (2007) further define activation of the experiential system as intuiting and the resulting outcome of intuiting as intuitive judgments. So, while intuition as defined here does not include experiential learning it is dependent upon and closely associated with experiential learning.

\subsubsection{Experiential Learning}

Humans have a bounded mental capacity with which to consciously attend to our surroundings (Betsch, T., 2008; Haidt, 2001; Hogarth, 2001; Simon, 1957). However humans also possess non-conscious, effortless routines for classifying, categorizing and associating events and objects in their environment. Therefore much of human learning occurs at a non-conscious level (Epstein, 2008; Hogarth, 2008) and this is referred to as experiential learning. Epstein, (2008) offers that experiential learning operates in a manner that is preconscious, automatic, non-verbal, imagistic, associative, holistic, intimately associated with affect, and minimally demanding of cognitive resources. Individuals are unaware that such learning is taking place and 
experiential knowledge is stored in the brain differently than from other types of knowledge (Dane and Pratt, 2007, p. 44).

Experiential learning is different from conscious learning because it is associative in nature and operates below consciousness. Experiential learning involves an ability to tally and correlate related events, objects, sensations, social interactions and emotions (Epstein, 2008; Hogarth, 2008). Over time, vivid, emotional or repetitive experiences occurring in specific environmental domains allow individuals to build cognitive frameworks, or schemas, which tie together the correlative characteristics within those domains of expertise (Epstein, 1990) and thus form experiential knowledge.

Schemas are cognitive structures, primarily generalizations from emotionally significant, intense or repetitive experiences (Epstein, 2008). As generalizations, schemas represent the aggregation of similar experiences and form a prototypical approximation of the association of emotions, events, sensory input, social structure and objects (Reynolds, 2006). Experiential learning occurs slowly, over long periods of time with continued experiences in specific domains. In contrast rational system learning acquires its knowledge by conscious, overt learning from books, lectures and other explicit sources of information, as well as from logical inference (Epstein, 2008).

\subsubsection{Intuiting}

Intuition works with and relies on the knowledge provided by experiential learning. Intuiting involves holistic association, a process in which environmental stimuli are matched with some deeply held, non-conscious, category, pattern or feature. 
In making these holistic associations, individuals map stimuli onto previously learned cognitive structures, or schemas. (Dane and Pratt, 2007; Epstein, 2008). This gives the intuiter knowledge about the typical structure of the environment (Deutch and Strack, 2008). The process involving intuiting thus allows an individual to match associative patterns of stimuli to similar patterns experienced in the past, along with the perceived success of prior responses and outcomes to those situations.

Holistic pattern matching occurs very rapidly compared to conscious, deliberate thought. The ability to rapidly recognize holistic patterns from previous experience appears to result from an activation of semantic networks (Anderson, 1983) that permit parallel processing in the brain, quickly matching associated stimuli by sorting through similar associations from the past. Parallel processing permits the intuiter to consider multiple pieces of information simultaneously, and affords the individual the capability of handling large amounts of information quickly. In contrast, deliberate, effortful and conscious processing is slower and seems to occur as a result of sequential processing (Betsch, T., 2008, p. 6).

Holistic association processes do not occur at a conscious level, instead, individuals engage in mental processes outside their conscious awareness (Bargh and Chartrand, 1999). Due to its non-conscious nature, intuiters seem unable to recount how they arrive at intuitive judgments (Cooksey, 1996, p. 14; Dane and Pratt, 2007; Reynolds, 2006). Hogarth (2001, p. 61) explains that intuitive thought induces responses without corresponding awareness 
Holistic associations also occur automatically, often the mere presence of stimuli is enough to trigger the process (Deutsch and Strack, 2008, p. 44), and research suggests that intuiting is at work within a quarter second of stimulus presentation (Barg, Chaiken, Raymond, and Hymes, 1996; Fazio, Sanbonmatsu, Powell, and Kardes, 1986; Hermans, De Houwer, and Eelen, 1994). Intuitive judgments are pervasive, appearing suddenly and effortlessly in consciousness, almost as an integral part of perception (Haidt, 2001, p. 819).

\subsubsection{Intuitive Judgments and Affective Outcomes}

Intuitive judgments, the result of intuiting, are an affective sense of a situationally appropriate response to stimuli, experienced as a feeling, either positive or negative, as opposed to words or numbers (Dane and Pratt, 2007; Haidt, 2001; Hogarth, 2008). As an example, Agor (1986) notes that executives often experience excitement and harmony as they make intuitive judgments. Or possibly a feeling of dread regarding the risk of a particular option might envelop decision makers as they approach a situation (Slovic and Peters, 2006).

While intuitive processes commonly result in affect, intuition can also be triggered by emotion and affect (Bless, 2000; Bolte, Goschke, and Kuhl, 2003; Dane and Pratt, 2007; Daniels, 2008; Hogarth, 2001). For example, positive mood has been linked to an increase in the use of intuition and a decrease in more rational approaches to decision making (Bless, 2000; Bolte, et al., 2003; Hanze, 1997; Hanze and Meyer, 1998; Hogarth, 2001, p. 65; Weiss and Cropanzano, 1996), while negative mood has been associated with reduced intuitive processing and increasing reliance on rationality 
(Bless, 2000). Burke and Miller (1999) document managers who describe intuitions being affectively initiated while Hogarth (2001) also suggests that affect can be an important input to intuitive thought.

Epstein (1990, p. 170) notes that schemas are "inductively derived from emotionally significant experiences". Deutsch and Strack (2008), as well as Sayegha and her colleagues (2004), propose that emotions tied to previous experiences are reactivated when associative stimuli is encountered, thereby influencing judgments of liking (e.g. Fazio and Olson, 2003). Generalizations provided by schemas also can provide an aggregated feeling toward associated stimuli, as suggested by Haidt (2001) and T. Betsch (2008).

Betsch (2008) and Haidt (2001) use the concept of valence to designate the net affective direction (good-bad, like-dislike) toward an object or situation manifested in intuitive judgments. A series of experiments demonstrate that immediate feelings associated with intuitive judgments regarding a current situation can reflect the emotional sum of similar prior experiences (Betsch, Hoffmann, Hoffrage, and Plessner, 2003; Betsch, Kaufmann, Lindow, Plessner and Hoffmann, 2006; Betsch, Plessner, Schwieren, and Gutig, 2001). Hammond, Hamm, Grassia, and Pearson (1987) describe the organizing principle of intuition as weighted averaging of emotional content, intensity and direction. When experienced, feelings can be attributed to the stimuli and may infer properties on the stimuli based on the aroused affect (Deutsch and Strack, 2008; Schwarz and Clore, 1988). 
Bowers, Regehr, Balthazard, and Parker. (1990), examining the non-conscious nature of problem solving, explored the neural mechanisms underpinning intuition that results in an affective outcome. In experimental settings these researchers asked subjects to compare two separate three-word sets and identify the single set that had a common connection. One set of words could be semantically connected through association with another unknown word; the other set of words was semantically unrelated. Bowers and his associates found that people were more apt to identify groups of words that were semantically connected even though they could not specifically identify the unknown connecting word. These authors suggest that nonconscious perceptions guided participants toward a conscious representation of these coherences in the form of a "hunch" or "gut feeling" that guided them in selecting the appropriate set. Bowers and his colleagues explained this in terms of the creation of an activation in mnemonic and semantic networks that spreads through neural pathways and eventually reaches a level sufficient to cross the threshold into conscious awareness and generate a hunch. For the decision maker, prior similar experiences are compared to the current situation based on a "goodness of fit" criterion, and the associations of relevant prior experiences are aggregated as general feelings toward outcomes and likely options. In subsequent replications, these judgments became more accurate when participants were induced into a positive rather than neutral or negative mood (Bolte, Goschke, and Kuhl, 2003; Sadler-Smith and Sparrow, 2008).

A further explanation of the bond between intuitive judgments and affect is provided by Antonio Damasio and his colleagues (Anderson, Bechara, Damasio, Tranel, 
and Damasio, 1999; Bechara, Damasio, and Damasio, 2000; Damasio, 1994), who introduce the concept of somatic markers. Somatic markers are links between experiential knowledge and bioregulatory states that constitute feelings and emotions (Volz and Von Cramon, 2008). When experiential knowledge is accessed in the intuiting process somatic markers generate visceral states matching those of previous experiences.

Thus intuitive judgments come to us as affective states that serve to orient us in decision making by biasing us toward a particular option in line with our experiential knowledge. The affective state forces attention on what we have experienced before as a positive or negative outcome and functions as an "automated alarm signal" that might lead one to quickly accept or reject an option out of hand or to limit conscious deliberation to fewer alternatives (Damasio, 1994, p. 173). Damasio (1994) suggests these affective states, somatic markers, are the mechanism through which emotion and feeling provide a bridge between rational and experiential processes (Damasio, 1994, p. 128).

\subsubsection{Summary of Intuition}

To summarize, intuition 1) performs holistic associations, 2) involves rapid processing of experiential information, 3) is non-conscious, 4) involves automatic processing without effortful deliberation, 5) may be precipitated by positive affect, and 6) results in affectively charged judgments that subjectively guide us in decision making. The experiential-intuitive system is more responsive to holistic, emotionally arousing, visual, context specific, and associative information, than is the rational 
system which is more responsive to abstract, analytical, factual, verbal, context-general information and logical argument. Research suggests all human behavior is influenced by a combination of both systems (Epstein, 2008).

Holistic pattern matching may explain the ability of chess masters to remember, more easily than novices, the locations of chess pieces positioned in mid-game configuration, yet be no more able to remember their locations when pieces are placed randomly on the board (Simon and Chase, 1973). The presence of rapid, intuitive decision making might explain why individuals performing under extreme time pressure, such as firefighters, pilots, emergency medical technicians, military personnel (Klein, 2003), and ball players (Raab and Johnson, 2008), are able to make fast yet effective decisions that do not require effortful deliberation. Common euphemisms in decision-making, such as "gut feeling" (Damasio, 1994; Haidt, 2001; Hayashi, 2001; Shapiro and Spence, 1997) or a feeling "in your bones" (Barnard, 1938) seem to speak to the affective nature of intuitive judgments (Dane and Pratt, 2007).

However, intuition shares some properties with other known cognitive phenomena, such as instinct, insight and heuristics. Common parlance often uses these terms synonymously, yet there are important distinctions between these concepts. An explanation of these differences may be helpful in resolving possible confusion.

\subsubsection{Intuition and Its Pretenders}

While instinct is a term often used synonymously with intuition, and both share characteristics of rapid, automatic and non-conscious response to stimuli, intuition and instinct are actually "two related yet separate constructs" (Sinclair, Ashkanasy, 
Chattopadhyay and Boyle, 2002, p. 145). Instinct represents "hard-wired" response to stimuli such as blinking in the presence of bright light, or flinching at a loud sound. These innate capabilities are inborn to individuals, do not require learning, therefore are not dependent upon the experiential learning system (Dane and Pratt, 2007; Hogarth, 2001).

Another common confound with intuition is insight, which also shares traits with intuition including automatic and non-conscious processing. Insights are sudden, unexpected thoughts that solve problems following a period of deliberation (Hogarth, 2001, p. 251). Insight may involve experiential processing as a result of an incubation period that begins with analytic thinking (Dane and Pratt, 2007). There are two fundamental differences, however, that separate the concepts of intuition and insight. Unlike intuition insight requires a length of time to manifest itself in cognition therefore it lacks the rapidity that is commonly associated with intuition. Additionally the result of insight usually affords the individual with a perceived awareness of the logical connections supporting a judgment, a trait that is not present in what we know as intuition (Dane and Pratt, 2007).

Heuristics and intuition are commonly equated in research literature. Decisionmaking using heuristics shares commonalities with intuitive decision-making in that they both occur rapidly and with little cognitive effort. Following Tversky and Kahneman (1974), heuristics are mental shortcuts that reduce the complex tasks of assessing probabilities and predicting values to simpler judgmental operations. Heuristics are often useful for quickly assessing probabilities and making decisions in 
uncertain situations, but may also lead to severe systematic biases and errors (e.g. Tversky and Kahneman, 1974).

Pioneering work surrounding heuristics (e.g. Tversky and Kahneman, 1974) proposes that humans have evolved a set of irrational shortcut strategies for judgments. Tversky and Kahneman (1974, p. 185) equate heuristics and intuition by suggesting decision makers are prone to heuristic biases when they think intuitively. Tversky and Kahneman (1971) write that intuitions should be "regarded with proper suspicion," and that decision-makers should "replace impression formation by computation whenever possible."

Further research demonstrates that heuristics and affectively based intuition are distinct. This is documented in three ways; first it appears that heuristic decision makers actually use conscious, analytical processes when they use heuristics, but are irrational because they fail to consider all information. Second, people seem to use different information bases when using heuristics and intuition. Finally, it appears heuristic decision-makers do not using parallel processing while intuitive decision makers do use parallel processing.

Heuristic decision makers are irrational because they are either reluctant or unable to take all relevant information into consideration (e.g. Gigerenzer, 2004; Glockner, 2008; Payne, Bettman, and Johnson, 1988). Heuristic decision makers might base decisions on what is considered to be the most important information, or use the most available or representative information, and alternatives based on other dimensions are ignored. For example, a common heuristic strategy such as "take-the- 
best" (Glockner, 2008), in which only the value of a single dominant dimension is considered, might lead a decision-maker to only consider the dimension of price for a consumer purchase.

There is evidence that decision makers using heuristics and those using intuition differ greatly in the information base each uses (Deutsch and Strack, 2008). Informational bases are the types of schemas that heuristics and intuitions each depend on (Dane and Pratt, 2007). Heuristic schemas are the result of limited, broad and general experiences that do not involve long-term exposure to a specific domain of expertise. On the other hand expert schemas associated with affect and intuition are the result of long-term exposure to explicit areas of expertise that allow for development of mental structures that are deep, complex and domain specific (Dane and Pratt, 2007). As simple, shallow cognitive frameworks, heuristic schemas are likely to be inadequate to allow a decision maker to process complex environmental stimuli. To effectively use intuition, the decision maker must be able to map the complexity of the stimuli to equally sophisticated expert schemas that can only be developed with extensive exposure to a specific area of expertise (Baylor, 2001; Blattberg and Hoch, 1990; Burke and Miller 1999; Weick, 1995).

Heuristic schemas are therefore relatively simple, represent very generalized knowledge, are domain independent (Dane and Pratt, 2007) and thus do not allow for parallel processing (Betsch, T., 2008). In contrast, complex expert schemas do allow for parallel processing (Betsch, T., 2008). Tilmann Betsch (2008) provides an illustration of the differences between heuristics and intuition in a parallel processing 
framework (see Figure A.1). The horizontal axis represents the degree to which parallel processing is possible and the vertical axis represents the amount of information that can be handled in the process. The line of consolidation represents the level of consolidation of prior information, which is the complexity of the schemas underlying the process. The intuitive ability to process large amounts of information quickly using parallel processing is represented in the upper right quadrant of the graph where highly complex schemas are accessible, while heuristic processing occurs within the lower left quadrant where simple schemas based on generalized knowledge prevail.

Tversky and Kahneman's work on heuristics strongly influenced decisionmaking theorists, including ethical decision theorists, to condemn irrational approaches to decision making that included processes influenced by affect and intuition (Betsch, T. 2008; Dane and Pratt, 2007; Haidt, 2001; Sadler-Smith and Sparrow, 2008, p. 310). While characteristics of heuristic decision making mimic those made with intuition, such as rapid decision-making and reduced cognitive load, recent research has uncovered critical differences between heuristics and intuition despite these superficial similarities. So, while decision-making literature has often confused heuristics and intuition, they seem to be quite separate human decision-making processes (Betsch, T., 2008; Sadler-Smith and Sparrow, 2008, p. 310).

\subsubsection{The Value of the Experiential System In Ethical Decision Making}

The role and value of the experiential system has arguably been neglected in research conducted on decision-making and ethical judgments (Garcia and OstroskySolis, 2006; Haidt, 2001; Sayegh, et al., 2004; Sadler-Smith, Hodgkinson and Sinclair, 
2008; Sonenshein, 2007). Indeed, many researchers lament that an overemphasis on rationality has been detrimental to ethical decision-making research (e.g. Betsch, T., 2008; Damasio, 1994; Haigt, 2001; Langley, Mintzberg, Pitcher, Posada and SaintMacary, 1995; Sonenshein, 2007).

No less a figure than Jonas Salk (1985) articulates that creativity depends on a merging of intuition and reason (Damasio, 1994), and Herbert Simon (1987) asserts that effective managers must not choose between analysis and intuition but rather must use both (Dane and Pratt, 2007). Significantly, research on the importance of intuition in decision-making is not an inherently anti-rational perspective; to the contrary social science research efforts that take intuition in to account recognize the importance of rational, effortful deliberation as it works conjointly with intuition (Haidt, 2001).

\section{$\underline{2.3 \text { Conjoint Intuition and Rationality Frameworks for Decision-Making }}$}

Epstein (2008, p. 27) offers that the rational system provides reasoning through the application of logic and verbal systems, but the experiential system provides a different kind of non-verbal reasoning using imagery in association with feelings. Hogarth (2001, p. 33) suggests that, typically, reasoning will start with the experiential mode and be modified by the rational, depending on circumstances. This makes sense considering the rapidity of intuition, but suggests other less typical relationships between the two systems may be possible.

Epstein $(1990 ; 2008)$ proposes a framework he labeled cognitive experiential self theory (CEST) as a model of how rational and experiential processes might work in tandem. According to CEST, the two systems interact both simultaneously and 
sequentially, with the experiential system usually reacting first to a stimulus. If this initial response tendency is identified by the rational system as inappropriate the rational system will suppress or adjust the response tendency. If it is not identified as inappropriate the tendency is automatically expressed.

Another possible sequence suggested by CEST (Epstein, 2008) is one in which the experiential system reacts to the rational system. A thought produced by the rational system can instigate emotions or produce associations in the experiential system. Once the process is set in motion the two systems then work simultaneously to influence the other, and research has demonstrated the influence of the two systems on each other results in conflicts and compromises between the experiential and rational systems (e.g. Denes-Raj and Epstein, 1994; Haidt, 2001; Reber, 1993; Yanko and Epstein, 1999).

Each system has both an advantage and a disadvantage in its relationship with and ability to influence the other. The rational system can understand the experiential system, while the experiential system cannot understand the rational system (Epstein, 2008). That is to say that the rational system can reason as to whether input from the experiential system is valid, but the reverse is not possible.

However, the experiential system has the ability to influence the rational system without the latter being aware of that influence. In the absence of awareness the experiential system is free to exercise influence over the rational (Epstein, 2008). An example might be a driver who exercises undue caution by not turning right at red lights despite there being no oncoming traffic and no rule to the contrary. 
Awareness of the operation of the experiential system by the rational system puts the latter in position to be in control (Epstein, 2008). So someone with a dread of flying is able to rationally overcome this emotion by reasoning that statistics favor the relative safety of air travel compared to automobiles. However, there are times when emotion might overcome rationalizations. For instance, Denes-Raj and Epstein (1994) offered decision makers a choice between drawing a red jelly bean from a jar in which 7 of 100 beans were red, or a jar from which 1 of 10 beans were red. Despite knowing the odds were less favorable, many decision makers opted to draw from the jar with the greatest absolute number of red beans because they "felt" they had a better chance.

Knowing that human decisions are the result of mutual influence between the two systems, an important aspect of the relationship between the experimental and rational systems is to what extent decision makers might rely on one system versus the other. Hammond (1981, 1986, 1990b) suggests a cognitive continuum exists between the poles of intuition and rational analysis in which a decision may fall between these extremes based on the relative influence of each system (see Figure A.2).

The modes of operation occurring between the intuitive and analytical poles of Hammond's cognitive continuum represent differing proportions of both intuition and analysis and result in what Hammond refers to as quasi-rationality. Quasi-rationality appears to be closely related to Heider's (1958) view of common sense and to Simon's (1986) concept of bounded rationality. In Hammond's theory quasi-rationality assumes no greater or lesser importance than either of the modes of cognition at the poles, it merely describes blended cognition (Cooksey, 1996). 


\subsubsection{Different Types of Decisions}

Hammond (1990b) suggests that different tasks, or different types of decisions, might call for one system, intuitive or rational, to be relatively more influential than the other and thus guide a decision that might fall closer to one pole of the continuum. Task properties that will tend to induce more intuitive or more analytical cognitive bias when making judgments include 1) the complexity of the task structure, 2) the ambiguity of the task structure and 3) the form of the task presentation (Cooksey, 1996) (see Figure A.3).

The complexity of the task structure incorporates consideration of the properties and nature of the cues available for judgment, such as the number of cues available to the decision maker, how cues are perceived or the redundancy of cues. Ambiguity of task content encompasses the nature of the organizing principles for combining the cues, including how familiar the decision maker is with the organizing principles of the task. An example might be how easy it is for the decision maker to create a spreadsheet comparing important cues and information in the decision, thus organizing information in a meaningful way. Form of task presentation involves the nature of cue decomposition such as the manner and modality of how information is presented to the decision maker, be it verbally, numerically, graphically, pictorially, audibly, etc. (Cooksey, 1996). Thus, for the decision maker, the characteristics of the task at hand should ideally determine the relative influence that the experiential and the rational systems have on the decision making process. 
Hammond and his associates (Hammond, Hamm, Grassia and Pearson, 1987) empirically tested the cognitive continuum across different types of decisions. They were able to document the cognitive continuum's predictive ability as decision makers used differing levels of intuition and rationality conjointly for different types of tasks in line with the cognitive continuum. More explicitly, highway engineers were asked to render judgments on three different tasks with varying levels of task complexity. Based on the subjects' relative use of intuition conjointly with analysis, the corresponding position of the subjects along the cognitive continuum was predicted by task characteristics (Cooksey, 1996).

Moreover, this research (Hammond et al., 1987) also made within-person comparisons of the quality of different modes of cognition, based on comparisons between decisions made by study subjects and expert judges. Importantly, these researchers also showed that under various conditions intuitive or quasi-rational cognition was at least as good as or actually outperformed purely analytical cognition. Specifically, these researchers demonstrate that the closer a subject was cognitively (i.e. using relatively more intuition or rationality in their decision) to the location predicted along the cognitive continuum by the complexity of task structure inherent in the decision type, the better their overall judgment performance was when compared to experts (Cooksey, 1996, p. 21).

Shapiro and Spence (1997) present a parallel perspective suggesting that problems lie on a structure continuum, similarly to Hammond's (1990b) concept of the complexity of the task structure. They suggest that well-structured problems, such as 
accounts receivable and order entry, lend themselves well to analytical reasoning whereas ill-structured problems, such as planning for research and development of new products, might be more effectively approached when intuition is given greater influence in decisions. Other researchers have also suggested that analytic reasoning is appropriate for well-defined problems but much less effective for poorly defined problems (e.g. Claxton, 1998; Hayashi, 2001; McMackin and Slovic, 2000; Plessner and Czenna, 2008).

Dane and Pratt (2007) offer a perspective that is consistent with Mathieson (2007) when they propose that the concept of problem structure is captured in the distinction between intellective and judgmental tasks for individual decision-making as suggested by Laughlin (1980) and Laughlin and Ellis (1986), as well as for group tasks as proposed in the McGrath (1984) circumplex. Intellective tasks involve a "definite objective criterion of success within the rules, operations and relationships of a conceptual system". Judgmental tasks involve "political, ethical, aesthetic or behavioral judgments for which there is no objective criterion or demonstrable solution" (Laughlin, 1980, p. 128). Consistently with Hammond (1990b), Laughlin (1980) suggests that the intellective-judgmental task relationship is a continuum rather than a dichotomy. Thus, Hammond's (1990b) cognitive continuum framework meshes well with other researchers who have come to similar conclusions.

\subsubsection{The Nature of Ethical Decisions Within the Context of Conjoint Frameworks}

If moral and ethical decisions represent a particular type of decision that is more judgmental than intellective, then, considering Hammond's (1990b) cognitive 
continuum, the task complexity of moral and ethical decisions might optimally call for relatively more influence from intuition than from rationality. Haidt (2001; Haidt and Kesebir, 2008) argues that moral decisions are judgmental because they are usually and most effectively processed when using the experiential system. Haidt (2001, p. 823-4) offers evidence to suggest that moral action covaries more with moral emotion than it does with moral reasoning, highlighting the importance of intuition's role compared to rationality in ethical decisions. For instance, Hart and Fegley (1995) and Colby and Damon (1992) both compared highly prosocial moral exemplars with nonexemplars and found the groups did not differ in their rational moral reasoning abilities. For example, in the former study adolescents who had been nominated by community leaders as having exhibited unusually positive commitments to the community and to the care of others were compared with peers. Comparisons revealed no significant differences is moral reasoning development, suggesting that ethical behaviors are not associated with moral reasoning ability. Further, a review of the validity of Rest's $(1979 ; 1986)$ Defining Issues Test (DIT), which is designed to measure rational moral reasoning, describes three studies demonstrating a relationship between DIT scores and negative moral behaviors, but none showing a positive relationship between DIT scores and morality (Thoma, Narvaez, Rest, and Derryberry, 1999).

Further evidence is provided by Haidt (2001) who turns to the study of psychopaths, individuals for whom reasoning has become disassociated with moral emotions, to support his position that ethical decisions may best be made intuitively. Cleckley's (1955) case studies demonstrate that psychopaths possess characteristically 
good intelligence and reasoning skills. Psychopaths know the rules of social behavior, and understand the harmful consequences to others when those rules are not followed. Yet psychopaths do not care about those consequences, demonstrating a general poverty of affective reactions particularly those normally triggered by the suffering of others (remorse, sympathy), condemnation by others (shame, guilt, embarrassment), or attachment to others (love, grief). (Hare (1993) provides a more recent discussion of psychopathic emotional deficiencies.)

In a series of observations and laboratory experiments, Antonio Damasio and his colleagues $(1994 ; 1999 ; 2000)$ demonstrate the inability of neurologically damaged subjects to make effective decisions in certain tasks, including moral decisions. For these subjects vetromedial prefrontal cortex (VMPFC) damage results in a syndrome resembling psychopathy (Anderson et. al., 1999). Specifically these individuals have suffered, either through accident or invasive surgery, lesions to areas of the brain that normally associate somatic markers with rationality in the reasoning process, resulting in chronic lack of emotional response. While these individuals retain their intellective abilities and factual knowledge, they appear to be solely reliant on rational analysis for decision making to the exclusion of the experiential system, and demonstrate serious deficiencies in their decision making abilities across a broad spectrum of judgmental decisions.

In sustaining VMPFC damage these individuals also demonstrate what appears to be a change in their value system. Damasio (1994) writes, "Some part of the value system remains and can be utilized in abstract terms, but is unconnected to real-life 
situations." These same people perform well on tasks that involve reasoning skills involving objects, space, numbers and words, but poorly on decisions that are in the personal and social domain. VMPFC damaged subjects perform poorly on contextual (Hogarth, 1996, p. 57), long-term oriented (Bechara, et al., 2000; Damasio, 1994, p. 11), social (Damasio, 1994, p. 38; Hogarth, p.57) and ethical decisions (Damasio, 1994, p. 179). These appear to be the types of decisions that involve highly complex and ambiguous task structures in Hammond's (1990b) framework.

Ethical questions often have solutions related to social roles and identities (Weber and Lindemann, 2008). Weber and Lindemann (2008) tested likelihood of use for calculation, recognition and affective decision modes across various decision contexts (ethical, relationship, school, consumer and routine). These researchers provide empirical evidence demonstrating that ethical decisions are influenced most strongly by role-based and affect-based modes.

These research results seem to call in to question the veracity of arguments that ethical decision-making should be a purely rational process, devoid of affective or intuitive influences (Haidt, 2001; Reynolds, 2006; Sonenshein, 2007). Fortunately, important new theoretical models have come forward to suggest how rationality and intuition might work conjointly in the process of ethical decision-making.

\subsubsection{Theoretical Models of Ethical Decision-Making that Conjointly Incorporate} Rationality and Intuition

Building on dual-processing cognition theory (Jacoby, 1996; Schneider \& Shiffrin, 1977) Reynolds (2006) proposes that ethical decision making can follow either 
a rational path, or a reflective path. In the latter, a decision maker is able to rapidly and subconsciously pattern match between a current ethical situation and non-consciously developed prior experiences in memory. Non-consciously developed prior experiences are aggregated over time as prototypical situations that represent the sum of sensory and emotional input and learning from past experiences. Reynolds (2006) proposes that individuals have the ability to match information in ethical dilemmas with information from similar prior experiences, resulting in an affectively charged state he identifies as intuition. Intuitively based decisions are appropriately the result of reflective responses to ethical situations. He suggests reflective responses, in which decision makers have familiarity with an ethical situation and can match a situational prototype to the current ethical situation, are quite common and may be more frequent than rational judgments. He proposes that rational judgments are only relied upon when an individual is not able to match prior experiences with a current ethical situation. Reynolds (2006) therefore makes an important contribution to our understanding of the ethical decision making process by suggesting that rational and affective functions work uniquely yet conjointly to consider information and bring the decision maker to an ethical judgment.

Following Reynolds (2006), Sonenshein (2007) similarly proposes that intuition works conjointly with rationality when people make ethical decisions. He suggests that pattern matching, inherent in intuiting, is followed by immediate, affective reactions to ethical situations he identifies as intuition. Intuition results in either good or bad feelings about decision options, which guide the decision maker. Sonenshein (2007) suggests that ethical decisions are primarily the result of intuitive influences, which are 
subsequently rationalized by the decision maker using logical means to justify an intuitively influenced decision. He therefore suggests that ethical decision-making is a process of sensemaking that extends from the non-conscious experiences and familiarity an individual has with a situation, to a resulting affective perception that provides guidance to the decision maker, through to a rational validation of that affective perception. Sonenshein (2007) also makes important contributions to our understanding of ethical decision making by suggesting that not only do affect and rationality play a conjoint role in the ethical decision making process, but that affect might play the dominant role in that process.

\subsubsection{Summary of Theoretical Dual Processing Models}

Together Reynolds (2006) and Sonenshein (2007) suggest that research that assumes people engage in a solely rational process to arrive at an ethical decision might be flawed; and that intuition might play a major role in ethical decision-making

processes. The modest literature oriented to understanding how affect and associated intuition plays a role in the process of ethical decision-making suggests that the decision maker might use both affective and rational functions conjointly to arrive at ethical decisions. This new stream of research has the potential to shift discussions of ethical decision-making away from covariant observations to an understanding of how decisions are made because these models address the comprehensive picture of information used by the decision maker. 


\subsection{Gaps and Inconsistencies in the Literature}

The literature surrounding ethical decision-making relies heavily upon investigation of explanatory independent variables and how they covary with ethical dependent variables (i.e. awareness, judgment, intent and behavior) rather than the actual cognitive processing through which ethical decisions unfold (McDevitt et al., 2007). This stream of research has identified a few variables that exhibit some regular correlation with ethicality but a satisfactory framework is yet to be identified for understanding ethical decision-making (Sonenshiem, 2007).

Underpinning traditional research in ethical business decision-making is an assumption that decision-makers should and do use rational processes to arrive at ethical decisions. This assumption of rationality for ethical decision-making, to the exclusion of intuition, is inconsistent with dual process theories that reflect current research in human cognition (Haidt, 2001; Reynolds 2006; Sonenshein, 2007). Nor is the assumption of rationality consistent with optimal decision-making within the Hammond (1990b) cognitive continuum framework.

Introduction of dual processing approaches to ethical decision-making models seems a reasonable course given the recognition of dual processing theory in cognition research (Haidt, 2001). Of the two identified frameworks that hinge on an assumption of dual processing to explain the process of ethical decision-making, Reynolds (2006) proposes that decisions could be either intuitively or rationally based but does not offer a way to test for these outcomes. Sonenshein's (2007) framework suggests intuitive decisions can be discerned by timing, as they would be more rapid than rationally based 
decisions. However, Sonenshein's assumption that rationality confirms intuition fails to account for those cases when intuition conflicts with rationality, and seems incompatible with Epstein's (2008) CEST model in which the rational and experiential systems influence each other. Unfortunately neither author offers empirical evidence to support their theory. Consequently it seems the contributions provided by Reynolds (2006) and Sonenshein (2007), while important milestones, provide at best a starting point from which further research must spring.

The present paper will attempt to address one of these gaps and inconsistencies. This research will take into account the unique aspects of ethical decisions, and will be predicated on the assumption that both the experiential and the rational systems are used in ethical decision making. The present paper will attempt to account for the use of dual processing in ethical decision making by examining the factors that might encourage the use of a more rational or intuitive process. The next chapter of this dissertation will hypothesize that presenting information in different ways to the decision maker might trigger a decision process that is more intuitive or more rational. Further, that the initial affective state of the decision maker, either positive or negative, might also influence whether the decision maker processes an ethical dilemma more rationally or intuitively. 


\section{CHAPTER 3}

\section{HYPOTHESES AND RESEARCH METHODOLOGY}

The previous chapter suggests that conjoint models of decision-making processes are salient frameworks to consider when examining the process of ethical decision making. Along with supporting evidence, this chapter proposes conjoint models as a lens to test a number of hypotheses suggesting that task information properties as well as affective states influence decision makers to process an ethical decision in a more rational or a more intuitive manner. Understanding how people process ethical decisions is an important step toward comprehending how ethical decisions are made.

\section{$\underline{3.1 \text { Model }}$}

A model of ethical decision processing based on the discussions that follow in this chapter is presented as Figure A.4. The present paper draws from literature that suggests that the modality of information presented to the decision maker, which represents the form in which that person receives information, might influence the individual to process that information in a more intuitive or rational way through the mental image vividness that the modality generates. Additionally, research suggests that the decision maker's affective state, either positive or negative, will influence that 
person to process decision information either more intuitively or rationally, respectively.

Importantly the proposed model focuses on factors that might have a bearing on the fundamental way people process the facts of a particular ethical dilemma. Previous research would suggest that, given the same set of material facts or circumstances, people might process these facts differently depending upon 1) the modality of the information that carried the facts to the decision maker and 2) the initial affective state of the decision maker going in to the decision.

What follows in this chapter provides a review of the underlying theoretical support for this model as well as a number of hypothetical propositions that can be inferred from this literature. It is suggested that people might process a decision more intuitively or more rationally when the facts and circumstances of a situation are held constant, but the modality of the perceived information changes, or the affective state of the decision maker is altered. If so this has important implications for understanding how people make ethical decisions.

\subsection{Hypotheses}

\subsubsection{Intuition and Information Modality}

Hammond's (e.g. 1990b) cognitive continuum theory (CCT) addresses the process of decision making from a conjoint basis as it focuses on the tension and distinction between intuitive and analytical thinking. Hammond's CCT is presented in Figure A.2. At one pole of the continuum, intuitive thinking can be thought of as reliance upon the experiential system, which rests upon an ability to pattern-match 
perceived stimuli with congruent experiences producing an affective reaction that guides decision-making. At the other pole analytic thinking is synonymous with rational, logical and effortful processing of information. Quasi-rationality occurs when decision makers rely on process strategies that conjointly utilize intuition and analysis to varying proportions (Cooksey, 1996).

The CCT is a framework for examining decision making processes in a wide variety of decisions dependent upon the task properties of a particular decision (See Figure A.3). Previous examinations of the CCT framework for decisions (e.g. Dunwoody, Haarbauer, Mahan, Marino and Tang, 2000; Hammond, Hamm, Grassia, and Pearson, 1987) demonstrated the validity of CCT across a variety of decisions but ethical decisions have not been examined within this framework. Due to its explanatory power across a spectrum of decision types, CCT potentially provides a framework for understanding how ethical decisions are made.

Recall that Mathieson (2007) suggests all ethical decisions can be classified similarly along a two dimensional continuum of simple to fuzzy and intellective to judgmental. While there is no research that directly compares her classification scheme and the task properties of CCT, ethical decisions would seem to be align consistently between the Mathieson (2007) framework and Hammond's (1990b) CCT when considering the CCT dimensions of complexity of task structure and ambiguity of task structure. 
However, the CCT task dimension that might vary among ethical decisions is the form of task presentation, including the modality of the information that is received by the decision maker. An important implication is that differences in the modality of the information that ethical decision makers are exposed to might cause some decision makers to make more rational decisions while others make more intuitive decisions.

\subsubsection{Information Modality as a Task Characteristic}

CCT suggests that decision makers are selectively capable of relying either on intuition or rational analysis based conditionally upon task item properties (See Figure A.3). CCT also suggests that decision makers will ordinarily use varying levels of intuition and analysis conjointly depending upon the nature of the task (Cooksey, 1996; Dunwoody et al., 2000). In CCT, task properties of a decision consist of three dimensions that include the complexity of task structure, the ambiguity of task content, and the form of task presentation. Each of these dimensions of task properties refers to cues, which are specific items of information (Cooksey, 1996).

Complexity of task structure refers to decision maker's consideration of properties that define the arrangement and makeup of a decision task. Ambiguity of task content encompasses the certainty or uncertainty of the decision task. The form of task presentation refers to the modality of how cues are presented to the decision maker, such as in pictures, in speech, or in writing. According to CCT, the modality of information, that is how information cues come to decision makers, influences the perception and decomposition of those cues by decision makers and has a bearing on 
how individuals process information by using relatively more rational or intuitive means. The form of task presentation is the focus of the below hypotheses due to the lack of research attention to this specific area in ethical decisions.

The form of task presentation, as determined by the modality of the information that is presented to the decision maker, can be either perceptually or functionally organized. Cooksey (1996, p. 22) suggests that if information presented to a decision maker is perceptually organized, such as in photographs, recorded messages, or in vividly descriptive text, then those modalities will tend to increase holistic pattern seeking and intuitive processing on the part of the decision maker. However, if cues are presented in a manner that is pallid the decision maker will be less inclined to process that information associatively focusing more on the logical implications of the facts rather than the associative context or holistic meaning of the information, and thus will rely less on intuitive processing and more on rational analysis. Further, if cues are presented in a functionally oriented way, such as with data points, measured quantities, or amounts and rates, then decision makers will be more prone to use rational processing that considers the cues sequentially. Thus, the CCT framework suggests that the modality of information presented to decision makers can influence them to be either more intuitive or more rational in their decision-making (Cooksey, 1996).

As previously reported in this paper, Hammond and his associates (1987) empirically documented the validity of the CCT in a field study observing experienced highway engineers as they engaged in discreet tasks involving three different types of decisions. The decision types, as categorized by the CCT framework, contained task 
characteristics that were typical of analytical and intuitive decisions, as well as quasirational decisions.

The form of task presentation was manipulated as the modality of the information presented to decision makers. Decision makers were provided with information cues in a variety of modalities either pictorially in filmstrips (perceptually organized), mathematical formulas (functionally organized) and bar graphs (quasiorganized). It was found that decision makers were prone to use different strategies of decision processing dependent upon information modality and in line with the CCT. For instance, those subjects who were presented filmstrips, perceptually organized information, tended to rely on more intuitive processing. Moreover, it also was found that those who made the best decisions (as compared to experts) were those who used intuitive or analytic processing strategies at the relative levels closest to those suggested by the CCT according to task characteristics (Cooksey, 1987).

Dunwoody and his associates (2000) conducted a further test of CCT using air traffic controller tasks. Presentation modality was manipulated using two different displays, one iconic, i.e. similar to a radar screen (perceptually organized), and the other a numeric display (functionally organized). Subjects were asked to make a series of decisions regarding each radar contact that varied on a seven-point scale between "ignore" and "defend". Here again, when the modality of information was presented more perceptually, as in the radar screen display, subjects tended to make decisions that were more intuitively based. As with Hammond et al. (1987), Dunwoody 
et al. (2000) found support for CCT suggesting people use intuitive and analytic processes contingently in line with the task characteristic dimensions of the CCT.

\subsubsection{Intuition, Affect, and Vivid Mental Imagery}

Cooksey's (1996) suggestion that information modality can affect the type of processing a decision maker uses is supported empirically by both Hammond et al.'s (1987) test of CCT, and subsequent support of CCT by Dunwoody and his associates (2000). These researchers demonstrated that altering how information is presented to decision makers seems to change the way people process that information, either rationally or intuitively. Additional clarity regarding the role of information modality on decision processes is provided by Paivio (e.g. 2007) who offers a parallel theoretical framework from the literature on perception. Paivio's framework, linking verbal and non-verbal perception, similarly proposes that changes in information modality can alter the manner of cognitive processing between the rational and the intuitive.

Paivio's $(1986,1991,2007)$ dual coding theory (DCT) suggests that cognition involves the cooperative interdependence of two functionally independent but interconnected systems, a verbal system specialized for dealing with language and a nonverbal system specialized for dealing with non-linguistic objects and events (Paivio, 2007, p. 33). In DCT the two perceptive systems symbolize reality for the preceptor in fundamentally different ways depending upon the modality of information coming to the perceiver (see Table A.2).

In the verbal system we experience and encode language, which can be perceived from visual, auditory, or even haptic (e.g. Braille) stimuli. The verbal system 
makes sense of reality indirectly using language symbols Paivio calls logogens, which are interpretable groups of language units (letters, words, phrases) that mean something to us and provide an understandable representation. Some logogens provide us with conceptual meaning (e.g. justice, trust, beauty) and others provide imagery indirectly following recognition (e.g. stick, glove, wrench).

In the nonverbal system visual objects, non-language sounds, emotions and other sensory input give rise to what Paivio refers to as imagens, which generate mental imagery directly and unconsciously. These images tap our experiences for associative meaning based on our familiarity with the objects and give rise to context through associations which are often congruently nested (e.g. justice in courts in government in America; stick with leaves on tree in forest) (Krasny, 2004; Paivio, 2007).

Representational meaning is conceptualized in DCT as direct activation of imagens by objects and logogens by words. The two systems are connected at the referential level at which the systems can cross-reference each other (see Figure A.5). The nonverbal, imagens system provides context to the verbal logogens side; and the verbal logogens side provides a logical framework to the nonverbal imagens side. The perceiver comes to a mental concept or understanding when logogens from the verbal side can be compared to related imagens from the non-verbal side, or when related logogens are rationally grouped (Krasny, 2004; Paivio, 2007).

DCT is a complimentary framework to the dual processing theory of cognition described above; the verbal and nonverbal systems are analogous to the rational and experiential systems, respectively, in dual processing theory. For instance, Paivio 
(2007) suggests the nonverbal system is older from an evolutionary perspective ( $p$. 257), is associative in nature and uses parallel processing (p. 51), that it is based on experiential or episodic knowledge (p. 33, 60), that the nonverbal system is intimately associated with affect and emotion (p. 191), and that it is preconscious (p. 179-180). Conversely the verbal system is a more advanced evolutionary system, is logical in nature and uses serial processing. The verbal system acquires procedural knowledge through conscious learning and logical inference (p. 33), and is a conscious system.

Mental imagery is an important concept in the function of the nonverbal system. By mental imagery I refer to concrete representations of perceptual experiences in working memory that draw from both perceptive stimuli and congruent prior experiences. These might often be referred to as "visualization" or "seeing in the mind's eye". Mental imagery is not a purely visual phenomenon; it includes mental representations associated with all sensory modalities (Krasny, 2004; MacInnis and Price, 1987; Sadoski and Paivio, 2001).

Mental imagery is coded in the nonverbal system in a way that evokes multiple associative pathways (Hong, 2006; Krasny, 2004). After encoding, the vividness of mental imagery is dependent upon cognitive elaboration, which refers to the number of associative pathways in memory that relate to a particular concept being perceived.

For instance, Kisielius and Sternthal $(1984,1986)$ suggest that written messages using devices such as pictures and instructions to image are likely to evoke mental imagery, which will increase the number of message-relevant associations in memory by providing contextual information. For decision-making processes, a substantial 
number of routes would be made available by which message-relevant information could be retrieved. In contrast, relatively few associative pathways are established in processing pallid information; hence, there would be few routes by which messagerelated information could be accessed (Hong, 2006). The activation of representations and associations is therefore direct in the case of non-verbal imagery and indirect in the case of verbal imagery (Paivio, 2007, p. 49).

The affective nature of mental imagery is an important component that ties it to the experiential system. For instance, Dewey (1934/1987) proposes that mental imagery allows us to internalize a situation according to past experiences, and that emotions are an ingrained quality of those experiences. Ahsen (1984) suggests that mental imagery includes not only the mental representation of a perception, but also its personal meaning and the affective/somatic response to that image. Experiential processing, including intuition, relies on schemas from previous congruent situations that have an affective valence. Bower (1981) suggests that affect is an integral component of our cognitive schemas about the social world, and memories for social stimuli are associated with a particular affective value (positive or negative) (AshtonJames and Ashkanasy, 2008).

Neurological research in brain activity suggests that visual external perception and visual mental imagery activate the same visual cortices in the brain (Kosslyn, Alpert, Thompson, Maljkovic, Weise, Chabris, Hamilton, Rauch, and Buonanno, 1993). Moyer, Bradley, Sorenson, Whiting, and Mansfield (1978) demonstrated that subjects made a similar pattern of responses with externally provided pictures and with 
internally generated images. Kisielius and Sternthal (1984) showed that attitude is similarly affected whether subjects generated images in response to verbal information or processed pictures that depicted the verbal information. Additionally auditory mental imaging also activates the same brain topographies as external auditory perceptions (Zatorre and Halpern, 1993). Even mental images relating to simulated movement are neurologically connected to the same process that controls actual sensory-motor activity (Kosslyn, 1994; Lang, Greenwald, Bradley and Hamm, 1993). It has also been found that mental imagery produces the same physiological effects that mirror external perceptions (Lang, et al., 1993). For decision makers, it seems external perceptions are functionally equivalent to internal mental imagery, the only difference being the intensity or vividness of the perception (Christensen, 2002; Hong, 2006).

Marks (1973) purports that vividness of mental imagery is related to the level of interest, meaningfulness and affect evoked by the stimulus which is imagined. Information may be described as vivid in that it is likely to attract and hold our attention and excite the imagination to the extent that it is 1) emotionally interesting, 2) concrete and imagery-provoking, and 3) proximate in a sensory, temporal or spatial way (Nisbett and Ross, 1980). Paivio (2007, p. 191) reports a study performed by Ley and Bryden (1983) in which participants memorized a list of high imagery and low imagery words that also varied in affective value. Words with high affective value are those that engender higher levels of intensity of either a positive or negative feeling. Recognition of emotional facial expressions was at the highest level when those subjects memorized words with high imagery that were also those high in affective value. In their 
explanation of results, these researchers suggest that memorization of high imagery and high affective value words activates emotive areas of the brain making that person more receptive to affective stimuli, much more so than high levels of either separately. Additionally, Goetz and Sadoski (1996) reviewed a 10-year program of research investigating the way imagery is related to emotional response in reading literary stories. They found that imagery and emotional response were moderately to strongly correlated in literary reading.

Taken together, evidence suggests that mental imagery is processed experientially and in an associative manner that evokes emotions and intuition when tied to familiar personal experiences that are coupled with the imagery. Vivid mental imagery also seems to be consistent with information that is perceptually organized. Consequently the presence of vivid mental imagery should promote use of the experiential system in decision-making processes. The greater the vividness of the mental imagery the more people might rely on intuitive processing. Mental imagery might be evoked indirectly through verbal information that is rich with vividness, or directly with vivid picture stimuli.

H1: When ethical dilemmas are presented in a written format and mental imagery is provoked through the addition of descriptive language that is unrelated to the material facts of the dilemma, case information is more likely to be intuitively rather than rationally processed.

$\mathrm{H} 2$ : When ethical dilemmas are presented in a written format and mental imagery is provoked through the addition of descriptive pictures that are 
unrelated to the material facts of the dilemma, case information is more likely to be intuitively rather than rationally processed.

H3: When ethical dilemmas are presented in a written format and mental imagery is provoked through the addition of both descriptive language and descriptive pictures that both are unrelated to the material facts of the dilemma, case information is more likely to be intuitively rather than rationally processed and to a greater extent than either descriptive text or pictures alone.

Perceptive stimuli that are vivid and able to create mental imagery might therefore have the potential to generate intuition and affect within the decision maker and influence the type of processing that individual uses to process an ethical decision to be either more intuitive or rational. Aside from information modality, some literature also suggests that the presence or absence of a pre-existing affective state might also have the same potential to influence processing to be either more intuitive or rational in an ethical decision. This possibility is explored in the following section.

\subsubsection{Affective Priming and Decision Processing}

Extensive literature suggests that the presence of a pre-existing affective state in a decision maker might influence an individual's decision processing to be more intuitive or rational. For instance, Kuhl and Kazen (1999) summarize research (Fiedler, 1988; Isen, 1984, 1987; Klinger, 1993; Kuhl, 1983a; Schwarz, 1990, Taylor, 1991) that suggests human decision processing and performance is affected by the affective disposition of the decision maker. Fiedler (1988), as an example, proposed that positive affect produces a "loosening style" which he characterized as creative and 
intuitive, whereas negative mood produces a "tightening style" which he described as being systematic and rigid.

Kuhl and Kazen (1999) propose the personality systems interactions theory (PSI) framework and provide supporting empirical evidence. PSI is designed to explain the relative ease with which the experiential system can be accessed by a decision maker. The PSI framework focuses on the ability of decision makers to cope with highly abstract matters that might require several steps toward a desired outcome. Highly abstract and complex matters involve the kind of decisions that match the descriptions of ethical dilemmas as provided above by Mathieson (2007), therefore PSI might have applicability in an examination of ethical decision making.

PSI offers neurobiological explanations to posit the existence of an inhibitory function that limits the degree to which an individual can make use of intuition when making associations between perceived stimuli and matching schemas. According to the PSI framework, an increase in positive affect promotes a release of the inhibitory function whereas significant reductions of positive affect increase the inhibition of this pathway (Kuhl and Kazen, 1999).

PSI theory proposes that positive affect supports a holistic, associative processing mode because the inhibitory function that moderates intuitive processing is attenuated, whereas negative affect supports an analytic processing mode because the inhibitory function is elevated (Bolte, Goschke and Kuhl, 2003). Thus, positive affect promotes the ability of a decision maker to more effectively use intuitive processing, 
and negative affect will inhibit the ability of a decision maker to use intuitive processing.

Isen $(2000$, p. 417) demonstrates in her research that the presence of a positive feeling cues positive material in memory, making access to such thoughts easier, and thus more likely that positive material will come to mind. This enhanced ability to engage in holistic, associative processing improves experiential processing leading to intuition. She proposes that experiential material in the mind might be organized and accessible in terms of its positive affective tone. If indeed schemas are organized based on positive affective tone, and considering that intuition is presented to the decision maker as affective information, then this directly links positive affect and intuition through schematic memory structure.

Isen (2000) points out that in those empirical studies using positive affective priming people had more diverse associations, a broader range of associations, and an enabled ability to see more similarities among items. This suggests a more extensive use of parallel processing in support of intuition. Specifically addressing decision making she points to work by Estrada, Isen and Young (1997) documenting positive affect's role in promoting integration of information for physicians making decisions. Physicians in whom positive affect had been induced applied associative information sooner to a diagnosis, and were less susceptible to rigid and inflexible thinking.

Based on their review of literature, Ashton-James and Ashkanasy (2008) also conclude that people in a positive mood are more likely to adopt creative, open constructive and flexible cognitive processing styles. Drawing particularly on Fiedler 
and Bess' (2000) work, they write that positive affect tends to promote a more schemabased, holistic processing style whereas negative affect induces a more exhaustive processing style that features a logical and detail oriented strategy.

In yet another summary by Sadler-Smith, Hodgkinson and Sinclair (2008), it is suggested that affect might assist or impede access to intuitive processing. For example, Elsbach and Barr (1999) used a highly structured decision protocol to demonstrate empirically that decision makers in a moderately negative mood more carefully executed the protocol steps, were more prone to execute steps in the prescribed order, and were more apt to rely on the outcome of the structured decision protocol as the primary basis for their decision. In another study, King, Burton, Hicks and Drigotas (2007) found support in tests of positive affect on non-rational beliefs and behaviors, such as superstitions, supporting the link between positive affect and the experiential system. Also cited in their review is Sinclair, Ashkanasy, Chattopadhyay, and Boyle (2002) who propose a theoretical model of decision making based on prior empirical work that includes affect as a moderator in decision processes and suggesting that "decision makers are inclined to use or eschew intuition depending on their affective states." They go on to propose that managers in positive affective states are more likely to use intuitive decision making than managers in negative affective states.

In another empirical study, Bolte, Goschke and Kuhl (2003) tested the relationship between affect and intuitive decision making ability. The introduction of a positive mood reliably improved the ability of subjects to make intuitive judgments. Overall, research on positive and negative affective priming seems to suggest that 
intuitive processing is enhanced under conditions of positive affect compared to neutral and negative affective states.

H4: In ethical dilemmas, decision-makers will rely to a greater extent on intuitive processing than rational processing when placed in a positive affective state as compared to a neutral affective state.

H5: In ethical dilemmas, decision-makers will rely to a greater extent on rational processing than intuitive processing when placed in a negative affective state as compared to a neutral affective state.

H6: In ethical dilemmas, decision-makers will rely to a greater extent on intuitive processing rather than rational processing when placed in a positive affective state as compared to a negative affective state.

\subsubsection{Decision Making Style and Decision Outcome}

Each predominant decision processing style, be it either intuitive or rational, organizes and processes information differently. Consequently these differences in processing ethical dilemma information might affect the nature of the decision outcome (Cooksey, 1996; Dunwoody et al., 2000; Hammond, 1987). Based on CCT, intuitive processing should lead to intuitive decision outcomes and rational processing should lead to rational decision outcomes.

H7: In ethical dilemmas, intuitive processing will lead to more intuitive decisions, whereas rational processing will lead to more rational decisions.

The current chapter hypothesizes that both the modality of information a decision maker receives as well as the decision maker's affective state going into a 
decision might influence the type of processing, intuitive or rational, that the decision maker might favor to deal with an ethical decision. By testing these relationships attention is drawn to the nature of decision making processes that a person might use to make an ethical decision. The next chapter focuses on the methodology used to test the above hypotheses. 


\section{CHAPTER 4}

\section{RESEARCH METHODOLOGY}

This section provides a general overview of the experimental methods used to test the hypotheses outlined in the previous chapter. Specific sections include an overview of the participants and recruitment, experimental design, experimental materials and sequence of events, manipulation of independent variables, confirmation of dependent variable constructs, measurement of dependent variables, manipulation check questions and pilot test results.

\section{$\underline{\text { 4.1 Participants and Recruitment }}$}

Participants were undergraduate students drawn from Management classes in the College of Business Administration at a large southwestern university. Participation was voluntary and participants were given course credit for taking part in the study. A total of 294 students participated in this study of which 123 were female and 171 were male. The mean of age of the participants was 23.54 years.

Research suggests that the power of a statistical test is an important consideration for duplication of results (Keppel and Zedeck, 1989; Potvin \& Schutz, 2000; Stevens, 1980) and must be a consideration for determining the number of participants in any study. A minimum power level requirement of .80 is considered acceptable for tests employing ANOVA procedures (Hair, Black, Babin, Anderson, and 
Tatham, 2006, p. 417; Cohen, 1988; Stevens, 1980; VanVoorhis and Morgan, 2001). Assuming an equal numbers of observations per cell based on an anticipated 25 observations per cell, the number of factors (levels) in the design and anticipating medium effect sizes for main and interaction effects, power levels were calculated to be .96 and 97 for main effects and .91 for interaction effects (Cohen, 1977). This exceeded minimum requirements.

\subsection{Experimental Design}

A 3 (mood state) x 4 (vividness of information) balanced factorial design was employed. There were three levels of the mood state variable (positive, versus neutral, versus negative affective state) and four levels of the vividness variables (pallid, versus pallid with images, versus narrative text, versus narrative text with images). For the twelve cells of the design the number of participants in cell each cell ranged from 22 to 28. The design is illustrated in Figure A.6.

All participants were randomly assigned to one of the four manipulations of vividness. However, because all participants in a session needed to be assigned to the same mood state, experimental times were randomly assigned to one of the three mood state conditions that were being examined. Preliminary piloting was conducted over the course of 20 weeks during two semesters of the school year. Students participated in the study for main effects over the course of 4 weeks. There were a total of 41 experimental sessions with each session lasting approximately 45 minutes. The number of participants in an experimental session ranged from a low of 1 to a high of 10 . 


\section{$\underline{4.3 \text { Overview of Procedures }}$}

All participants reported to a behavioral laboratory in the College of Business Administration building. After collecting consent forms and ensuring appointments matched with session times, participants were seated in a large 25 x 30 room. The room was subdivided with 10 individual carrels lined up against opposite sides of the perimeter of this room. Care was given to insure independence of responses while in the experimental setting through the use of carrels which prevented participants from viewing the materials given to the other participants and their responses.

After being seated at each individual carrel, the research session began with an explanation of the importance of the research effort. Participants were encouraged to take their time on the materials, to read all content and directions carefully and to be as honest as possible with their answers. Participants were then told that each part of the research session would require that all participants wait until the last participant had completed their work prior to moving to next part. All participants were asked not to talk with each other and to focus their attention on their own materials The experimenter was present in the room at all times to minimize unwanted distractions, to answer questions, and to move the participants forward through each step of the experiment.

Following the initial instructions, a short film clip was played to manipulate the initial affective state of the participants. Participants then completed the first of three questionnaires, which contained a scale to assess their affective state. Following this questionnaire, a short case was distributed to all participants. The case described an 
ethical dilemma in which the vividness manipulation was embedded. Some participants also received an envelope of images (pictures) associated with the case, and were asked to view the images after reading the case. Participants were then asked to record the time of day (hours, minutes and seconds) at the moment they finished reading the case and/or viewed the associated images by referring to a digital clock in the room. Following the recording of the time of day, participants were asked to respond to a second questionnaire. This questionnaire contained a description of two alternatives to solve the dilemma described in the case. Participants were to indicate their preference for one of two options and the extent they agreed with the selection of this alternative. After recording their decision participants then completed a third questionnaire that contained the remainder of the dependent variables. After completing the third questionnaire all participants were debriefed and dismissed from the experimental laboratory.

\subsection{Manipulation of Independent Variables}

\subsubsection{Manipulation of Initial Affective State}

The initial affective state was manipulated through one of three video clips that all participants viewed on a screen that was centered in front of the experimental room and through the distribution of candy in the positive affective state condition. Participants could view the video that was developed for each of the experimental conditions by rotating their chairs 90 degrees to face the screen on one of the far walls of the room. . Participants in each session viewed the same video clip as a group. Video clips were designed to induce either a positive, negative or neutral mood. Mood 
induction through video presentation was selected because it was found to be the most effective method of inducing mood in experimental participants in a meta-analysis conducted by Westermann, Spies, Stahl and Hesse (1996). In their review Westermann and his colleagues (1996) found video presentations to be more effective at both positive and negative mood induction over other methods such as imagining (think feel), pictures, sounds, social interaction or facial expression.

In the positive affective state condition, a humorous video was selected to facilitate laughing and corresponding emotional states of joy and happiness. This video ran for approximately 5 minutes and was clip of a Drew Carey skit from the television show "Whose Line Is It Anyway?" To enhance feelings of positive mood, those participants were also given a small bag of candy just before viewing the video. The technique of providing small gifts of candy to induce positive mood has been successfully employed by Alice Isen in her work (e.g. Isen, 2000, p. 423; Estrada et al, 1997) and was used in this study as a supplement to increase the positive mood generated by the video.

In the negative affective state condition, a video was selected to facilitate experiencing emotional states of sadness and distress. The specific video ran for approximately 5 minutes and consisted of an animated clip of a small child who had lost her father in the September $11^{\text {th }} 2001$ terrorist attacks.

In the neutral affective state condition, a video was selected that would be unlikely to arouse either positive or negative emotions. The specific video ran for 
approximately 5 minutes and was a clip of an individual walking on a treadmill while describing a workout program.

After viewing the film clip in their respective conditions, participants were asked to re-adjust their chair so as to face their carrel. All participants were then asked to complete the first of three questionnaires. This questionnaire consisted of the Positive and Negative Affect Scale (PANAS) (Watson, Clark, and Tellegen, 1988). It was used to check the manipulation of the participant's affective state and to act as a buffer between surveys to support the cover story. The PANAS scale is discussed more fully in the section in this chapter dealing with manipulation checks.

\subsubsection{Manipulation of Vividness}

All participants received same case information describing an ethical dilemma. The case vignette presented a hypothetical situation where a company had discovered a gasoline refining process that promised to significantly increase gas mileage, commensurately lower the cost of gasoline, and provide a sizable economic benefit for the world economy as a whole. This process was made possible by processing gasoline with an imaginary substance called "sulathium". However, the only place on earth that sulathium could only be found was in a very small area of Louisiana inhabited by a unique agrarian community who were very tightly bound to their land and their austere and simple lifestyle. Because they value their land and lifestyle, the members of the community had just refused a generous offer for their land from the company indicating that no further offers for the land at any price would be considered. After reading the case, two options were described, whether the company should proceed with the use of 
political pressure (e.g. eminent domain) to force the people from the land or whether the company should abandon the gasoline processing project and allow the people to continue their lives undisturbed as the community members wished.

The vividness manipulation was accomplished through variation in the manner in which the case information was presented. There were four experimental conditions. These included a pallid or baseline condition where information was presented in a factual and matter-of-fact manner through a bullet point description of the elements of the case. The presentation of the case information was designed to offer the cold facts of the case in a way that minimized mental imaging of the people or the land involved.

In the remaining three conditions, a pallid + images condition, a narrative text condition, and a narrative text + images condition, the information presented was designed to enhance vividness of mental imagery regarding aspects of the people in the community, the land they lived on and their lifestyle. While presenting the identical material facts of the case, the narrative version described details that might lead to vivid mental images of the community. For example, a section of the pallid version reads:

- The people in this area decided as a group that they do not want to sell.

- The people in this area believe they have a way of life that is important to them.

- The people value their community.

- The people believe there is no other place they can move to together and maintain their way of life.

- The people believe the area is irreplaceable for them to maintain their way of life.

- The people believe living together and their way of life means more to them than the money the company is offering.

- The people consider their decision final and will not consider any other offers. 
In the narrative condition the same factual information as in the pallid version of the case was presented but in a narrative or story form. Additional text was embedded in the narrative that provided vivid imagery to the reader but was designed not to alter the material facts of the case. The commensurate section of the above pallid version in vivid narrative text reads:

Mr. Vincent rises to announce the decision for the community. As he stands his brow furrows atop soft brown eyes and between his thick graying hair and his full beard. He rests his leathered and calloused hands on the table and speaks in a firm voice with a distinct Cajun accent. Mr. Vincent says the community has decided that they do not want to sell their land. The people feel they have their own way of life that is important to them. They value their community and they believe there is no other place that they can move to as a community to maintain their way of life. The people believe that this land is irreplaceable for them to maintain their way of life. They feel that their community and cherished way of life mean more to them than the money the company is offering. The other leaders and the family members nod in agreement, making assurances that this is their final decision and that they will not consider any other offers.

When images (pictures) were presented in two of the above conditions, with pallid or narrative text, these provided vivid illustrations of the people, the land, and their lifestyle. The images consisted of a series of 23 color photographs, presented no more than four images to a page on six separate pages and without captions or written descriptions. The images consisted of faces of individuals and groups, houses, farming activities and landscapes that coincided with the descriptions in the narrative text vignette. The images were adapted from internet searches and aggregated to form a 
coherent and believable representation of the people and place involved in the vignette. (These cases and images are provided for review in Appendix B.)

\subsection{Strategy for Scale Reduction}

The dependent measures for outcome confidence, approach confidence and decision recall confidence each contained three scale items. The dependent measures for intuitive self report and rational self report both contained ten scale items. Prior to establishing the constructs to be used the analysis for main effects, a two step process for scale reduction was employed. The first step was to use exploratory factor analysis (EFA) to suggest scale item reduction for the nine confidence items and also for the twenty self report items. The second step was to perform a confirmatory factor analysis (CFA) to validate separation of the scale items into individual constructs as suggested by theory or to determine if items collapsed into higher order constructs.

All nine confidence items were aggregated together into a single EFA for examination. Common factor analysis (SPSS Principal Axis Factoring) was used, with oblique (SPSS Oblimin) rotation. Common factor analysis, combined with oblique rotation, is preferred in situations such as this when the methodological purpose is to uncover latent constructs (Fabrigar, Wegener, MacCallum \& Strahan, 1999; Hair, 2006, p.117-119 \& 127). When all items were included in the factor analysis a Kaiser-MeyerOlkin (KMO) measure test yielded adequate multi-collinearity to perform a factor analysis (.823). Bartlett's test of sphericity was not significant $(p<.000)$. The factor analysis revealed three factors emerging with eigenvalues above 1.0, together explaining $73.5 \%$ of variance, and the pattern matrix revealed that these aligned 
precisely with the three separate confidence constructs. This suggests that the three confidence constructs are sufficiently reduced.

Similarly a separate EFA examined the twenty self report items that comprised the self report constructs for intuition and rationality. Again using common factor analysis combined with oblique rotation a KMO test yielded adequate multi-collinearity (.811), and Bartlett's test of sphericity was not significant $(p<.000)$. The factor analysis revealed six factors emerging with eigenvalues above 1.0. However, the first two factors alone explained $42.9 \%$ of variance. The pattern matrix for factor 1 demonstrated that items $11,12,13$ and 14 in the rational self report cluster grouped together, and factor 2 demonstrated that items 3, 4, 5, and 6 in the intuitive self report cluster grouped together. This EFA analysis suggests that reduction of the intuitive self report and the rational self report should be made to include only those items.

Following the two EFA analysis, the proposed constructs were examined together in a Confirmatory Factor Analysis (CFA) using Structural Equation Modeling (SEM) techniques with Lisrel software. An examination using CFA would confirm whether the separate scales should be combined to form a higher order construct.

The results of the CFA suggested that outcome confidence, approach confidence, decision recall confidence, intuitive self report and rational self report should remain as separate constructs. The CFA model using each of these constructs separately demonstrated that scale items loaded to the suggested latent constructs as expected $\left(\chi^{2}=231.08 ; p=.00 ; \mathrm{GFI}=.91 ; \mathrm{NFI}=.94 ; \mathrm{RMSEA}=0.062\right)$. Dependent 
measures with multiple items were therefore used as suggested by the confirming EFA and CFA two step strategy.

\section{$\underline{4.6 \text { Measurement of Dependent Variables }}$}

\subsubsection{Decision Time}

Decision makers who rely primarily on intuitive processing have much shorter deliberation time for decisions than those who use more rational approaches for a decision (Cooksey, 1996; Dane and Pratt, 2007; Glockner, 2008; Epstein, 2008). Intuitive processing is rapid and involves associative parallel processing as compared to rational processing which is slower and serial in nature (Betsch, 2008). Participants were asked to self report their time for making their decision about the case by recording the time of day (hours, minutes, seconds) immediately after reading the case vignette and again immediately after making their decision. The time difference, in seconds, is used as the dependent measure of decision time.

\subsubsection{Decision Outcome Confidence}

Decision makers using intuitive processing are more confident of the appropriateness of their decisions than those using rational approaches (Cooksey, 1996; Dunwoody et al., 2000; Hammond, 1990b; Hammond et al., 1987). Intuitive decision makers rely on somatic markers (Damasio, 1994 ) that result in a "gut feeling" that assures the decision maker a certain course of action is proper giving them a high degree of confidence in the appropriateness of their decision outcome. Decision makers using rational approaches use calculative processing, and these decision makers realize 
that calculations are subject to the possibility of error (Dunwoody et al., 2000). Therefore rational decision makers are less confident as to whether they arrived at the best possible decision outcome.

Decision outcome confidence was measured using a modified version of a scale employed by Dunwoody and his associates (2000). It should be noted that while Dunwoody et al. (2000) used the concept of "confidence differential" to contrast decision outcome confidence and decision approach confidence into a single construct, the present research separated these two concepts into distinct constructs. The reason for this separation is based on work by Hammond and his colleagues (1987) whose results suggest the need to keep both constructs distinct. Decision outcome confidence was assessed using a three item scale where participants indicated how confident they were that they made the best possible decision, how confident they were that their decision was the best solutions to the dilemma, and how confident they were that their solution represents the best alternative for this situation. The response scale for all three items ranged from (1) not confident to (7) very confident. Coefficient alpha for this three item scale was .76.

\subsubsection{Decision Approach Confidence}

Decision makers using intuitive processing are much less confident about the approach that they used to make a decision than are those using more rational processing (Dunwoody et al., 2000; Hammond, 1987). Rational decision makers are more aware of and more assured by the logic and precision in the approach that they bring to bear on a problem. Intuitive decision makers depend primarily on feelings, and 
while they feel strongly that a particular decision provides the best outcome they commonly are less sure that mere feelings provide an optimal approach (Cooksey, 1996; Dunwoody et al., 2000). Decision approach confidence was measured using a three item scale where participants indicated how confident they were that the approach they used to arrive at their decision was appropriate, that how they arrived at their decision was a valid process, and the degree of confidence in the thought processes used to arrive at their conclusion. The response scale for all three items ranged from (1) not confident to (7) very confident. Coefficient alpha for this three item scale was .80 .

\subsubsection{Decision Recall Confidence}

Intuitive decision makers are typically unable to recall precisely how they arrived at their decision while rational decision makers using deliberate conscious methods can (Cooksey, 1996, p. 14; Dane and Pratt, 2007; Reynolds, 2006). The rational decision maker's ability to recount the steps leading up to an intuitive decision is herein called decision recall confidence. Decision recall confidence was measured using a three item scale where participants indicated how confident they were that they could tell another person about the steps that they used to come to their decision. Scale items included how confident they were that they could express in precise terms the approach that they used to make their decision, how confident they were that they would be able to explain to another person how they came to their conclusion, and how confident they were that they could accurately describe the thought processes leading up to their decision. The response scale for all three items ranged from (1) not confident to (7) very confident. Coefficient alpha for this three item scale was .85 . 


\subsubsection{Intuitive Processing Self Report}

Decision makers using predominantly intuitive processing are more likely to report that they used their heart and their feelings to make decisions (Novak and Hoffman, 2005). Intuitive processing self report was measured using a ten item scale assessing intuitive task specific thinking that was developed by Novak and Hoffman (2005). For example, this scale asks respondents the degree they believed statements to be true, such as "I relied on my sense of intuition", "I trusted my hunches", and "I used my gut feelings" when solving this problem. Responses are made on a scale ranging from (1) definitely false to (5) definitely true. The construct for intuitive processing self report based on four scale items suggested by the data reduction procedures described above yielded a coefficient alpha reliability of .868 .

\subsubsection{Rational Processing Self Report}

Decision makers using predominantly rational processing are more likely to report that they used logical analysis and a conscious step-wise process to make decisions (Novak and Hoffman, 2005). Rational processing self report was measured using a ten item scale developed by Novak and Hoffman (2005) For example, Respondents were asked to respond to the degree they believed statements to be true, such as "I tackled this decision systematically", "I used clear rules", and "I reasoned things out carefully". Response were made using a scale ranging from (1) definitely false to (5) definitely true. The construct for rational processing self report based on four scale items 
suggested by the data reduction procedures described above yielded a coefficient alpha reliability of .804 .

\subsubsection{Decision Outcome and Dilemma Information}

The vignette used in this study was designed to offer two alternative choices to resolve the ethical dilemma presented in the case. One alternative was intended to appeal to individuals operating from a utilitarian (Sprigge, 1988) or consequentialist (Fried, 1978; Kamm, 2007; Kujala and Pietilainan, 2004) perspective. This perspective is rationally based because it centers on a calculative approach (Fried, 1978; Kamm, 2007; Sprigge, 1988) that favors choosing an alternative to a dilemma that might bring the most good, or the least harm, to the greatest number of people. From this viewpoint a decision maker logically weighs the relative merits of actions that are "right or wrong depending on whether they increase or decrease happiness in the world" (Sprigge, 2007, p. 9), where a "calculation requires that we...maximize the good" (Kamm, 2007, p. 11). Decisions reflective of this type of outcome are believed to be non-emotional (Ellis, p. 169-170; Hayry, 1994, p. 97), impersonal (Ellis, 1992, p. 158) and objective (Kamm, 2007, p. 136) approach to ethical dilemmas.

A second alternative in the vignettes was designed to appeal to those operating from a non-consequentialist (Fried, 1978; Kamm, 2007) point of view. Here the decision maker subjectively assesses whether the people involved in a dilemma have an inviolate immunity from harm resulting from a decision that might affect them. In comparison to a consequentialist approach, a non-consequentialist would ignore the 
overall benefit to society in favor of protecting the moral rights of a smaller number of people, suggesting that the general consequences of a decision should be ignored in favor of giving people their due regarding justifiable claims (Kujala and Pietilainen, 2004). Fried (1978, p. 9) suggests that "consequentialism subordinates the right to the good" whereas non-consequentialism is an absolutist perspective that proposes the degree of goodness is separate from the correctness of action. The defense of rights and justice are therefore central concepts in non-consequentialist approaches to ethics (Kujala and Pietilainen, 2004, p. 3). When specific rules or laws have not been formally set down to protect the legal rights of people in certain contexts, decision makers must subjectively assess whether the moral rights in question represent justifiable claims, a process that largely relies upon emotion (Kujala and Pietilainen, 2004).

With these differences in mind a question was constructed reflecting this dichotomy to resolving the ethical dilemma presented in the case. Participants were asked to indicate whether they favored "Option A: The company should move forward with the gasoline processing plan, use political pressure to force the group off the land, and begin the gasoline processing operations." or "Option B: The company should respect the wishes of the people in the group, allow them to remain on the land, and abandon the gasoline processing plan." Participants were then asked to indicate the option they agreed with and the strength of their conviction on a six point scale ranging from (1) strongly agree to (3) slightly agree for Option A, and from (4) slightly agree to (6) strongly agree for Option B. A six point scale was used so that participants were 
not given the choice of a neutral position; they were therefore forced to choose one option over the other.

Option A, favoring the company's position, with resulting broad benefits to a great number of people at the expense of a few clearly represents a consequentialist perspective. Those who rely on a more calculative approach might be swayed with a consideration of the facts in which a weighing of the benefits and harm to either side would favor this option. Option B, allowing the people to remain on the land undisturbed, is designed to be a non-consequentialist perspective. The inalienable rights, if any, that the community of people might have with regard to their claim to the land might be more favored from this subjective position.

\subsection{Piloting}

As previously mentioned in this section, vividness was varied by the type of information presented in case that the participants read. This included a pallid "bullet point" listing of facts or a more vivid rendition of the same facts in a narrative text, as well as the inclusion of vivid images representing the people, place and lifestyle depicted in the vignette. To check whether the manipulation of vividness was successful an, eight item scale developed by Miller, Hadjimarcou \& Miciak (2000) was adopted for use in this study. Questions asked participants on a response scale ranging from (0) "no picture comes to mind" to (6) "extremely clear and vivid" the extent to which they experienced vivid mental imagery regarding the faces of the people, how the people dress, how they talk, the sounds and aromas in the community, how the people 
live their lives, and how they farm their land. Coefficient alpha for this eight item scale was .870 .

Piloting testing examined whether the baseline or pallid version of the case differed from the pallid + images condition, the narrative text condition, and the narrative text + images condition. In testing these potential differences, participants were randomly assigned to one of the four levels of vividness. Cell size ranged from 9 to 15. Using ANOVA procedures in a one way design a significant main effect of vividness manipulation was obtained $\left(\mathrm{F}_{3,48}=14.640, p<.000\right)$. Using Bonferroni procedures the mean for the pallid condition $(\mathrm{M}=1.46)$ significantly differed as expected in terms of the level of vividness when compared with the means of the Pallid + Images $(M=4.08)$, the Narrative Text condition $(M=3.60)$ and the Narrative Text + Pictures Condition $(M=3.94)$. There were no other significant differences. The extant literature differentiates the level of vividness in the factual presentation of the material presented in the pallid version from the more vivid presentation of material presented in the remaining conditions. However, it does not differentiate among the remaining three conditions by theorizing that these conditions should differ from each other. Thus, the manipulation of vividness was considered to be successful.

A pilot study was completed to verify whether participants viewing the humorous video and receiving candy experienced a more positive affective state when compared with participants viewing the sad video or participants viewing the neutral video. The scale used to test affect differences was the Positive and Negative Affect Scale (PANAS) (Watson, Clark and Tellegren, 1988) (e.g. Adams, Treadway, and 
Sepina, 2008; George \& Zhou, 2007; Russell, 2008). The PANAS scale consists of ten items that measure positive affect (e.g. "enthusiastic", "excited", "proud") and ten items measuring negative affect (e.g. "irritated", "nervous", "scared"). Feelings are described on a response scale ranging from 1 to 5 for each of the twenty items, with higher numbers representing more intense feelings. Responses to each set of ten items were summed to obtain a measure of current positive and negative affect for each participant.

To test for differences among the three treatments, participants were randomly assigned to one of the three video conditions. Cell size ranged from 10 to 20 . Using ANOVA procedures in a one way design, there was a significant main effect of the video type on the response measure of positive affect $\left(\mathrm{F}_{2,45}=17.522, p<.000\right)$. As expected, using Bonferroni procedures, the PANAS positive affect score was significantly higher for participants that experienced the humorous video and received candy $(M=33.60)$ then for participants viewing the neutral video $(M=27.36)$, or the sad video $(M=20.64)$.

Using similar ANOVA procedures in a one way design there was a main effect of video type on the negative affect response variable $\left(\mathrm{F}_{2,45}=24.111, p<.000\right)$. As expected, using Bonferroni procedures, the participants viewing the sad video experienced higher levels of negative affect $(M=20.64)$ then participants viewing the neutral video $(\mathrm{M}=15.00)$ or humorous video $(\mathrm{M}=11.45)$

The next section of the present paper will report on the analysis of results of the study in testing the hypotheses from the previous chapter. 


\section{CHAPTER 5}

\section{RESULTS}

This chapter describes the results for tests of each of the hypotheses presented in Chapter 3. Analysis was performed using analysis of variance (ANOVA) procedures for each dependent measure. Hypotheses 1-3 were tested simultaneously as were hypotheses $4-6$ in a 3 (mood state) $x 4$ (vividness of information) balanced factorial design. Hypotheses 1-3 examine the relationship of vividness to the dependent measures. Hypotheses 4-6 examine the relationship of affective state to the dependent measures. The results of all F-tests are reported in Table A.3. Following significant F-tests, Bonferroni procedures were used to test for differences between means. The results of these tests are reported in Tables A.4 and A.5. Hypothesis 7 examines the relationship between processing style, either intuitive or rational, and its relationship to the decision direction. This hypothesis was tested separately. The significance criterion for all statistical tests was an alpha of .05.

All dependent measures assessed the extent that the participants engaged in rational versus intuitive processing. Dependent measures were composed of indirect measures of rational/intuitive processing including: decision time, outcome confidence, approach confidence, decision recall confidence, as well as more direct 
self-report measures including intuitive processing self report, and rational processing self report. Theory suggests that rational compared to intuitive processing: requires more time to make a decision, and results in lower levels of outcome confidence (that the best decision was made), higher levels of approach confidence (that processes used were correct), and higher levels of decision recall confidence (an ability to recount the steps used in the decision process). Remaining dependent measures assessed the extent that participants reported using either intuitive processing (intuitive self report) or rational processing (rational self report). A summary of these dependent measures and their relationship to either intuitive or rational processing is presented in Table A.6.

A correlation table describing the relationships among the dependent measures is presented in Table A.7. Notice that confidence measures were positively correlated to each other, contrary to the expectation that outcome confidence should be inversely related to approach confidence and decision recall confidence measures. All three confidence measures were correlated to rational self report, although it was expected that outcome confidence would be inversely related to rational self report. The correlation between intuitive self report and outcome confidence was in the expected direction. Surprisingly intuitive self report was also positively related to approach confidence. Contrary to expectations, decision time was negatively related to approach confidence and decision recall confidence. However, decision time was 
inversely related to outcome confidence and intuitive self report in line with expectations.

\section{$\underline{5.1 \text { Hypothesis } 1-3}$}

Hypotheses 1, 2, and 3 proposed that increased levels of imagery vividness will be related to increased levels of intuitive decision making style in ethical decisions. Using analysis of variance (ANOVA) procedures a main effect of vividness on the response measure of approach confidence was significant $\left(\mathrm{F}_{(11,282)}=\right.$ 3.77, $p<.05)$. Main effects for vividness on decision time $\left(\mathrm{F}_{(11,282)}=2.42, p=.07\right)$, outcome confidence $\left(\mathrm{F}_{(11,282)}=0.95, p=.42\right)$, decision recall confidence $\left(\mathrm{F}_{(11,282)}=\right.$ $0.77, p=.51)$, intuitive self report $\left(\mathrm{F}_{(11,282)}=0.54, p=.65\right)$, or rational self report $\left(\mathrm{F}_{(11,282)}=1.598, p=.19\right)$ were not significant.

Given the significant main effect of vividness on approach confidence, comparisons of cell means were conducted using Bonferroni tests. Results indicated that the mean for approach confidence was significantly higher in the pallid condition $(\mathrm{M}=6.00)$ than in the vivid narrative condition $(\mathrm{M}=5.51, p<.05)$. This supported Hypothesis 1 predicting lower levels of rational processing in the narrative compared to the pallid condition. Means for approach confidence were also higher when the pallid condition $(\mathrm{M}=6.00)$ was compared with the pallid with images condition $(\mathrm{M}=5.48, p<.05)$. This supported Hypothesis 2 predicting higher levels of rational processing in the pallid compared to the pallid with images condition. Means did not differ when the pallid condition $(\mathrm{M}=6.00)$ was compared to the 
narrative in combination with vivid imagery condition $(M=5.64)$, though in the correct direction. Thus, for the response measure of approach confidence there was support for Hypotheses 1 and 2 but not 3 .

\subsection{Hypothesis 4-6}

Hypotheses 4, 5 and 6 examined whether the use of positive affective priming would be associated with more intuitive processing, and whether negative affective priming would be associated with more rational processing. Using analysis of variance (ANOVA) procedures a main effect of affect on the response measure of outcome confidence was significant $\left(\mathrm{F}_{(11,282)}=3.80, p<.05\right)$. Findings also demonstrated a significant relationship between affective priming and approach confidence $\left(\mathrm{F}_{(11,282)}=2.94, p=.05\right)$, and between affect and decision recall confidence $\left(\mathrm{F}_{(11,282)}=5.70, p<.01\right)$. Neither decision time $\left(\mathrm{F}_{(11,282)}=0.72, p=.49\right)$, intuitive self report $\left(\mathrm{F}_{(11,282)}=1.28, p=.28\right)$, nor rational self report $\left(\mathrm{F}_{(11,282)}=0.28\right.$, $p=.75)$ demonstrated significant main effects for affect.

Analysis using the Bonferroni tests indicated that the mean for outcome confidence was significantly higher in the negative affect condition $(M=5.25)$ than in the neutral affect condition $(\mathrm{M}=4.77, p<.05)$. Bonferroni tests also revealed that approach confidence was significantly higher in the positive affect condition $(\mathrm{M}=$ 5.79) than in the neutral affect condition $(\mathrm{M}=5.45, p<.05)$. Bonferroni tests further revealed that decision recall confidence was significantly higher in the positive affect condition $(M=5.87)$ than in the neutral affect condition $(M=5.50, p$ 
$<.05)$, and that decision recall confidence was significantly higher in the negative affect condition $(M=5.98)$ than in the neutral affect condition $(M=5.50, p<.01)$. Means did not significantly differ for outcome confidence when positive affect $(\mathrm{M}=$ 5.00) was compared to neutral affect $(M=4.77)$, nor did means differ significantly for approach confidence when negative affect $(M=5.75)$ was compared to neutral affect $(M=5.45)$.

Consequently, for the dependent measure of outcome confidence the pattern of mean differences suggests that participants in a negative affective state were processing decisions more intuitively. Also, for the dependent measures of approach confidence and decision recall confidence, the pattern of means differences suggests that people in a positive affective state are processing decisions more rationally than in a neutral affective state. These findings were inconsistent with hypotheses 4,5 and 6.

\section{$\underline{5.3 \text { Hypothesis } 7}$}

There is some a priori evidence to suggest that consequentialist-based decisions are the result of rationally influenced decision processing and that nonconsequentialist-based decisions are the result of intuitively oriented decision making (e.g. Haidt, 2001; Kamm, 2007; Kujala and Pietilainen, 2004). Recall that a consequentialist perspective is calculative in nature and favors the sum of the greater good or benefit of society over individuals or groups, and the non-consequentialist perspectives are subjectively based favoring perceptions of inviolate rights of 
individuals or groups with justifiable claims over the benefit of society. Consequently "option A" of the vignette was developed to contain elements of a consequentialist perspective and "option B" a non-consequentialist perspective. Hypothesis 7 proposes that intuitive processing will lead to more intuitive decisions in alignment with these options.

An exploratory study was undertaken to examine this possibility. After reading either the pallid version of the vignette or the narrative version of the vignette, participants were instructed to make their decision either rationally or intuitively. In the rational condition participants were instructed to make their decision based on cold logic and block any emotions that they might have about the decision. Participants were further primed to be rational by having them list all of the important facts in the case prior to their decision. In the intuitive condition participants were asked to make their decision by relying on their emotions and gut feelings about the case. Further priming in the intuitive condition was accomplished by having the participants report which emotions they experienced after reading the case from a list of positive and negative emotions that were provided by the experimenter.

An omnibus F-test using ANOVA procedures comparing the four groups (pallid text with intuitive priming, pallid text with rational priming, narrative text with intuitive priming and narrative text with rational priming) within a single model demonstrates that experimental conditions were significantly different $\left(\mathrm{F}_{(3,72)}=4.61\right.$, 
$p<.01)$ with respect to the type of decision they made. Post hoc tests using Bonferroni procedures were then used to test for anticipated differences in the type of decision. When participants received the narrative vignette combined with instructions to be intuitive or instructions to be rational, those receiving the intuitive instructions more strongly preferred a non-consequentialist decision favoring the "right of the individuals" in the case $(\mathrm{M}=4.12)$ while those receiving the rational instructions more closely favored a decision representing the consequentialist perspective of the "greater good for the largest number of people" $(\mathrm{M}=2.38, p<$ .01). Additionally the narrative vignette combined with instructions to be intuitive $(\mathrm{M}=4.12)$ significantly differed from the pallid vignette combined with rational instructions $(\mathrm{M}=2.75, p<.05)$. Participants in the former conditions more strongly favored the non-consequentialist right of the people while the participants in the latter condition favored the consequentialist perspective that sided with the company. Significant means differences were not found between the narrative version combined with intuitive priming $(\mathrm{M}=4.12)$ and the pallid version with intuitive priming $(\mathrm{M}=2.95)$. These results are summarized in Table A.8.

The next chapter will discuss these findings and implications. 


\section{CHAPTER 6}

\section{DISCUSSION}

This study examined the role of intuitive and rational processing when individuals are involved in an ethical dilemma. It was expected that individuals would process decision information more intuitively when in a positive affective state, and also when vivid mental imagery was evoked through characteristics of decision information modality such as descriptive narrative text or images. It was further expected that individuals would process decision information more rationally when in a negative affective state, and when mental imagery was attenuated. Measures of processing style included direct measures such as decision time, as well as indirect measures such as decision outcome confidence, decision approach confidence, decision recall confidence, intuitive self-report and rational-self report.

A summary of results for each hypothesis across the various dependent measures is presented in Table A.9. Contrary to expectations, the outcome measures of intuitive self-report and rational self-report were not correlated. It was expected that these measures would be negatively correlated to each other. Another observation regarding the dependent measures that diverged from expectations was that the three confidence measures showed some degree of inter-correlation, and that 
outcome confidence was positively, rather than negatively, correlated to approach and decision recall confidence measures.

While the results for this study are reported separately for the independent variables of vividness and affective state, it should be noted that they were examined simultaneously in each separate ANOVA. While interaction effects between these two independent variables were not hypothesized, possible interactions were tested as a matter of post experimental interest. No significant interaction effects were found.

An alternative method to examine the variables of interest would have been to use a single MANOVA test instead of separate ANOVA tests for each dependent measure. MANOVA techniques would have the advantage of accounting for the shared variance between the dependent measures (Hair, et al., 2006). Huberty and Morris (1989) provide guidance with respect to use of these alternative methodological procedures. They suggest that it is appropriate to use separate ANOVA tests for multiple dependent measures when either (1) outcome variables are conceptually independent, that is to say that there is not a "variable system" among the outcome measures, (2) when the research is exploratory in nature, and (3) when some or all of the outcome measures in the current study have been studied previously in univariate contexts. The present study qualifies on all three conditions as there is not a variable system among the dependent measures, this research is 
being conducted in an area that has not been previously explored, and the various dependent measures have been taken from separate prior studies.

\section{$\underline{6.1 \text { The Impact of Vividness }}$}

Regarding the impact of vividness on the response variables, the hypotheses suggested that decision makers exposed to information about an ethical dilemma containing vivid narrative text, visual images, and a combination of vivid narrative text and visual images would process decision information more intuitively when compared to a pallid condition which presented the information in a factual manner. It was found that participants responding to a pallid, non-vivid description of an ethical dilemma were significantly more likely to report to be more confident about the approach they used to reach their decisions (approach confidence) than participants responding to the more vivid narrative version, and the more vivid version containing images of the people involved. Approach confidence was a measure of how confident decision makers were that they used the best approach in making their decision. Based on the extant literature (Cooksey, 1996; Dunwoody et al., 2000; Hammond et al., 1987b) higher scores on this measure reflected rational processing.

Surprisingly participants receiving a more vivid version containing both narrative text and images did not differ on approach confidence from participants receiving the information in a pallid manner although the means were in the predicted direction. It is possible that conflicting images resulted from the 
combination of stimuli might have served to reduce the imagery vividness. In piloting, lower vividness scores for the combination of vivid narrative text and images were observed compared to either the narrative or image condition. One could speculate when people first read a narrative that describes individuals, then see those individuals for the first time, there may be an inconsistency between their mental imagery of these individuals and their actual appearance. Consequently this combination of cues might have resulted in conflicting mental imagery that reduced the expected impact of this condition.

The expected impact of vividness on the rest of the decision measures, including decision time, decision outcome confidence, decision recall confidence, intuitive self-report and-rational self report, was not found. Only the means for the measure of decision recall confidence, though not significant, were in the expected direction.

The lack of a stronger impact for vividness across the multiple dependent variables does not appear to be due to an inability to manipulate the vividness of the presentation of the ethical dilemma. Vividness was measured using a recognized scale (Miller, Hadjimarcou, and Miciak, 2000) and piloting did separate response means for the pallid version from the vivid versions including the narrative text, pallid text with images, and narrative text with images. The fact that the difference between the levels of vividness for the narrative text, images, or a combination of the two, were not significantly different from each other was inconsequential. The 
extant literature provides no guidance as to the relative differences in vividness across these different modes of presentation. Consequently while piloting provided a firm foundation that the manipulation of vividness was successful, the lack of consistent results across dependent measures might be a result of a tenuous association between processing styles and these metrics which are indirect, new and relatively untested in the context of ethical dilemmas. These issues are described in more detail in latter sections of this discussion.

\subsection{The Impact of Affect}

Regarding the impact of affective state on the various response variables, it was hypothesized that people placed in a positive affective state would process their decision more intuitively than people in a neutral affective state, that people placed in a negative affective state would process their decision more rationally than people in a neutral affective state, and that people in a positive affective state would process their decision more intuitively than people in a negative affective state. None of these hypotheses were supported across any of the dependent measures. .

However, for the response variables of outcome confidence, approach confidence, and decision recall confidence results were contrary to expectations. Note that higher levels of outcome confidence should be an indication of more intuitive processing, while higher levels of both approach confidence and decision recall confidence should be an indication of people responding more rationally. 
For outcome confidence it was found that participants in the negative affective state condition compared to participants in a neutral affective state condition responded more intuitively. For approach confidence, participants in the positive affective state condition compared to the neutral affective state condition responded more rationally. For decision recall confidence it was found that people in the positive affective condition, as well as the negative affective condition, both processed information more rationally than participants in the neutral condition.

The apparent inconsistency might be explained by suggesting that for ethical decisions intensity of emotions (or arousal) is more influential than the valence of emotional direction in how people process ethical decision information. It is possible that the realm of ethical decision making might foster different responses to emotional stimuli than in a more general decision making context. Speculation in this area suggests that somehow the affective nature of ethical decisions might be very different from that in decision making in general. Haidt and Kesebir (2008) suggest that moral intuitions are indeed different from intuitions that are related to perceptions of other kinds of facts, and they suggest that there are three reasons why this might be so. They contend that accuracy for moral intuitions require social consensus, while assessments of plain facts do not. Further, they surmise that moral facts have existential implications while plain facts do not. Finally these researchers also contend that the fundamental relationship between the two realms of intuition and rationality in dual processing theory might be altered in the domain of morality. 
Their observation is that rationality has more independence from the intuitive side when dealing with plain facts, but in evaluating moral facts rationality is subservient to intuition. The implication here is that it might not be possible to apply findings regarding use of intuition in the area of decision making research to the narrower arena of ethical decision making.

Support for this conclusion is also provided by findings indicating that the means for both the positive and the negative affective states were both higher than the mean for the neutral affective condition for two confidence measures indicating more rational processing in both cases. Additionally there were no significant means differences on any of the confidence measures between positive and negative affect, further suggesting that responses for the two charged affective conditions were similar. Consequently any emotion, regardless of its valence, might have a similar relationship to confidence response measures. It is possible that emotionally aroused participants might have attended more to the stimuli, possibly causing them to be more confident about their answers across the board. This is consistent with the argument that a certain level of emotional arousal is required for effective human performance (Kaufman, 1999).

Another possible explanation is that the initial affective state generated by priming was altered when participants read the vignette and that it was the vignette itself that provided the emotional state in which the decision was made. This seems a less likely possibility given that means for the neutral affective state were 
significantly lower than either positive or negative affect for all three confidence measures.

As with the manipulation for vividness, pilot studies for affect demonstrated successful manipulation of affect in the appropriate directions. The metric used for piloting, PANAS, is a well recognized and widely used scale in the literature on emotions. Consequently, there is evidence that emotions were manipulated as intended. Therefore findings reported here might be related to the alternative explanations as described above and not necessarily a failure to manipulate the intended variables. Additionally it is suspected that the rational orientation of business students in the subject pool might have made it difficult for participants to admit that they took emotional considerations into account when making their decisions.

\section{$\underline{6.3 \text { Decision Outcomes }}$}

It was hypothesized and there was support that people who were primed to be more rational made more rational ethical decisions and people primed to be more intuitive made more intuitive ethical decisions. That is, individuals rationally primed more often made decisions that sided with a consequentialist, or calculative, perspective. Likewise people who were more intuitively primed tended to make decisions that favored a more non-consequentialist, or subjective position. The findings here suggest that the original model presented in Figure A.4 could be collapsed into a more parsimonious model as offered in Figure A.7. Specifically 
that the separation of decision processing style and decision outcome might not be warranted, and that they could be combined into a single dependent variable.

\subsection{Limitations: Measurement Issues and Non-Findings}

The extant literature for the manipulations of vividness, affect, as well as the various dependent measures used, were theoretically and primarily based on the decision making literature and not the more specific area of ethical decision making. Therefore the manipulations and adapted scales from non-ethical decision making research allow for the possibility that these manipulations and measurement scales do not translate well into a different domain. Additionally, decision time was the only direct dependent measure based on the behavior of the participants, and the other dependent measures are indirect, therefore one step removed from the actual processes that can be observed

More specifically, decision time might have been problematic as a dependent measure because some decision makers might have relied upon a heuristic provided by only a single fact or piece of information rather than considering all information. If this is the case then rational decision makers would be able to make rapid decisions, thus making it difficult to distinguish them from people processing intuitively.

Decision outcome confidence as a dependent variable was not supported for the vividness manipulation, and while this dependent measure was significant for the affect manipulation the results were contrary to expectations. The nature of ethical 
decision making is such that there are at least two options that are similarly appealing but only one can be selected to the exclusion of the other. The context of the decision may not allow the possibility of a satisfactory solution for all parties. As a result outcome confidence might suffer for all respondents regardless of decision that is made. Consequently, decision makers can never be fully satisfied or confident that a single option was the best option available. Supporting this speculation, the mean for outcome confidence $(M=4.99)$ was lower than either approach confidence $(M=5.66)$ or decision recall confidence $(M=5.78)$. Alternatively, the decision that was made forced participants to select from one of only two options. If participants were able to imagine another alternative they might have been much less confident as to whether their selection was the best outcome regardless of their processing style. Therefore it might have been more appropriate to word the items to ask whether the chosen outcome was the best solution to the problem of the options offered.

Self-report dependent measures for intuition and rationality were not related to the manipulation of vividness or affect. Notably, there was a distinct lack of correlation between the scales for intuitive self report and rational self report. This suggests that these measures were independent and the possibility that participants use both intuitive and rational processing at the same time, rather than one or the other exclusively. This is suggested by the dual processing cognition theory (Jacoby, 1996; Sloman, 1996; Stanovich and West, 1998). Another consideration is that the 
business student sample that were involved in this study are trained in rational utilitarian decision making, consequently it might be difficult for them to describe themselves as intuitive decision makers in a self-report format. Trained as rational thinkers to use rational decision making tools, these participants might describe themselves as rational regardless of situation. This might explain the higher average score across all participants in all conditions for rational self report $(\mathrm{M}=3.82)$ compared to the same figure for intuitive self report $(M=3.29)$. An inability for participants to admit to or express their intuitive or emotional side might naturally bias self report measures.

\section{$\underline{6.5 \text { Implications and Future Directions }}$}

The present study finds limited support that vivid versions of information do induce more associative, intuitive processing when participants are confronted with ethical dilemmas. However, stronger support is needed before any firm conclusions can be drawn. The implication of such findings, if supported, is that ethical decision makers might process information differently when the modality of information presented to the decision maker differs. For instance, a decision maker being presented a list of facts in an ethical decision might process more rationally whereas a decision maker who is presented a narrative story of a situation, or one who is given pictures of the affected people, might process these same facts more intuitively. Affective state might also alter the way people make ethical decisions but perhaps not in the same way it affects people making other kinds of decisions. 
Arousal, or emotional intensity, might be more important than the valence of the emotion for ethical decisions. Further research is needed to sort this out. Additionally, research could attend to whether emotional states peripheral to the decision or whether the important emotionality stems from inside the dilemma itself in influencing the type of decision that is made.

From a broader perspective, considering the significance of unexplained results, as well as unexpected relationships between dependent measures, the possibility of the unique nature of the ethical decision making domain should be taken into account. The methodology employed in this study attempted to use techniques that had been applied in the broader realm of decision making and apply them to the more narrow area of ethical decision making. It is possible that the methods employed might not translate well between these research areas. For instance, consider the dependent measure of outcome confidence. For an ethical dilemma, considering there are at least two possible outcomes with compelling outcomes, any decision made might be less than satisfactory. Consequently the nature of the area of ethical decisions might be so unique that decision making models from other domains do not apply and might be of limited use.

Findings in this study did tentatively suggest that ethical decisions might be resolved quite differently depending on whether information is processed intuitively or rationally. More rational processing favored a decision that favored a larger number of people. Consequently, if future research indicates that the type of decision 
in an ethical decision does vary as a function of the type of processing this is an extremely important consideration justifying continuance of this stream of research. 
APPENDIX A

TABLES \& FIGURES 
Table A.1. Comparison of Experiential and Rational System Characteristics.

Source: Epstein (2008)

\begin{tabular}{|c|c|}
\hline $\begin{array}{c}\text { Experiential System } \\
\text { (An Automatic Learning System) }\end{array}$ & $\begin{array}{c}\text { Rational System } \\
\text { (A Conscious Learning System) }\end{array}$ \\
\hline 1. Preconscious & 1. Conscious \\
\hline 2. Automatic & 2. Deliberative \\
\hline $\begin{array}{l}\text { 3. Concrete: Encodes reality in images, } \\
\text { metaphors, and narratives }\end{array}$ & $\begin{array}{l}\text { 3. Abstract: Encodes reality in symbols, } \\
\text { words, and numbers }\end{array}$ \\
\hline 4. Holistic & 4. Analytic \\
\hline $\begin{array}{l}\text { 5. Associative: Connections by similarity } \\
\text { and contiguity }\end{array}$ & 5. Cause and effect relations \\
\hline 6. Intimately associated with affect & 6. Affect-free \\
\hline $\begin{array}{l}\text { 7. Operates by hedonic principle, (what } \\
\text { feels good) }\end{array}$ & $\begin{array}{l}\text { 7. Operates by reality principle (what is } \\
\text { logical and supported by evidence) }\end{array}$ \\
\hline $\begin{array}{l}\text { 8. Acquires its schemas by learning from } \\
\text { experience }\end{array}$ & $\begin{array}{l}\text { 8. Acquires its beliefs by conscious learning } \\
\text { and logical inference }\end{array}$ \\
\hline 9. Outcome oriented & 9. More process oriented \\
\hline $\begin{array}{l}\text { 10. Behavior mediated by "vibes" from } \\
\text { past experience }\end{array}$ & $\begin{array}{l}\text { 10. Behavior mediated by the conscious } \\
\text { appraisal of events }\end{array}$ \\
\hline $\begin{array}{l}\text { 11. Rapid processing: Oriented toward } \\
\text { immediate action }\end{array}$ & $\begin{array}{l}\text { 11. Slower processing: Capable of long } \\
\text { delayed action }\end{array}$ \\
\hline $\begin{array}{l}\text { 12. Resistant to change: Changes with } \\
\text { repetitive or intense experience }\end{array}$ & $\begin{array}{l}\text { 12. Less resistant to change: Can change } \\
\text { with speed of thought }\end{array}$ \\
\hline $\begin{array}{l}\text { 13. Crudely differentiated: Broad } \\
\text { generalization gradient; categorical } \\
\text { thinking }\end{array}$ & $\begin{array}{l}\text { 13. More highly differentiated nuanced } \\
\text { thinking }\end{array}$ \\
\hline $\begin{array}{l}\text { 14. Crudely integrated: Situationally } \\
\text { specific; organized in part by cognitive- } \\
\text { affective modules. }\end{array}$ & $\begin{array}{l}\text { 14. More highly integrated: Organized in } \\
\text { part by cross-situational principles }\end{array}$ \\
\hline $\begin{array}{l}\text { 15. Experienced passively and } \\
\text { preconsciously: We are seized by our } \\
\text { emotions }\end{array}$ & $\begin{array}{l}\text { 15. Experienced actively and consciously: } \\
\text { We believe we are in control of our thoughts }\end{array}$ \\
\hline $\begin{array}{l}\text { 16. Self-evidently valid: "Experiencing is } \\
\text { believing" }\end{array}$ & $\begin{array}{l}\text { 16. Requires justification via logic and } \\
\text { evidence }\end{array}$ \\
\hline
\end{tabular}




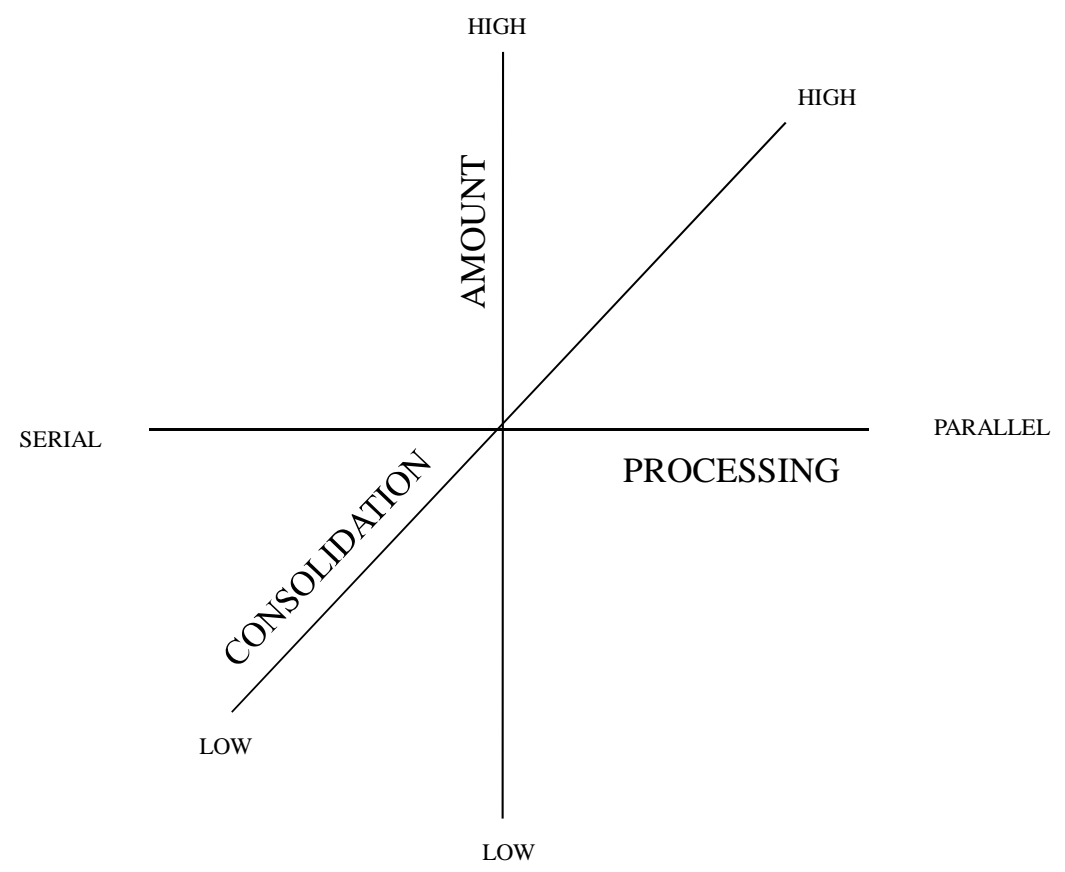

Figure A.1. Characteristics of Processing Strategies in Judgment and Decision Making Intuitive strategies fall into the upper right quadrant. Source: T. Betsch (2008). 


\begin{tabular}{|c|c|c|c|}
\hline & INTUITION & $\begin{array}{c}\text { QUASI- } \\
\text { RATIONALITY }\end{array}$ & ANALYSIS \\
\hline $\begin{array}{c}\mathrm{C} \\
\mathrm{H} \\
\mathrm{A} \\
\mathrm{R} \\
\mathrm{A} \\
\mathrm{C} \\
\mathrm{T} \\
\mathrm{E} \\
\mathrm{R} \\
\mathrm{I} \\
\mathrm{S} \\
\mathrm{T} \\
\mathrm{I} \\
\mathrm{C} \\
\mathrm{S}\end{array}$ & $\begin{array}{l}\text { Rapid information processing } \\
\text { Simultaneous cue use } \\
\text { Judgment process not retraceable } \\
\text { Local rules unavailable } \\
\text { High confidence in outcome } \\
\text { Low confidence in process } \\
\text { Errors normally distributed } \\
\text { Inconsistent (low cognitive } \\
\text { control) } \\
\text { Low cognitive effort required } \\
\text { Leads to interpersonal conflict } \\
\text { Reliance on pictorial/non- verbal } \\
\text { cues } \\
\text { Raw cue data/events stored in } \\
\text { memory } \\
\text { Emphasizes right brain hemisphere } \\
\text { Resistant to new cues } \\
\text { Cues evaluated at perceptual level } \\
\text { Vicarious functioning (including } \\
\text { shifting cue utilization weights) } \\
\text { Weighted average organizing } \\
\text { principle }\end{array}$ & $\begin{array}{l}\text { Involves aspects of both } \\
\text { poles of the continuum-a } \\
\text { blend. We tend to operate } \\
\text { in this region of the } \\
\text { continuum in daily life. } \\
\text { Quasi-rationality may be } \\
\text { more or less intuitive or } \\
\text { analytical depending upon } \\
\text { the relative mix of intuitive } \\
\text { and analytical } \\
\text { characteristics demanded } \\
\text { by the information } \\
\text { environment. }\end{array}$ & $\begin{array}{l}\text { Slow information processing } \\
\text { Sequential cue use } \\
\text { Judgment process retraceable } \\
\text { Local rules unavailable and used } \\
\text { Low confidence in outcome } \\
\text { High confidence in process } \\
\text { Errors few, but large when they } \\
\text { occur } \\
\text { Consistent (high cognitive } \\
\text { control) } \\
\text { High cognitive effort required } \\
\text { Leads to resolvable conflict } \\
\text { Reliance on quantitative cues } \\
\text { Complex organizing principles } \\
\text { stored in memory } \\
\text { Emphasizes left brain hemisphere } \\
\text { Responsive to new cues } \\
\text { Cues evaluated at measurement } \\
\text { level } \\
\text { Vicarious functioning obviated by } \\
\text { concrete organizing principle } \\
\text { Task specific organizing principle }\end{array}$ \\
\hline
\end{tabular}

Figure A.2. Hammond's Cognitive Continuum

Hammond's cognitive continuum suggesting the characteristics of intuitive, analytical and conjoint decision processing strategies and providing the basis for the cognitive continuum theory (CCT). Source: Cooksey (1996). 


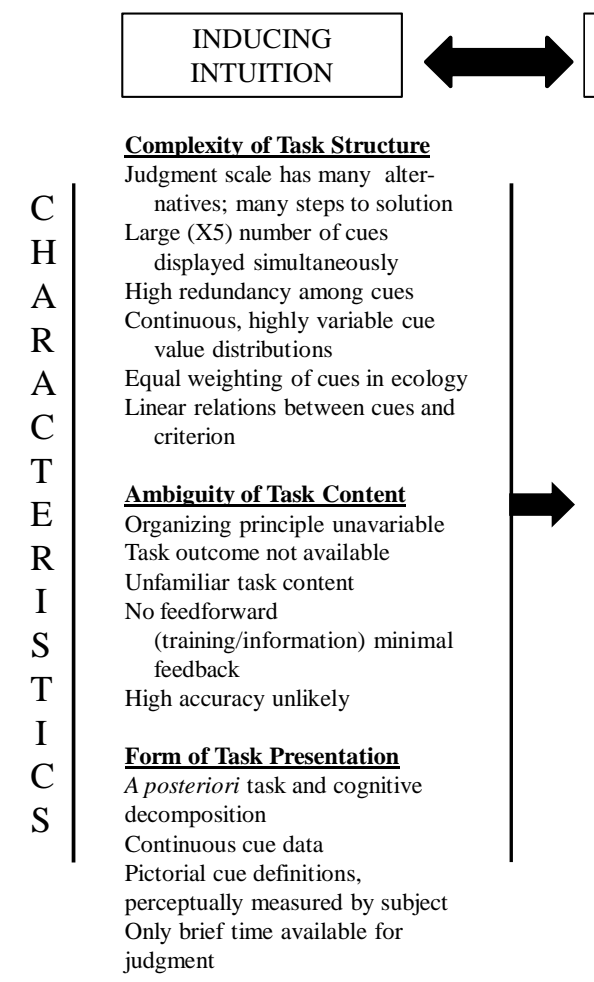

Tasks which induce quasirationality will show a mixture of intuitioninducing elements as well as analysis-inducing

elements. Relative balance in the mixture will predict the pole toward which cognition would move.

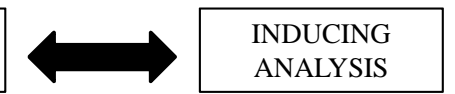

Complexity of Task Structure

Judgment scale has few

alternatives, few steps to solution

Small (2-4) number of cues displayed sequentially

Low redundancy among cues Dichotomous cues; values discrete; distribution unknown

Unequal weighting of cues in ecology

Nonlinear relations between cues and criterion

Ambiguity of Task Content Organizing principle readily available

Task outcome readily available Highly familiar task content Feedforward (prior skill/information); cognitive feedback

High accuracy likely

Form of Task Presentation A priori task \& cognitive

decomposition

Dichotomous or discrete cue data Quantitative cue definitions

objectively measured

Long time available for judgment

Figure A.3. Hammond's Task Continuum

Hammond's task continuum based on cognitive continuum theory (CCT) depicting the archetypical task properties of intuitive and analytical decisions at the poles. Source:

Cooksey (1996). 
Table A.2. Symbolic Systems of Perception

Orthogonal relationship between symbolic systems of perception described in dual coding theory (DCT), with examples of modality specific information represented in each system.

Source: Paivio (2007)

\begin{tabular}{|lll|}
\hline $\begin{array}{l}\text { Sensorimotor } \\
\text { Systems }\end{array}$ & Verbal & Symbolic Systems \\
\hline Visual & Visual language & Nonverbal \\
Auditory & Auditory language & Envil Objects \\
Haptic & Braille, handwriting & "Feel" of objects \\
Gustation & N/A & Taste memories \\
Olifaction & N/A & Smell memories \\
Emotion & N/A & Felt emotions \\
\hline
\end{tabular}

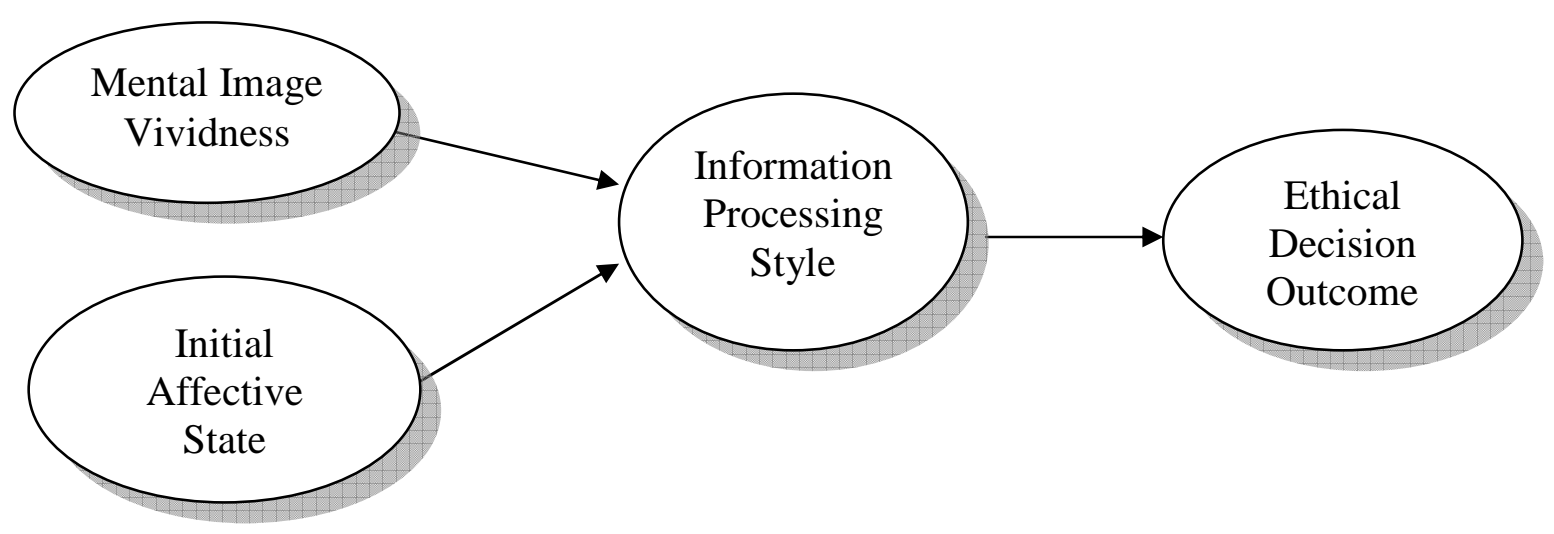

Figure A.4. Proposed Model

A suggested model of ethical decision making, proposing that mental imagery vividness created by information modality, as well as the affective state of the decision maker, are two factors that influence the type of information processing, either intuitive or rational, employed by the decision maker. 


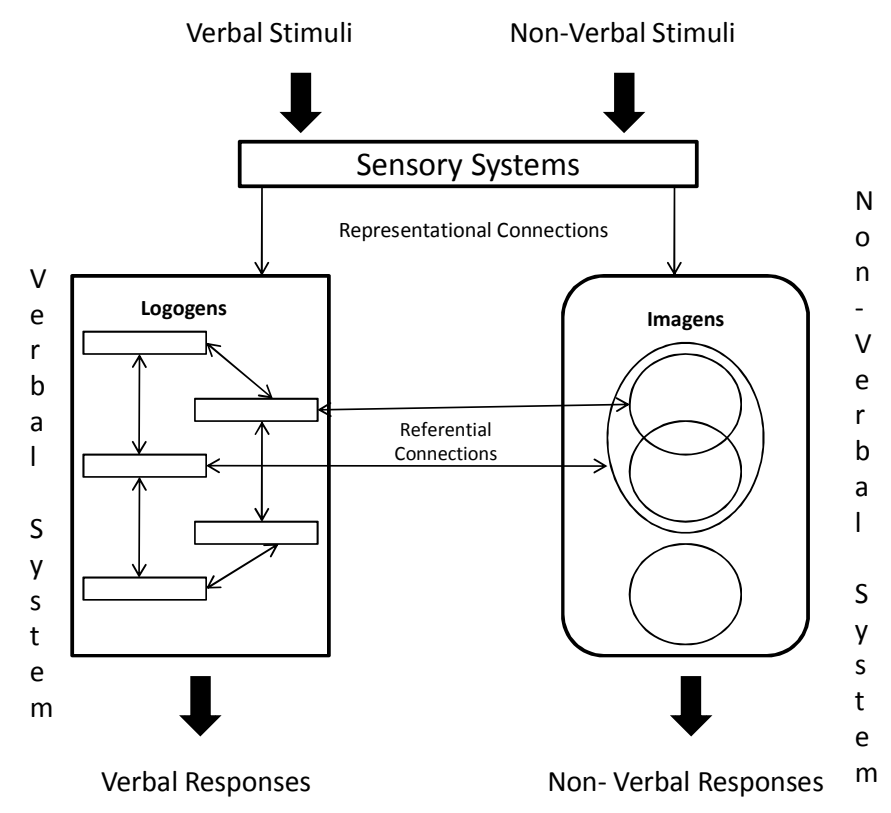

Figure A.5. A Structural Model of Dual Coding Theory

Paivio's (2007, p. 34) dual coding theory, suggests separate systems for processing verbal (or semantic) and nonverbal (or representational) stimuli. These systems are linked with referential connections in which verbal stimuli can generate mental imagery and associative meaning in the nonverbal system. 


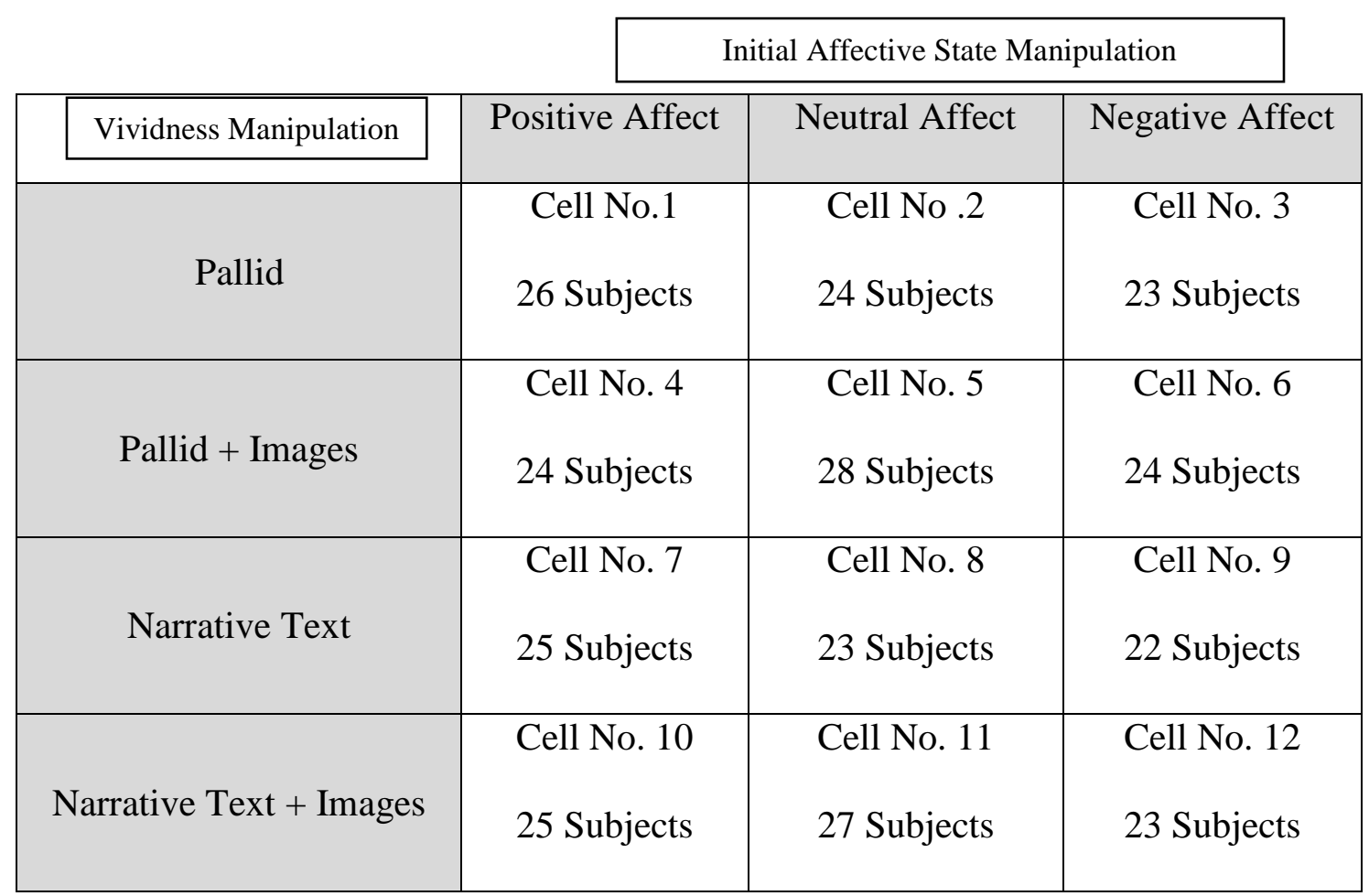

Figure A.6. ANOVA Cell Design for the Present Study 
Table A.3. ANOVA Results for Affective State and Vividness

\begin{tabular}{lllllll}
\hline $\begin{array}{l}\text { Dependent } \\
\text { Variable }\end{array}$ & Source of Variation & SS & df & MS & F & $p$ \\
\hline
\end{tabular}

Decision Time

$\begin{array}{lllrll}\text { Affective State } & 1358.314 & 2 & 679.157 & 0.725 & .485 \\ \text { Vividness } & 6805.264 & 3 & 2268.421 & 2.423 & .066\end{array}$

Outcome

Confidence

$\begin{array}{lrrrrr}\text { Affective State } & 10.687 & 2 & 5.34 & 3.800 & .024 \\ \text { Vividness } & 4.00 & 3 & 1.33 & 0.950 & .417\end{array}$

Approach

Confidence

$\begin{array}{lrrrrr}\text { Affective State } & 5.92 & 2 & 2.96 & 2.940 & .054 \\ \text { Vividness } & 11.401 & 3 & 3.80 & 3.774 & .011\end{array}$

Decision Recall

Confidence

$\begin{array}{lrrrrr}\text { Affective State } & 12.548 & 2 & .6 .2: & 5.701 & .004 \\ \text { Vividness } & 2.55 & 3 & .8 & 0.774 & .509\end{array}$

Intuitive Self Report

$\begin{array}{lrrrrr}\text { Affective State } & 2.806 & 2 & 1.403 & 1.289 & .277 \\ \text { Vividness } & 1.770 & 3 & .590 & 0.542 & .654\end{array}$

Rational Self Report

\begin{tabular}{lrrrrr} 
Affective State & .319 & 2 & .159 & 0.283 & .754 \\
Vividness & 2.701 & 3 & .900 & 1.598 & .190 \\
\hline
\end{tabular}


Table A.4. Vividness Means Comparisons

\begin{tabular}{lcccc}
\hline Dependent Variable & Pallid & $\begin{array}{c}\text { Pallid }+ \\
\text { Images }\end{array}$ & Narrative & $\begin{array}{c}\text { Narrative + } \\
\text { Images }\end{array}$ \\
\hline Decision Time & $81.3_{\mathrm{A}}(27.88)$ & $90.9_{\mathrm{A}}(39.31)$ & $84.1_{\mathrm{A}}(29.10)$ & $78.2_{\mathrm{A}}(23.01)$ \\
Outcome Confidence & $5.04_{\mathrm{A}}(1.40)$ & $4.79_{\mathrm{A}}(1.15)$ & $5.06_{\mathrm{A}}(1.11)$ & $5.09_{\mathrm{A}}(1.09)$ \\
Approach Confidence & $6.00_{\mathrm{A}}(0.83)$ & $5.48_{\mathrm{B}}(1.19)$ & $5.51_{\mathrm{B}}(0.93)$ & $5.64_{\mathrm{AB}}(1.07)$ \\
$\begin{array}{l}\text { Decision Recall } \\
\text { Confidence }\end{array}$ & $5.91_{\mathrm{A}}(1.12)$ & $5.68_{\mathrm{A}}(1.03)$ & $5.68_{\mathrm{A}}(1.13)$ & $5.83_{\mathrm{A}}(0.97)$ \\
Intuitive Self Report & $3.39_{\mathrm{A}}(1.08)$ & $3.19_{\mathrm{A}}(1.08)$ & $3.35_{\mathrm{A}}(1.02)$ & $3.22_{\mathrm{A}}(1.02)$ \\
Rational Self Report & $3.93_{\mathrm{A}}(0.73)$ & $3.68_{\mathrm{A}}(0.80)$ & $3.78_{\mathrm{A}}(0.68)$ & $3.87_{\mathrm{A}}(0.76)$ \\
\hline
\end{tabular}

Non-matching subscript letters represent significant means differences at $\alpha=.05$. Standard deviations in parenthesis.

Table A.5. Affective State Means Comparisons

\begin{tabular}{lccc}
\hline Dependent Variable & Positive Affect & Negative Affect & Neutral Affect \\
\hline Decision Time & $80.7_{\mathrm{A}}(27.44)$ & $85.8_{\mathrm{A}}(34.83)$ & $84.8_{\mathrm{A}}(30.03)$ \\
Outcome Confidence & $4.99_{\mathrm{AB}}(1.22)$ & $5.25_{\mathrm{A}}(1.11)$ & $4.77_{\mathrm{B}}(1.21)$ \\
Approach Confidence & $5.79_{\mathrm{A}}(1.00)$ & $5.75_{\mathrm{AB}}(0.99)$ & $5.45_{\mathrm{B}}(1.08)$ \\
Decision Recall Confidence & $5.87_{\mathrm{A}}(1.02)$ & $5.98_{\mathrm{A}}(1.04)$ & $5.50_{\mathrm{B}}(1.07)$ \\
Intuitive Self Report & $3.42_{\mathrm{A}}(0.95)$ & $3.27_{\mathrm{A}}(1.19)$ & $3.17_{\mathrm{A}}(1.00)$ \\
Rational Self Report & $3.86_{\mathrm{A}}(0.66)$ & $3.82_{\mathrm{A}}(0.77)$ & $3.77_{\mathrm{A}}(0.81)$ \\
\hline
\end{tabular}

Non-matching subscript letters represent significant means differences at $\alpha=.05$. Standard deviations in parenthesis. 
Table A.6. Higher Levels of Dependent Measures and Associated Processing Styles

\begin{tabular}{l|cccccc} 
& $\begin{array}{c}\text { Decision } \\
\text { Time }\end{array}$ & $\begin{array}{c}\text { Outcome } \\
\text { Confidence }\end{array}$ & $\begin{array}{c}\text { Approach } \\
\text { Confidence }\end{array}$ & $\begin{array}{c}\text { Decision } \\
\text { Recall } \\
\text { Confidence }\end{array}$ & $\begin{array}{c}\text { Intuitive } \\
\text { Self Report }\end{array}$ & $\begin{array}{c}\text { Rational } \\
\text { Self Report }\end{array}$ \\
\hline Intuitive & $\mathrm{X}$ & $\mathrm{X}$ & & & $\mathrm{X}$ & \\
Rational & $\mathrm{X}$ & & $\mathrm{X}$ & $\mathrm{X}$ & & $\mathrm{X}$ \\
\cline { 2 - 6 }
\end{tabular}

Table A.7. Correlations Between Dependent Measures

\begin{tabular}{l|cccccc|}
\multicolumn{1}{l}{} & $\begin{array}{c}\text { Decision } \\
\text { Time }\end{array}$ & $\begin{array}{c}\text { Outcome } \\
\text { Confidence }\end{array}$ & $\begin{array}{c}\text { Approach } \\
\text { Confidence }\end{array}$ & $\begin{array}{c}\text { Decision } \\
\text { Recall } \\
\text { Confidence }\end{array}$ & $\begin{array}{c}\text { Intuitive } \\
\text { Self Report }\end{array}$ & $\begin{array}{c}\text { Rational } \\
\text { Self Report }\end{array}$ \\
\hline Decision Time & - & $-.203^{* *}$ & $-.181^{* *}$ & $-.176^{* *}$ & $-.125^{*}$ & -.093 \\
Outcome Conf & $-.203^{* *}$ & - & $.334^{* *}$ & $.359^{* *}$ & $.176^{*}$ & $.271^{* *}$ \\
Approach Conf & $-.181^{* *}$ & $.334^{*}$ & - & $.520^{* *}$ & $.116^{*}$ & $.412^{* *}$ \\
Dec Recall Conf & $-.176^{* *}$ & $.359^{* *}$ & $.520^{* *}$ & - & .086 & $.425^{* *}$ \\
Intuitive S.R & $-.125^{*}$ & $.126^{*}$ & $.116^{*}$ & .086 & - & -.001 \\
Rational S.R. & -.093 & $.271^{* *}$ & $.412^{* *}$ & $.425^{* *}$ & -.001 & - \\
\cline { 2 - 6 } & & & & &
\end{tabular}

$*$ Significant at $.05 . * *$ Significant at .01 


\section{Table A.8. Decision Outcome Means Comparisons}

\begin{tabular}{|c|c|c|}
\hline Vignette Used & $\begin{array}{l}\text { Instructions } \\
\text { to Be } \\
\text { Rational }\end{array}$ & $\begin{array}{c}\text { Instructions } \\
\text { to Be } \\
\text { Intuitive }\end{array}$ \\
\hline \multirow{2}{*}{$\begin{array}{c}\text { Pallid } \\
\text { Vivid Text }\end{array}$} & $2.75_{\mathrm{A}}(1.51)$ & $2.95_{\mathrm{AB}}(1.51)$ \\
\hline & $2.38_{\mathrm{A}}(1.20)$ & $4.12_{\mathrm{B}}(1.50)$ \\
\hline
\end{tabular}

Non-matching subscript letters represent significant means differences at $\alpha=.01$. Standard deviations in parenthesis.

Table A.9. Support for Hypotheses by Response Variable

\begin{tabular}{|c|c|c|c|c|c|c|c|}
\hline Hypotheses & $\begin{array}{c}\text { Decision } \\
\text { Time }\end{array}$ & $\begin{array}{l}\text { Outcome } \\
\text { Conf }\end{array}$ & $\begin{array}{l}\text { Approach } \\
\text { Conf }\end{array}$ & $\begin{array}{c}\text { Decision } \\
\text { Recall Conf }\end{array}$ & $\begin{array}{l}\text { Intuitive } \\
\text { Self Report }\end{array}$ & $\begin{array}{c}\text { Rational } \\
\text { Self } \\
\text { Report }\end{array}$ & $\begin{array}{l}\text { Decision } \\
\text { Outcome }\end{array}$ \\
\hline H1 & & & Supported & & & & \\
\hline $\mathrm{H} 2$ & & & Supported & & & & \\
\hline H3 & & & & & & & \\
\hline $\mathrm{H} 4$ & & & $\begin{array}{c}\text { Significant } \\
\text { But Contrary }\end{array}$ & $\begin{array}{l}\text { Significant } \\
\text { But Contrary }\end{array}$ & & & \\
\hline H5 & & $\begin{array}{c}\text { Significant } \\
\text { But } \\
\text { Contrary }\end{array}$ & & $\begin{array}{l}\text { Significant } \\
\text { But Contrary }\end{array}$ & & & \\
\hline H6 & & & & & & & \\
\hline H7 & & & & & & & Supported \\
\hline
\end{tabular}




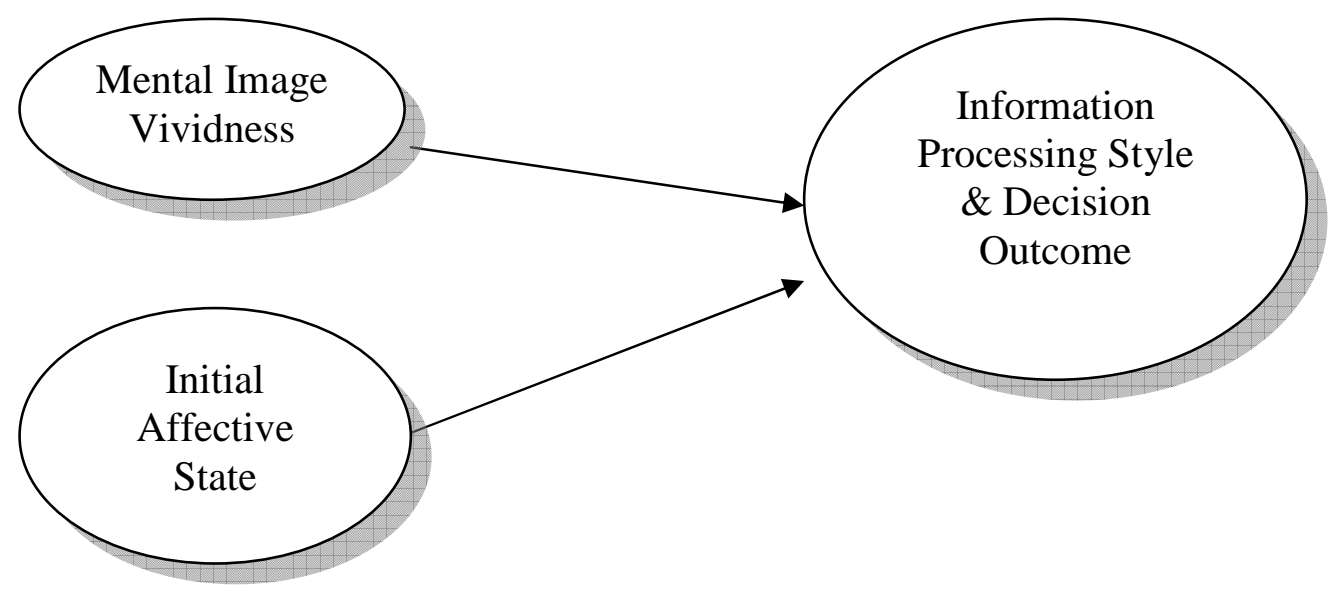

Figure A.7. Revised Model 
APPENDIX B

CASES \& MANIPULATION MATERIALS 


\section{Decision Case \# 8}

A corporation has been doing research and just discovered a complex process that will benefit people all over the world, as well as the company. It has been found that processing gasoline with a crystal substance called sulathium will provide significant benefits:

\section{Sulathium and Its Benefits}

- It increases gasoline mileage by $25 \%$.

- It means that the cost of gasoline to consumers will decrease by $25 \%$.

- About $70 \%$ of the world's population will benefit with lower fuel prices and a higher standard of living.

- There is an economic benefit to the U.S. economy of 125 billion dollars per year.

- The company will make a profit of 50 million dollars the first year alone.

\section{Location of the Sulathium}

- The only place on earth with enough pure sulathium to allow for a commercially viable operation is an isolated area of about 25 square miles.

- In order to get the sulathium the company will have to purchase this area and permanently move the people who live in this area.

- The company contacted the people in this area telling them why they are interested.

\section{Offer and Response}

- The company made a generous offer to buy this area from the people that live there.

- The people in this area decided as a group that they do not want to sell.

- The people in this area believe they have a way of life that is important to them.

- The people value their community.

- The people believe there is no other place they can move to together and maintain their way of life.

- The people believe the area is irreplaceable for them to maintain their way of life.

- The people believe living together and their way of life means more to them than the money the company is offering.

- The people consider their decision final and will not consider any other offers.

\section{Political Pressure}

- The company's corporate attorney believes that political pressure from the regional government can be used to force the people to accept the offer and move them from the land.

- The corporate attorney is sure that when the economic benefits are explained to the regional government that political pressure will succeed in getting the people to move.

Please continue on the next page.... 


\section{The Case of the People on the Land}

\section{Sulathium and Its Benefits}

A corporation has been doing research and just discovered a complex process that will benefit people all over the world, as well as the company. It has been found that processing gasoline with a crystal substance called sulathium will provide significant benefits. For instance, it increases gasoline mileage by twenty five percent, so the cost of gasoline to consumers will then decrease by twenty five percent. Also, about seventy percent of the world's population will benefit with lower fuel prices and a higher standard of living. Additionally there is an economic benefit to the U.S. economy of one hundred and twenty five billion dollars per year, and the company will make a profit of fifty million dollars the first year alone.

\section{Location of the Sulathium}

However, the only place on earth with enough pure sulathium to allow for a commercially viable operation is an area of land of about 25 square miles. In order to get the sulathium the company will have to purchase the land and permanently move the people who live there. The company contacted the people on the land and told them about why they are interested.

The people live deep in the Mississippi River delta in south Louisiana on land surrounded by the mouth of the Mississippi river, and the people of the community on this land are called the Minims. They reject material things and modern conveniences to live an austere and simple existence tilling the land, firmly believing in their simple way of life.

\section{Meeting With the People}

It is a warm summer day, with a gentle breeze blowing through the Spanish moss that hangs from the cypress trees as the company representatives walk from the boat landing up to the settlement and toward the community's old rustic white clapboard meetinghouse. They walk with one of the senior leaders of the community, Mr. Dugas, whose ruddy, wrinkled face reveals his years of outdoor work in the southern sun. Mr. Dugas answers their questions about the settlement in a quiet Cajun drawl.

As they walk, on either side of them is the settlement, with small, plain, but well kept houses and yards, each painted distinctly in different pastel colors. They see children who run and play between the houses, their shrieks catch the attention of the few horses who stand tied to posts outside of some of the front doors. In the distance, through a clearing, they see someone plowing a field with a team of horses. As the representatives get to the meetinghouse, they see long benches for chairs and a simple hand crafted table. Through the open windows come the sounds of songbirds calling from the tops of the cypress trees, along with the gentle scent of juniper and wild blackberry that grows in thickets just beyond the clearing around the meetinghouse.

\section{In the Meetinghouse}

As the company representatives sit at the table, they meet with the three senior leaders of the community, Mr. Dugas, Mr. Landry and Mr. Vincent. Each are dressed in plain, modest work clothes that are similar in style to the clothes that members of the community wear, most of whom have assembled in the meetinghouse on benches at the far end of the room away from the 
meeting table. The community leaders listen with great interest to the reasons why the company wants to purchase the land and the company representatives present a generous offer. The three community leaders speak quietly among themselves, and then consult with members of the families who are gathered.

\section{The Decision}

Mr. Vincent rises to announce the decision for the community. As he stands his brow furrows atop soft brown eyes and between his thick graying hair and his full beard. He rests his leathered and calloused hands on the table and speaks in a firm voice with a distinct Cajun accent. Mr. Vincent says the community has decided that they do not want to sell their land. The people feel they have their own way of life that is important to them. They value their community and they believe there is no other place that they can move to as a community to maintain their way of life. The people believe that this land is irreplaceable for them to maintain their way of life. They feel that their community and cherished way of life mean more to them than the money the company is offering. The other leaders and the family members nod in agreement, making assurances that this is their final decision and that they will not consider any other offers.

\section{The Next Day}

The company's corporate attorney believes that political pressure from the state of Louisiana can be used to force the people to accept the offer and move them from the land. The company attorney is sure that when the economic benefits are explained to Louisiana state legislators, political pressure will succeed in getting the people to move.

Please continue on the next page.... 

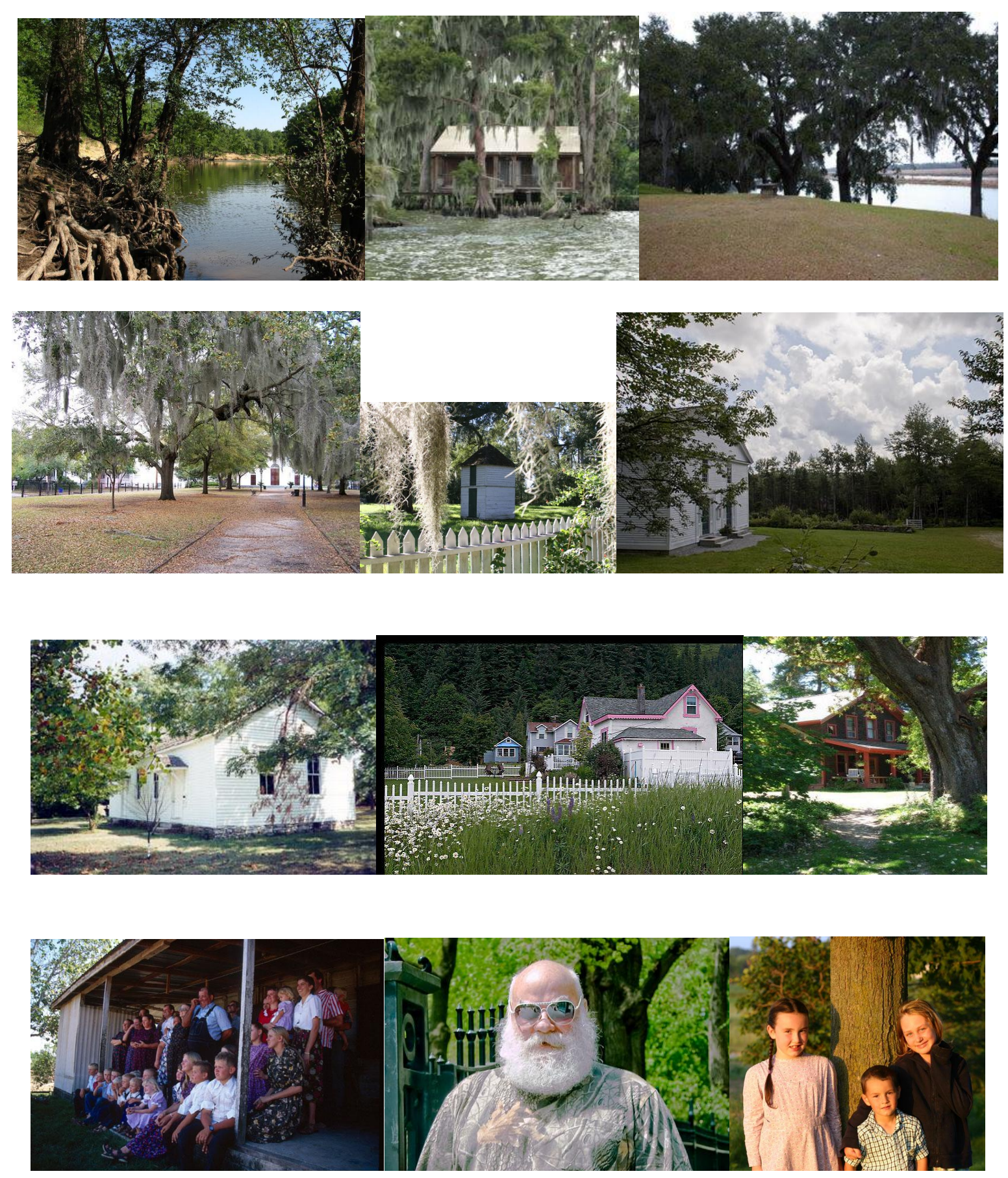

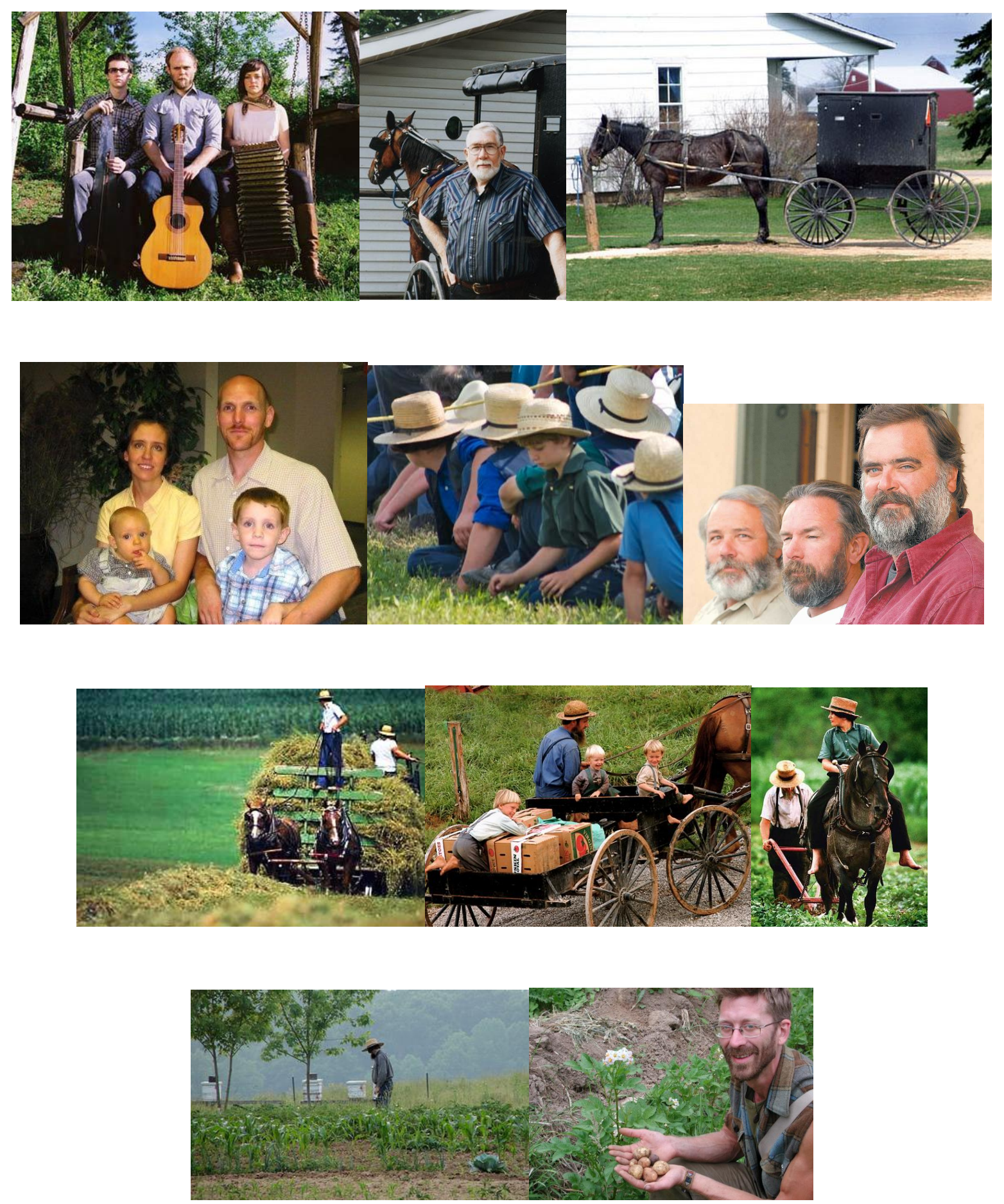
APPENDIX C

MEASUREMENT SCALES 
Vividness Scale
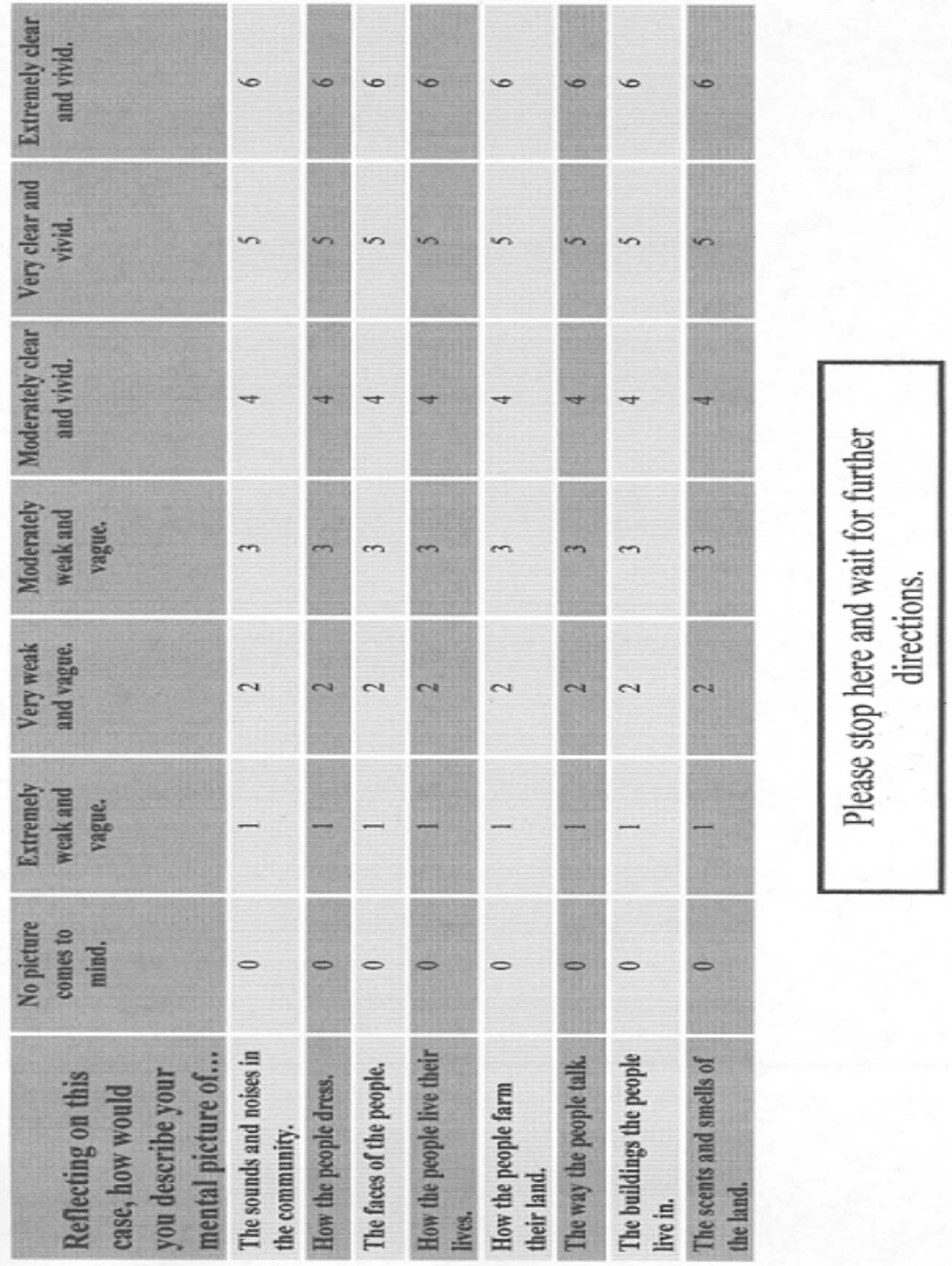
PANAS Scale (Manipulation Check)

This scale consists of a number of words and phrases that describe different feelings and emotions. Read each item and then mark the appropriate answer in the space next to that word. Indicate to what extent you feel this way right now. Use the following scale to record your answers:

\begin{tabular}{|c|c|c|c|c|}
\hline $\begin{array}{l}\mathbf{1} \\
\text { very slightly } \\
\text { or not at all }\end{array}$ & $\begin{array}{c}2 \\
\text { a little }\end{array}$ & $\begin{array}{c}\mathbf{3} \\
\text { moderately }\end{array}$ & $\begin{array}{c}\mathbf{4} \\
\text { quite a bit }\end{array}$ & $\begin{array}{c}\mathbf{5} \\
\text { extremely }\end{array}$ \\
\hline 1. & rested & & 11. & \\
\hline 2. & able & & 12. & rmined \\
\hline 3. & ressed & & 13. & \\
\hline 4. & & & 14. & ntive \\
\hline 5. & ited & & 15. & \\
\hline 6. & amed & & 16. & \\
\hline 7. & & & 17. & usiastic \\
\hline 8. & ired & & 18. & \\
\hline 9. & & & 19. & \\
\hline 10. & ous & & 20. & \\
\hline
\end{tabular}

\section{PLEASE STOP HERE AND WAIT FOR FURTHER INSTRUCTIONS}


PANAS Scale (Manipulation Check)

\section{$\underline{\text { Scales }}$}

positive affect: $=(\mathrm{p} 1+\mathrm{p} 4+\mathrm{p} 5+\mathrm{p} 8+\mathrm{p} 9+\mathrm{p} 12+\mathrm{p} 14+\mathrm{p} 17+\mathrm{p} 18+\mathrm{p} 19)$

negative affect: $=(\mathrm{p} 2+\mathrm{p} 3+\mathrm{p} 6+\mathrm{p} 7+\mathrm{p} 10+\mathrm{p} 11+\mathrm{p} 13+\mathrm{p} 15+\mathrm{p} 16+\mathrm{p} 20)$ 
Decision Time Sheet

\section{PLEASE LOOK AT THE CLOCK AND WRITE THE TIME DOWN RIGHT NOW:}

HOUR:

MINUTE:

SECOND: 
Confidence Scales

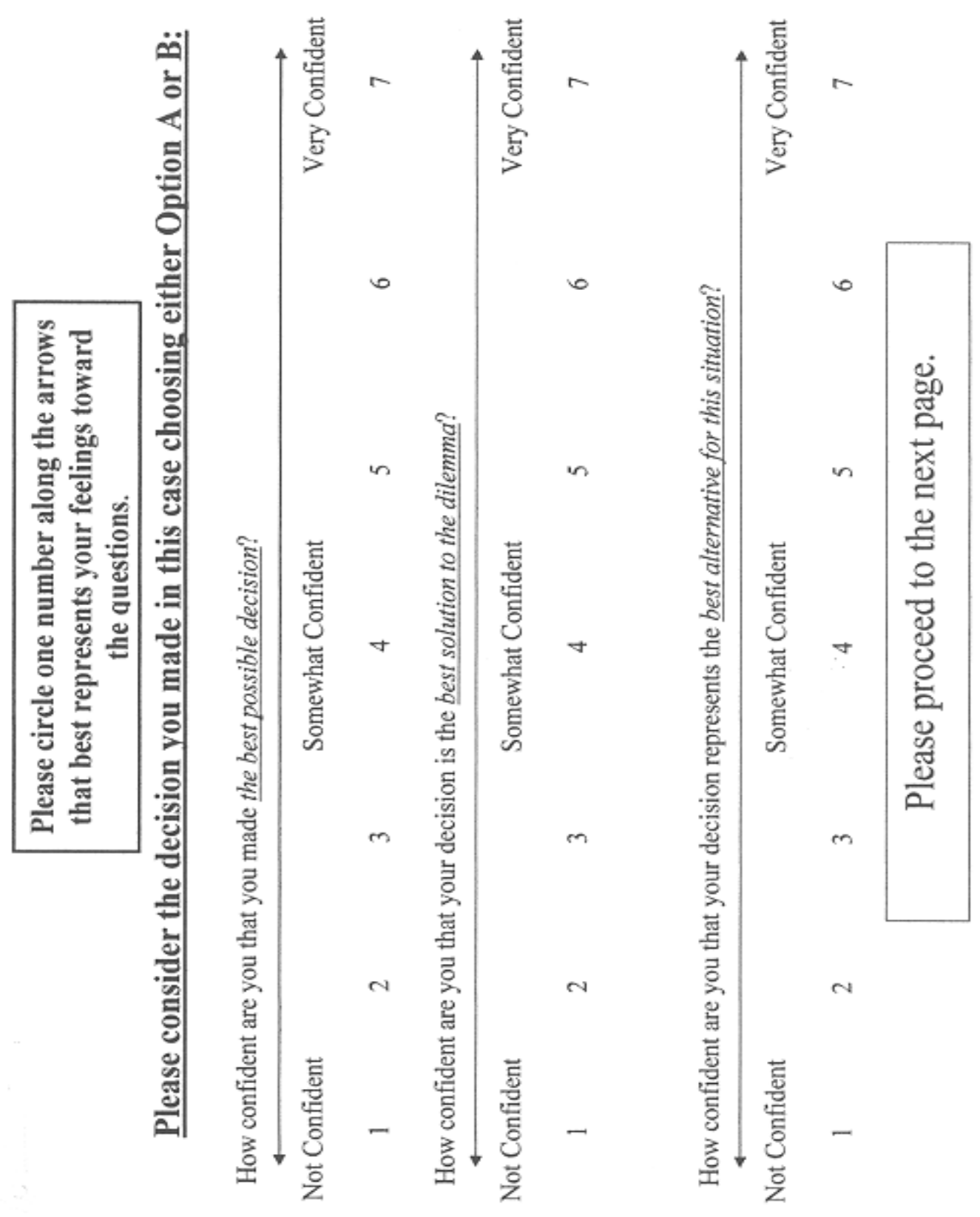


Confidence Scales

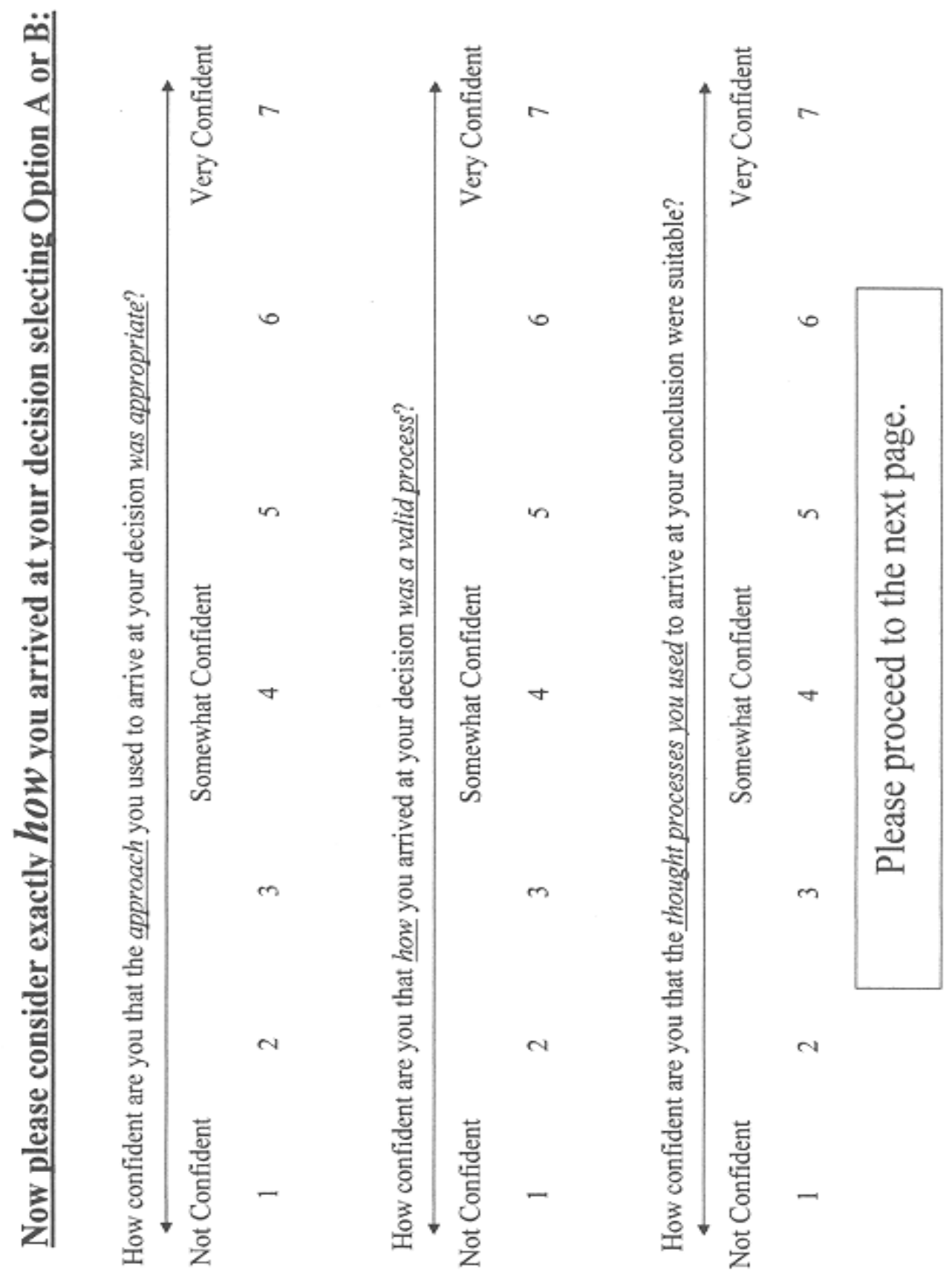


Confidence Scales

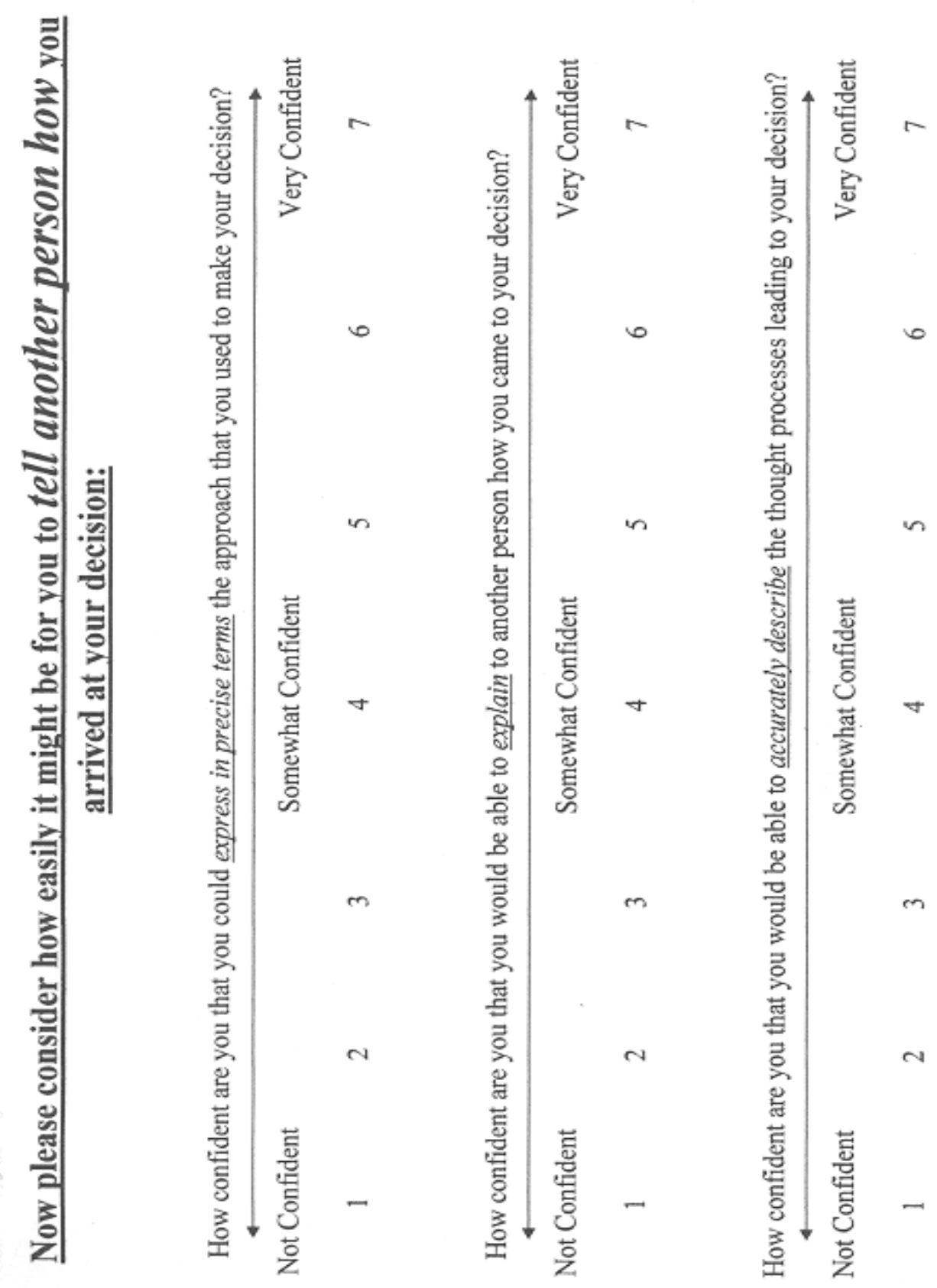


Please consider again exactly how you made your decision on the case. Answer the questions below based on whether you believe the statement to be true or false regarding the decision process that you used. Use the following scale to circle your response:

\begin{tabular}{|c|c|c|c|c|c|}
\hline & $\begin{array}{l}\text { Definitely } \\
\text { False }\end{array}$ & $\begin{array}{l}\text { Mostly } \\
\text { False }\end{array}$ & $\begin{array}{c}\text { Equally } \\
\text { True and } \\
\text { False } \\
\text { OR } \\
\text { Undecided }\end{array}$ & $\begin{array}{l}\text { Mostly } \\
\text { True }\end{array}$ & $\begin{array}{l}\text { Definitely } \\
\text { True }\end{array}$ \\
\hline $\begin{array}{l}\text { I used my heart as my } \\
\text { guide for my decision. }\end{array}$ & 1 & 2 & 3 & 4 & 5 \\
\hline $\begin{array}{l}\text { I went by what felt } \\
\text { good to me. }\end{array}$ & 1 & 2 & 3 & 4 & 5 \\
\hline $\begin{array}{l}\text { I relied on my sense of } \\
\text { intuition. }\end{array}$ & 1 & 2 & 3 & 4 & 5 \\
\hline I used my instincts. & 1 & 2 & 3 & 4 & 5 \\
\hline I trusted my hunches. & 1 & 2 & 3 & 4 & 5 \\
\hline I used my gut feelings. & 1 & 2 & 3 & 4 & 5 \\
\hline $\begin{array}{l}\text { I used free } \\
\text { association - where one } \\
\text { idea leads to the next. }\end{array}$ & 1 & 2 & 3 & 4 & 5 \\
\hline I had flashes of insight. & 1 & 2 & 3 & 4 & 5 \\
\hline $\begin{array}{l}\text { I relied on my first } \\
\text { impressions. }\end{array}$ & 1 & 2 & 3 & 4 & 5 \\
\hline $\begin{array}{l}\text { The decision just } \\
\text { popped into my head. }\end{array}$ & 1 & 2 & 3 & 4 & 5 \\
\hline
\end{tabular}




\begin{tabular}{|c|c|c|c|c|c|}
\hline & $\begin{array}{l}\text { Definitely } \\
\text { False }\end{array}$ & $\begin{array}{l}\text { Mostly } \\
\text { False }\end{array}$ & $\begin{array}{c}\text { Equally } \\
\text { True and } \\
\text { False } \\
\text { OR } \\
\text { Undecided }\end{array}$ & $\begin{array}{l}\text { Mostly } \\
\text { True }\end{array}$ & $\begin{array}{c}\text { Definitely } \\
\text { True }\end{array}$ \\
\hline $\begin{array}{l}\text { I approached this } \\
\text { decision analytically. }\end{array}$ & 1 & 2 & 3 & 4 & 5 \\
\hline $\begin{array}{l}\text { I reasoned things out } \\
\text { carefully. }\end{array}$ & 1 & 2 & 3 & 4 & 5 \\
\hline $\begin{array}{l}\text { I tackled this decision } \\
\text { systematically. }\end{array}$ & 1 & 2 & 3 & 4 & 5 \\
\hline $\begin{array}{l}\text { I figured things out } \\
\text { logically. }\end{array}$ & 1 & 2 & 3 & 4 & 5 \\
\hline $\begin{array}{l}\text { I applied precise rules } \\
\text { to come to my decision. }\end{array}$ & 1 & 2 & 3 & 4 & 5 \\
\hline I used clear rules. & 1 & 2 & 3 & 4 & 5 \\
\hline $\begin{array}{l}\text { I was very aware of my } \\
\text { thinking process. }\end{array}$ & 1 & 2 & 3 & 4 & 5 \\
\hline $\begin{array}{l}\text { I was very focused on } \\
\text { the steps involved in } \\
\text { making my decision. }\end{array}$ & 1 & 2 & 3 & 4 & 5 \\
\hline $\begin{array}{l}\text { I was very focused on } \\
\text { what I was doing to } \\
\text { arrive at my decision. }\end{array}$ & 1 & 2 & 3 & 4 & 5 \\
\hline $\begin{array}{l}\text { I arrived at my } \\
\text { decision by carefully } \\
\text { assessing the } \\
\text { information in front of } \\
\text { me }\end{array}$ & 1 & 2 & 3 & 4 & 5 \\
\hline
\end{tabular}


Decision Scale

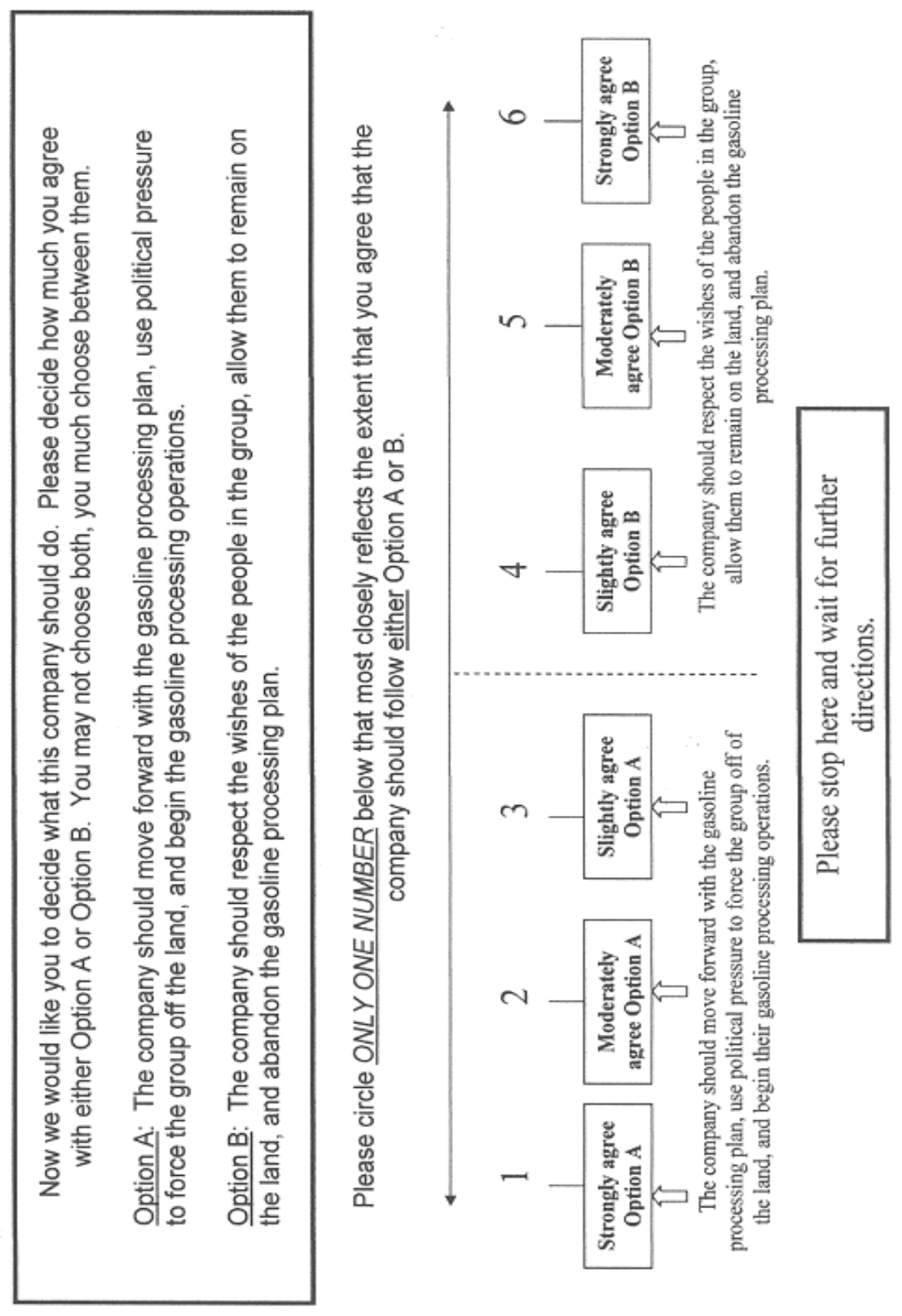




\section{REFERENCES}

Adams, G.L., Treadway, D.C., \& Sepina, L.P. 2008. The role of dispositions in politics perception formation: The predictive capacity of negative and positive affectivity, equity sensitivity and self efficacy. Journal of Managerial Issues, 4: 543-563.

Agor, W.A. 1986. The logic of intuition: How top executives make important decisions. Organizational Dynamics, 14(3): 5-18.

Ahsen, A. 1984. ISM: The triple code model for imagery and psychophysiology. Journal of Mental Imagery, 8(4): 15-42.

Alexander, C.S., \& Becker, H.J. 1978. The use of vignettes in survey research. Public Opinion Quarterly, 42: 93-104.

Anderson, J.R. 1983. The architecture of cognition. Cambridge, MA: Harvard University Press.

Anderson, S.W., Bechara, A., Damasio, H., Tranel, D, \& Damasio, A.R. 1999. Impairment of social and moral behavior related to early damage in human prefrontal cortex.

Neuroscience, 2(11): 1032-1037.

Asch, S. E. 1955. Opinions and social pressure. Scientific American, 193(5): 31-35.

Ashton, R, \& White, K.D. 1980. Sex differences in imagery vividness: An artifact of the test. British Journal of Psychology, 71: 35-38.

Ashton-James, C., \& Ashkanasy, N.M. 2008. Affective events theory: A strategic perspective. In W.J. Zerbe, C.E.J. Hartel, \& N.M. Ashkanasy (Eds.), Research on emotion in organizations, Vol. 4: Emotions, ethics and decision-making: 1-34. Bingley, UK: JAI Press.

BankruptcyData.com. 2008. The 15 largest bankruptcies. Accessed 14 August 2008.

Available at: http://www.bankruptcydata.com/Research/15_Largest.htm

Bar-Hillel, M. 1973. On the subjective probability of compound events. Organizational Behavior and Human Performance, 9: 396-406. 
Bargh, J.A.. Chaiken, S., Raymond, P., \& Hymes, C. 1996. The automatic evaluation effect: Unconditionally automatic activation with a pronunciation task. Journal of Experimental Social Psychology, 32: 185-210.

Bargh, J.A., \& Chartrand, T.L. 1999. The unbearable automaticity of being. American Psychologist, 54: 462-479.

Barnard, C.I. 1938. The functions of the executive. Cambridge, MA: Harvard University Press.

Barnett, T. 2001. Dimensions of moral intensity and ethical decision making: An empirical study. Journal of Applied Social Psychology, 31(5): 1038-1057.

Baron, R.M., \& Kenny, D.A. 1986. The moderator-mediator variable distinction in social psychology research: Conceptual, strategic and statistical considerations. Journal of Personality and Social Psychology, 51: 1173-1182.

Bass, K., Barnett, T., \& Brown, G. 1998. The moral philosophy of sales managers and its influence on ethical decision making. The Journal of Personal Selling and Sales Management, 18(2): 1-17.

Bass, K., Barnett, T., \& Brown, G. 1999. Individual difference variables, ethical judgments, and ethical behavioral intentions. Business Ethics Quarterly, 9(2): 83205.

Baucus, M.S., \& Beck-Dudley, C.L. 2005. Designing ethical organizations: Avoiding the long-term negative effects of rewards and punishments. Journal of Business Ethics, 56: $355-370$.

Baylor, A. L. 2001. A U-shaped model for the development of intuition by level of expertise. New Ideas in Psychology, 19: 237-244.

Beams, J. D., Brown R.M., \& Killough, L.N. 2003. An experiment testing the determinants of non-compliance with insider trading laws. Journal of Business Ethics, 45(4): 309-323.

Bechara, A., Damasio, H., \& Damasio, A.R. 2000. Emotion, decision making and the orbitofrontal cortex. Cerebral Cortex, 10: 294-307.

Bell, D.E. 1982. Regret in decision making under uncertainty. Operations Research, 30: 961-981.

Bell, D.E. 1985. Disappointment in decision making under uncertainty. Operations Research, 33: 1-27. 
Betsch, T. 2008. The nature of intuition and its neglect in research on judgment and decision making. In H. Plessner, C. Betsch, \& T. Betsch (Eds.) Intuition in judgment and decision making: 23-37. New York: Laurence Earlbaum Associates/Taylor \& Francis Group.

Betsch, T., Hoffman, K., Hoffrage, U. \& Plessner, H. 2003. Intuition beyond recognition: When less familiar items are liked more. Experimental Psychology, 50: 49-54.

Betsch, T., Kaufmann, M., Lindow, F. Plessner, H., \& Hoffmann, K. 2006. Different principles of information integration in implicit and explicit attitude formation. European Journal of Social Psychology, 36: 887-905.

Betcsh, T., Plessner, H. Schwieren, C., \& Gutig, R. 2001. I like it but I don't know why: A value-account approach to implicit attitude formation. Personality and Social Psychology Bulletin, 27: 242-253.

Blattberg, R.C., \& Hoch, S.J. 1990. Database models and managerial intuition: $50 \%$ model + 50\% manager. Management Science, 36: 887-899.

Bless, H. 2000. The interplay of affect and cognition: The mediating role of general knowledge structures. In J.P. Forgas (Ed.), Feeling and Thinking: The role of affect in social cognition: 201-222. New York: Cambridge University Press.

Bobek, D.D., Roberts, R.W., \& Sweeney, J.T. 2007. The social norms of tax compliance: Evidence from Australia, Singapore and the United States. Journal of Business Ethics, 74: 49-64.

Bolte, A., Goschke, T., \& Kuhl, J. 2003. Emotion and intuition: Effects of positive and negative mood on implicit judgments of semantic coherence. Psychological Science, 14: 416-421.

Bower, G.H. 1981. Mood and memory. American Psychologist, 36(2): 129-148.

Bowers, K.S., Regehr, G., Balthazard, C., \& Parker, K. 1990. Intuition in the context of discovery. Cognitive Psychology, 22(1): 72-110.

Brabeck, M. 1984. Ethical characteristics of whistle-blowers. Journal of Research in Personality, 18: 41-53.

Brady, E. N. \& Wheeler, G. E. 1996. An empirical study of ethical predispositions. Journal of Business Ethics, 15(9): 927-940.

Brans, J.P. 2000. Ethics and decision. European Journal of Operational Research, 136: 340-352. 
Browning, J., \& Zahriskie, N.B. 1983. How ethical are industrial buyers? Industrial Marketing Management, 12: 219-224.

Bruce, W. 1994. Ethical people are productive people. Public Productivity \& Management Review, 7(3): 241-252.

Burke, L.A., \& Miller, M.K. 1999. Taking the mystery out of intuitive decision making. Academy of Management Executive, 13(4): 91-99.

Busemeyer, J.R., \& Townsend, J.T. 1993. Decision field theory: A dynamic-cognitive approach to decision making in an uncertain environment. Psychological Review, 100(3): 432-459.

Cader, R, Campbell, S., \& Watson, D. 2005. Cognitive continuum theory in nursing decision-making. Journal of Advanced Nursing, 49(4): 397-405.

Caldwell, D.F., \& Moberg, D. 2007. An exploratory investigation of the effect of ethical culture in activating moral imagination. Journal of Business Ethics, 73: 193-204.

Campbell, D. 1988. Task complexity: A review and analysis. Academy of Management Review, 13: 40-52.

Campos, A., Gonzalez, M.A., \& Amor, A. 2002. The Spanish version of the vividness of visual imagery questionnaire: factor structure and internal consistency reliability. Psychological Reports, 90: 503-506.

Campos, A., \& Perez, M.J. 1988a. Vividness of movement imagery questionnaire: relations with other measures of mental imagery. Perceptual and Motor Skills, 67: 607-610.

Campos, A., \& Perez, M.J. 1988b. Visual elaboration scale as measure of imagery. Perceptual and Motor Skills, 66: 411-414.

Campos, A., Perez-Fabello, M.J., \& Gomez-Juncal, R. 2004. Gender and age differences in measured and self-perceived imaging capacity. Personality and Individual Differences, 37: 1383-1389.

Campos, A, \& Sueiro, E. 1983. Sex and age differences in visual imagery vividness. Journal of Mental Imagery, 17(3-4): 91-94.

Cardaci, M. (2000). The Mental Clock Model: Studies on the estimation of time. In R. Buccheri, V. Di Gesù, \& M. Saniga (Eds.), Studies on the structure of time: From physicsto psycho(patho)log: 2754-2760. New York: Kluwer Academic/Plenum.

Cappon, D. 1993. The anatomy of intuition. Psychology Today, 26: 40-91. 
Cappon, D. 1994. Intuition and management: Research and application. Westport, CT: Quorum Books.

Carson, T.L. 2003. Self-interest and business ethics: some lessons of the recent corporate scandals. Journal of Business Ethics, 43(4): 389-394.

Chatman, J.A., \& Barsade, S.G. 1995. Personality, organizational culture, and cooperation: Evidence from a business simulation. Administrative Science Quarterly, 40: 423-443.

Chavez, G.A., Wiggins III, R.A., \& Yolas, M. 2001. The impact of membership in the ethics officer association. Journal of Business Ethics, 34(1): 39-56.

Cherry, J., \& Fraedrich, J. 2000. An empirical investigation of locus of control and the structure of moral reasoning: Examining the ethical decision making processes of sales managers. The Journal of Personal Selling and Sales Management, 20(3): 173-188.

Cherry, J., Lee, M., \& Chien, C.S. 2003. A cross-cultural application of a theoretical model of business ethics: Bridging the gap between theory and data. Journal of Business Ethics, 44(4): 359-376.

Chonko, L.B., \& Hunt, S.D. 1985. Ethics and marketing management: A behavioral model of ethical and unethical decision making. Journal of Business Ethics, 6: 265-280.

Christensen, G.L. 2002. Mental simulations, anticipations, and dreams: Toward a theory of consumption vision in consumer behavior. Unpublished doctoral dissertation, Pennsylvania State University.

Claxton, G. 1998. Knowing without knowing why. Psychologist, 11(5): 217-220.

Cleckley, H. 1955. The mask of sanity. St. Louis, MO: C.V. Mosby.

Clore, G.L., Wyer, R.S., and Dienes, B. 2001. Affective feelings as feedback: Some cognitive consequences. In L.L. Martin \& G.L. Clore (Eds.), Theories of mood and cognition: A user's handbook: 27-62. Mahwah, NJ: Erlbaum.

Cohen, J. 1977. Statistical power analysis for the behavioral sciences. New York: Academic.

Cohen, J. 1988. Statistical power analysis for the behavioral sciences $\left(3^{\text {rd }}\right.$ edition). Hillsdale, NJ: Erlbaum. 
Cohen, J.R., Pant, L.W., \& Sharp, D.J. 2001. An examination of differences in ethical decision making between Canadian business students and accounting professional. Journal of Business Ethics, 30(4): 319-336.

Colby, A. \& Damon, W. 1992. Some do care: Contemporary lives of moral commitment. New York: Free Press.

Cooksey, R.W. 1996. Judgment analysis: Theory, methods and applications. New York: Academic Press.

Damasio, A.R. 1994. Descartes' error: Emotion, reason and the human brain. New York: Grosset/Putnam.

Dane, E., \& Pratt, M.G. 2007. Exploring intuition and its role in managerial decision making. Academy of Management Review, 32(1): 33-54.

Daniels, K. 2008. Affect and information processing. In G.P. Hodgkinson \& W.H. Starbuck (Eds.), The Oxford handbook of organizational decision making: 325341. New York: Oxford University Press.

Deal, T. E. \& Kennedy, A. 1999. The new corporate cultures. New York: Perseus.

DeConinck, J. B., \& Lewis, W.F. 1997. The influence of deontological and teleological considerations and ethical climate on sales managers' intentions to reward or punish sales force behavior. Journal of Business Ethics, 16(5): 497-506.

Denes-Raj. V. \& Epstein, S. 1994. Conflict between experiential and rational processing: When people behave against their better judgment. Journal of Personality and Social Psychology, 66: 817-829.

Descartes, R. 1637. Discourses on the method and principles of philosophy.

Dewey, J. 1934/1987. Art as experience. In J. Boydston (Ed.), The later works of John Dewey, 1925-1953, vol. 10. Carbondale, IL: Southern Illinois University Press.

Deutsch, R., \& Strack, F. 2008. Variants of judgment and decision making: The perspective of the reflective-impulsive mind. In H. Plessner, C. Betsch \& T. Betsch (Eds.), Intuition in judgment and decision making: 39-53. New York: Laurence Earlbaum Associates/Taylor \& Francis Group.

Dunwoody, P.T., Haarbauer, E., Mahan, R.P., Marino, C. \& Tang, C. 2000. Cognitive adaptation and its consequences: A test of cognitive continuum theory. Journal of Behavioural Decision-Making, 13: 55-59. 
Elias, R. Z. 2002. Determinants of earnings management ethics among accountants. Journal of Business Ethics, 40(1): 33-45.

Ellis, A. 1992. Utilitarianism and international ethics. In T. Nardin \& D.R. Mapel (Eds.), Traditions of international ethics: 158-179. New York: Cambridge.

Ellsberg, D. 1961. Risk, ambiguity, and the savage axioms. Quarterly Journal of Economics, 7: 643-669.

Elm, D R., \& Nichols, M.L. 1993: An investigation of the moral reasoning of managers. Journal of Business Ethics, 12: 817-833.

Elsbach, K.D., \& Barr, P.S. 1999. The effects of mood on individual's use of structured decision protocols. Organization Science, 10: 181-198.

Emiliani, M.L. 2004. Is management education beneficial to society? Management Decision, 42: 481-498.

Epstein, S. 1990. Cognitive-experiential self-theory. In L. Pervin (Ed.), Handbook of personality: Theory and research: 165-192. New York: Guilford Press.

Epstein, S. 1994. Integration of the cognitive and the psychodynamic unconscious. American Psychologist, 49: 709-724.

Epstein, S., Pacini, R., Denes-Raj, V., \& Heier, H. 1996. Individual differences in intuitiveexperiential and analytical-rational thinking styles. Journal of Personality and Social Psychology, 71(2), 390-405.

Epstein, S. 2008. Intuition from the perspective of cognitive-experiential self-theory. In H. Plessner, C Betsch \& T. Betsch (Eds.), Intuition in judgment and decision making: 23-37. New York: Laurence Earlbaum Associates/Taylor \& Francis Group.

Ergeneli, A. \& Arikan, S. 2002. Gender differences in ethical perceptions of salespeople: An empirical examination in Turkey. Journal of Business Ethics, 40(1): 247-260.

Ernest, C.A. 1983. Imagery and verbal ability and recognition memory for pictures and words in males and females. Educational Psychology, 3: 227-244.

Estrada, C.A., Isen, A.M., \& Young, M.J. 1997. Positive affect facilitates integration of information and decreases anchoring in reasoning among physicians.

Organizational Behavior and Human Decision Processes, 72: 117-135.

Evans, D.A. 2006. Subject perceptions of confidence and predictive validity in financial information cues. Journal of Behavioral Finance, 7(1): 12-28. 
Fabrigar, L.R., Wegener, D.T, MacCallum, R.C. \& Strahan, E.J. 1999. Evaluating the use of exploratory factor analysis in psychological research. Psychological Methods, 3: 272-299.

Fazio, R.H., Sanbonmatsu, D.M., Powell, M.C., \& Kardes, F.R. 1986. On the automatic evaluation of attitudes. Journal of Personality and Social Psychology, 50: 229-238.

Fazio, R.H., \& Olson, M.A. 2003. Implicit measures to social cognition research: Their meaning and use. Annual Review of Psychology, 54: 297-327.

Ferrell, O. C., \& Gresham, L.G. 1985. A contingency framework for understanding ethical decision making in marketing. Journal of Marketing, 49 (Summer): 87-96.

Ferrell, O. C., \& Skinner, S.J. 1988. Ethical behavior and bureaucratic structure in marketing research organizations. Journal of Marketing Research, 25 (February): 103-109.

Fiedler, K. 1988. Emotional mood, cognitive style and behavior regulation. In K. Fiedler \& J. Forgas (Eds.), Affect, cognition and social behavior: 100-119. Gottingen, Germany: Hogrefe.

Fiedler, K., \& Bess, H. 2000. The formation of beliefs and the interface of affective and cognitive processes. In N.H. Frijda, A. Sorrentino \& R. Manstead (Eds.), Emotions and belief: How feelings influence thought. Studies in emotion and social interaction: 144-170. New York: Cambridge University Press.

Fleischman, G., \& Valentine, S. 2003. Professionals' tax liability and ethical evaluations in an equitable relief innocent spouse case. Journal of Business Ethics, 42(1): 27-44.

Ford, R.C., \& Richardson, W.D. 1994. Ethical decision making: A review of the empirical literature. Journal of Business Ethics, 13: 205-221.

Forsyth, D.R. 1980. A taxonomy of ethical ideologies. Journal of Personality and Social Psychology, 38(1): 75-184.

Forsyth, D.R. 1992. Judging the morality of business practices: The influence of personal moral philosophies. Journal of Business Ethics, 11(5/6): 461-470.

Frederickson, J.W. \& Iaquinto, A.L. 1989. Inertia and creeping rationality in decision processes. Academy of Management Journal, 32: 543-576.

Fried, C. 1978. Right and wrong. Cambridge, MA: Harvard University Press. 
Fritzsche, D. J., \& Becker, H. 1983. Ethical behavior of marketing managers. Journal of Business Ethics, 1: 291-299.

Fritzsche, D.J., \& Oz, E. 2007. Personal values' influence on the ethical dimension of decision making. Journal of Business Ethics, 75: 335-343.

Garcia, A.E.V., \& Ostrosky-Solis, F. 2006. From morality to moral emotions. International Journal of Psychology, 41(5): 348-354.

Ge, L., \& Thomas, S. 2008. A cross cultural comparison of the deliberative reasoning of Canadian and Chinese accounting students. Journal of Business Ethics, 82(1): 189-211.

George, J. M., \& Zhou, J. 2007. Dual tuning in a supportive context: Joint contributions of positive mood, negative mood, and supervisory behaviors to employee creativity. Academy of Management Journal, 50(3): 605-622.

Giacalone, R.A., \& Jurkiewicz, C.L. 2003. Right from wrong: The influence of spirituality on perceptions of unethical business activities. Journal of Business Ethics, 46(1): 85-97.

Gigerenzer, G. 2004. Fast and frugal heuristics: The tools of bounded rationality. In D. Koehler \& N. Harvey (Eds.), Handbook of judgment and decision making: 62-88. Oxford: Blackwell.

Glockner, A. 2008. Does intuition beat fast and frugal heuristics? A systematic empirical analysis. In H. Plessner, C. Betsch \& T. Betsch (Eds.), Intuition in judgment and decision making: 23-37. New York: Laurence Earlbaum Associates/Taylor \& Francis Group.

Goetz, E.T., \& Sadoski, M. 1996. Imaginative processes in literary comprehension. In R.J. Kreuz \& MS. MacNealy (Eds.), Empirical approaches to literature and aesthetics: 221-240. Norwood, NJ: Ablex.

Granitz, N.A. 2003. Individual, social and organizational sources of sharing and variation in the ethical reasoning of managers. Journal of Business Ethics, 42(2): 101-124.

Granitz, N.A., \& Ward, J.C. 2001. Actual and perceived sharing and ethical reasoning and moral intent among ingroup and outgroup members. Journal of Business Ethics, 33(4): 299-322.

Grayson, C.J., Jr. 1973. Management science and business practice. Harvard Business Review, July-August: 41-48. 
Greene, J.D., Sommerville, R.B., Nystrom, L.E., Drley, J.M., \& Cohen, J.D. 2001. An fMRI Investigation of Emotional Engagement in Moral Judgment. Science, 293: 2105-2108.

Greenwald, A.G., \& Banaji, M. 1995. Implicit social cognition: Attitudes, self-esteem, and stereotypes. Psychological Review, 102: 4-27.

Grossberg, S., \& Gutowski, W.E. 1987. Neural dynamics of decision making under risk: Affective balance and cognitive-emotional interactions. Psychological Review, 94(3): 300-318.

Grover, S. L. \& Hui, C. 1994. The influence of role conflict and self-interest on lying in organizations. Journal of Business Ethics, 13: 293-303.

Gundlach, M.J., Douglas, S.C., \& Martineo, M.J. 2003. The decision to blow the whistle: A social information processing framework. Academy of Management Review, 28(1): 107-123.

Guy, M.E. 1990. Ethical decision making in everyday work situations. Westport, CT: Greenwood Press.

Haidt, J. 2001. The emotional dog and its rational tail: Asocial intuitionist approach to moral judgment. Psychological Review, 108: 814-834.

Haidt, J, \& Kesebir, S. 2008. In the forest of value: Why moral intuitions are different from other kinds. In H. Plessner, C. Betsch \& T. Betsch (Eds.), Intuition in judgment and decision making: 209-229. New York: Laurence Earlbaum Associates/Taylor \& Francis Group.

Hair, J.F., Black, W.C., Babin, B.J., Anderson, R.E., \& Tatham, R.L. 2006. Multivariate data analysis: Sixth edition. Upper Saddle River, NJ: Pearson Prentice Hall.

Hammond, K.R. 1981. Principles of organization intuitive and analytical cognition (Report No. 231). Center for Research on Judgment and Policy, University of Colorado, Boulder, CO.

Hammond, K.R. 1986. A theoretically based review of theory and research in judgment and decision making (Report No. 260). Center for Research on Judgment and Policy, University of Colorado, Boulder, CO.

Hammond, K.R. 1987. Toward a unified approach to the study of expert judgment. In J. Mumpower, L. Phillips, O. Renn \& R. Uppoluri (Eds.), Expert judgment and exert systems: 1-16. Berlin: Springer-Verlag. 
Hammond, K.R. 1990b. Intuitive and analytical cognition: Information models. In A.P. Sage (Ed.), Concise encyclopedia of information processing in systems and organizations: 301-312. Oxford: Pergamon Press.

Hammond, K.R., Hamm, R.M., Grassia, J., \& Pearson, T. 1987. Direct comparison of the relative efficiency on intuitive and analytical cognition. IEEE Transactions on Systems, Man, and Cybernetics, 17: 753-770.

Hanze, M. 1997. Mood and the stoop interference effect. Psychologische Beitrage, 39(3): 229-235.

Hanze, M., \& Meyer, H.A. 1998. Mood influences on automatic and controlled semantic priming. The American Journal of Psychology, 111(2): 265-278.

Hare, R.D. 1993. Without conscience. New York: Pocket Books.

Harshman, R.A., \& Paivio, A. 1987. Paradoxical sex differences in self-reported imagery. Canadian Journal of Psychology, 41: 287-302.

Hart, D. \& Fegley, S. 1995. Prosocial behavior and caring in adolescence: Relations to self-understanding and social judgment. Child Development, 66: 1346-1359.

Hartman, E.M. 2008. Reconciliation in business ethics: Some advice from Aristotle. Business Ethics Quarterly, 18(2): 253-265.

Hayashi, A.M. 2001. When to trust your gut. Harvard Business Review, 79(2): 59-65.

Hayry, M. 1994. Liberal utilitarianism and applied ethics. NY: Routledge.

Hegarty, W. H. \& Sims, H.P. Jr. 1978. Some determinants of unethical decision behavior: An experiment. Journal of Applied Psychology, 63(4): 451-457.

Hegarty, W. H. \& Sims, H.P. Jr. 1979. Organizational philosophy, policies and objectives related to unethical decision behavior: A laboratory experiment. Journal of Applied Psychology, 64(3): 331-338.

Heider, F. 1958. The psychology of interpersonal relations. New York: John Wiley \& Sons.

Hermans. D., De Houwer. J., \& Eelen, P. 1994. The affective priming effect: Automatic evaluation of evaluative information in memory. Cognition and Emotion, 8: 515533.

Hogarth, R.M. 2001. Educating intuition. Chicago: University of Chicago Press. 
Hogarth, R.M. 2008. On the learning of intuition. In H. Plessner, C. Betsch \& T. Betsch (Eds.), Intuition in judgment and decision making: 23-37. New York: Laurence Earlbaum Associates/Taylor \& Francis Group.

Hong, J.Y. 2006. Matching the advertising creative strategy to the thinking mode: The moderating effect of product type on the effectiveness of imagery-evoking advertising tactics. University of Texas at Austin: Unpublished dissertation.

Hoo, Q.C., Si-Maan, W., \& Ignatious, J. 2008. Is the love of money universal amongst aspiring Malaysian managers? Journal of Corporate Governance, 7(2): 7-19.

Huberty, C.J., \& Morris, J.D. 1989. Multivariate analysis versus multiple univariate analyses. Psychological Bulletin, 105(2): 302-308.

Hunt, S.D., \& Vasquez-Perraga, A.Z. 1993. Organizational consequences, marketing ethics, and sales force supervision. Journal of Marketing Research, 30(1): 78-90.

Hunt, S.D., \& Vitell, S. 1986. A general theory of marketing ethics. Journal of Macromarketing, 6(Spring): 5-16.

Isen, A.M. 1984. Towards understanding the role of affect in cognition. In R.S. Wyler \& T.K. Srull (Eds.), Handbook of social cognition, Vol. 3: 179-236. Hillsdale, NJ: Erlbaum.

Isen, A.M. 1987. Positive affect, cognitive processes, and social behavior. In L. Berkowitz (Ed.), Advances in experimental social psychology, Vol. 20: 203-253. New York: Academic Press.

Isen, A.M. 2000. Positive affect and decision making. In M. Lewis \& J.M. Haviland-Jones (Eds.), Handbook of emotions: 417-435. New York: Guilford Press.

Izraeli, D 1988. Ethical beliefs and behavior among managers: A cross-cultural perspective. Journal of Business Ethics, 7: 263-271.

Jacoby, L.L. 1996. Dissociating automatic and consciously-controlled effects of study/test compatibility. Journal of Memory and Language, 35: 32-52.

Janis, I.L., \& Mann, L. 1977. Decision making: A psychological analysis of conflict choice and commitment. New York: The Free Press.

Jones, T.M. 1991. Ethical decision making by individuals in organizations: An issuecontingent model. Academy of Management Review, 16(2): 368-395.

Jones, T. M., \& Gautschi, F.H. III. 1988. Will the ethics of business change? A survey of future executives. Journal of Business Ethics, 7: 231-248. 
Jovanovic, S., \& Wood, R.V. 2007. Dialectical interactions: Decoupling and integrating ethics in ethics initiatives. Business Ethics Quarterly, 17(2): 217-238.

Kahneman, D., \& Tversky, A. 1979. Prospect theory: An analysis of decision under risk. Econmetrica, 47: 263-291.

Kamm, F.M. 2007. Intricate ethics: Rights, responsiblilities, and permissible harm. NY: Oxford University Press.

Kaptein, M., \& Schwartz, M. 2008. The effectiveness of business codes: A critical examination of existing studies and the development of an intergrated research model. Journal of Business Ethics, 77(2): 111-127.

Kaynama, S.A., King, A., \& Smith, L.W. 1996. The impact of a shift in organizational role on ethical perception: A comparative study. Journal of Business Ethics, 15(5): 581-590.

Keppel, G. \& Zedeck, S. 1989. Data analysis for research design. New York: W.H. Freeman \& Co.

Khatri, N. \& Ng, H.A. 2000. The role of intuition in strategic decisoin making. Human Relations, 53: 57-86.

Kidwell, J.M., Stevens, R.E. \& Bethke, A.L. 1987. Differences in the ethical perceptions between male and female managers: Myth or reality. Journal of Business Ethics, 6: 489-493.

Kim, S.Y., \& Chun, S.Y. 2003. A study of marketing ethics in Korea: What do Koreans care about? International Journal of Management, 20(3): 377-383.

King, L.A., Burton, C.M., Hicks, J.A., \& Drigotas, S.M. 2007. Ghosts, UFO's and magic: Positive affect and the experiential system. Journal of Personality and Social Psychology, 92(5): 905-919.

Kisielius, J, \& Sternthal, B. 1984. Detecting and explaining vividness effects on attitudinal judgments. Journal of Marketing Research, 21: 54-64.

Kisielius, J, \& Sternthal, B. 1986. Examining the vividness controversy: An availabilityvalence interpretation. Journal of Consumer Research, 12(March): 418-431.

Klein, G. 2003. Intuition at work: Why developing your gut instincts will make you better at what you do. New York: Doubleday/Random House. 
Klinger, E. 1993. Clinical approaches to mood control In D.M. Wegner \& J.W. Pennebaker (Eds.), Handbook of mental control: 344-369. Englewood Cliffs, NJ: Prentice Hall.

Kohlberg, L., 1969. Stage and sequence: The cognitive-developmental approach to socialization. In D.A. Gosln (Ed.), Handbook of Socialization Theory and Research: 347-380. Chicago: Rand McNally.

Kohut, G. F. \& Corriher, S. E. 1994. The relationship of age, gender, experience and awareness of written ethics policies to business decision making. SAM Advanced Management Journal, 59(1): 32-39.

Kosslyn, S.M. 1994. Image and brain. Cambridge, MA: The MIT Press.

Kosslyn, S.M., Alpert, N.M., Thompson, W.L., Maljkovic, V., Weise, S.B., Chabris, C.F., Hamilton, S.E., Rauch, S.L., \& Buonanno, F. S. 1993. Visual mental imagery activates topographically organized visual cortex: PET investigation. Journal of Cognitive Neuroscience, 5: 263-287.

Krasny, K.A. 2004. Imagery, affect and the embodied mind: Implications for reading and responding to literature. Unpublished doctoral dissertation, Texas A\&M University College Station, TX.

Kuhl, J. 1983a. Emotion, cognition and motivation: The functional significance of emotions to problem solving. Sprache und Kognition, 4: 228-253.

Kuhl, J., \& Kazen, M. 1999. Volitional facilitation of difficult intentions: Joint activation of intention memory and positive affect removes Stroop interference. Journal of Experimental Psychology, 128(3): 382-399.

Kujala, J. \& Pietilainen, T. 2004. Female managers' ethical decision making: A multidimensional approach. Journal of Business Ethics, 53(1/2), 153-163.

Kutner, M.H., Nachtsheim, C.J., Neter, J., \& Li, W. 2005. Applied Linear Statistical Models. New York: McGraw-Hill.

Laczniak, G., \& Inderrieden, E.J. 1987. The influence of stated organizational concern upon ethical decision making. Journal of Business Ethics, 6: 297-307.

Ladkin, D. 2006. When deontology and utilitarianism aren't enough: how Heidegger's notion of "dwelling" might help organisational leaders resolve ethical issues. Journal of Business Ethics, 65: 87-98.

Lang, P.J., Greenwald, M.K., Bradley, M.M., \& Hamm, A.O. 1993. Looking at pictures: affective, facial, visceral, and behavioral reactions. Psychophysiology, 30: 261-273. 
Langley, A., Mintzberg, H., Pitcher, P., Posada, E., \& Saint-Macary, J. 1995. Opening up decision-making: The view from the black stool. Organizational Science, 6(1): 260-279.

Latif, D.A. 2001. The relationship between pharmacists' tenure in the community setting and moral reasoning. Journal of Business Ethics, 31(2): 131-141.

Laughlin, P. 1980. Social combination processes of cooperative problem-solving groups on verbal intellective tasks. In M. Fishbein (Ed.), Progress in social psychology, vol.1: 127-155. Hillsdale, NJ: Lawrence Erlbaum Associates.

Laughlin, P.R., \& Ellis, A.L. 1986. Acquisition of procedural knowledge about a pattern of stimuli that cannot be articulated. Cognitive Psychology, 20: 24-37.

Leven, S.J., \& Levine, D.S. 1996. Multiattribute decision making in context: A dynamic neural network methodology. Cognitive Science, 20: 271-299.

Levine, D.S. 2000. Introduction to Neural and Cognitive Modeling. Mahwah, NJ: Lawrence Earlbaum Associates.

Ley, R. G., \& Bryden, M.P. 1983. Right hemisphere involvement in imagery and affect. In E Percmen \& J. Brown (Eds.), Cognitive processing in the right hemisphere. New York: Academic.

Lichtenstein, S., \& Slovic, P. 1971. Reversals of preference between bids and choices in gambling decisions. Journal of Experimental Psychology, 89: 46-55.

Loe, T.W., Ferrell, L., \& Mansfield, P. 2000. A review of empirical studies assessing ethical decision making in business. Journal of Business Ethics, 25: 185-204.

Loewenberg, F.M. \& Dolgoff, R. 1996. Ethical decisions for social work practice $\left(5^{\text {th }}\right.$ ed.). Itasca, IL: F. E. Peacock.

Loomes, G., \& Sugden, R. 1982. Regret theory: An alternative of rational choice under uncertainty. Economic Journal, 92: 805-824.

Loomes, G., \& Sugden, R. 1986. Disappointment and dynamic consistency in choice under uncertainty. Review of Economic Studies, 53: 271-282.

Lopes, L.L. 1987. Between hope and fear: The psychology of risk. Advances in Experimental Social Psychology, 20: 255-295.

Luce, M.F., Payne, J.W., \& Bettman, J.R. 1999. Emotional trade-off difficulty and choice. Journal of Marketing Research, 36: 143-159. 
Lund, D. 2008. Gender differences in ethics judgment of marketing professionals in the United States. Journal of Business Ethics, 77(4): 501-515.

MacInnis, D.J. \& Price, L.L. 1987. The role of imagery in information processing: Review and extensions," Journal of Consumer Research, 13(4): 473-491.

Mann, L. 1992. Stress, affect and risk taking. InY.J. Frank (Ed.), Risk-taking behavior, Y.J. 202-230. Chichester: John Wiley \& Sons.

March, J.G. 1978. Bounded rationality, ambiguity, and the engineering of choice. Bell Journal of Economics, 9(2): 587-608.

Marks, D.F. 1973. Visual imagery differences in recall of pictures. British Journal of Psychology, 64, 17-24.

Mathews, M.C. 1987. Codes of ethics: Organizational behavior and misbehavior. Research in Corporate Social Performance, 9: 107-130.

Mathieson, K. 2007. Towards a design science of ethical decision support. Journal of Business Ethics, 76: 269-292.

McCabe, D.L., Trevino, L.K., \& Butterfield, K.D. 1996. The influence of collegiate and corporate codes of conduct on ethics-related behavior in the workplace. Business Ethics Quarterly, 6: 461-476.

McConkey, K.M., \& Nogrady, H. 1986. Visual elaboration scale: Analysis of individual and group version. Journal of Mental Imagery, 10: 37-46.

McDevitt, R., Giapponi, C., \& Tromley, C. 2007. A model of ethical decision making: The integration of process and content. Journal of Business Ethics, 73: 219-229.

McGrath, J.E. 1984. Groups: Interaction and performance. Englewood Cliffs, NJ: Prentice-Hall.

McKelvie, S.J. 1986. Effects of format of the vividness of visual imagery questionnaire on content validity, split-half reliability, and the role of memory in test-retest reliability. British Journal of Psychology, 77: 229-236.

McKendall, M., DeMarr, B., \& Jones-Rikkers, C. 2002. Ethical compliance programs and corporate illegality: Testing the assumptions of the corporate sentencing guidelines. Journal of Business Ethics, 37: 367-383.

McMackin, J., \& Slovic, P. 2000. When does explicit justification impair decision making? Journal of Applied Cognitive Psychology, 14: 527-541. 
Mellers, B., Schwartz, A., \& Ritov, I. 1999. Emotion-based choice. Journal of Experimental Psychology: General, 128(3): 332-345.

Miceli, M.P., Dozier, J.B., \& Near, J.P. 1991. Blowing the whistle on data fudging: A controlled field experiment. Journal of Applied Social Psychology, 21(4): 271-295.

Miceli, M.P., Near, J.P., \& Dworkin, M. 2008. Whistle-blowing in organizations. New York: Routledge.

Micewski, E.R., \& Troy, C. 2007. Business ethics-deontology revisited. Journal of Business Ethics, 72: 17-25.

Miller, D.W., Hadjimarcou, J., \& Miciak, A. 2000. A scale for measuring advertisementevoked mental imagery. Journal of Marketing Communications, 6: 1-20.

Molloy, D.C., \& Agarwal, J. 2003. Factors influencing ethical climate in a nonprofit organization: An empirical investigation. International Journal of Nonprofit \& Voluntary Sector Marketing, 8(3): 224-251.

Monga, M. 2007. Managers' moral reasoning: Evidence from large Indian manufacturing organizations. Journal of Business Ethics, 71(2): 179-194.

Morgan, R.B. 1993. Self and co-worker perceptions of ethics and their relationships to leadership and salary. Academy of Management Journal, 36(1): 200-214.

Moyer, T.J., Bradley, D.R., Sorenson, M.H., Whiting, J.C., \& Mansfield, D.P. 1978. Psychophysical functions for perceived and remembered size. Science, 200 (April): 330-332.

Murphy, K.R., Herr, B.M., Lockhart, M.C., \& Maguire, E. 1986. Evaluating the performance of paper people. Journal of Applied Psychology, 71 (4): 654-661.

Myers, R. 2003. Ensuring ethical effectiveness: New rules mean virtually every company will need a code of ethics. Journal of Accountancy, 195(2): 28-33.

Narchal, R., \& Broota, K.D. 1988. Sex differences in vividness of mental imagery under eyes open and eyes closed conditions. Journal of Mental Imagery, 12: 81-88.

Near, J.P., \& Miceli, M.P. 1985. Organizational dissidence: The case of whistle-blowing. Journal of Business Ethics, 4: 1-16.

Nelson, D.L., \& Quick, J.C. 2006. Organizational behavior: Foundations, realities, and challenges, $5^{\text {th }}$ edition. Mason, $\mathrm{OH}$ : Thompson South-Western. 
Nisbett, R., \& Ross, L. 1980. Human inference: Strategies and shortcomings of social judgment. Englewood Cliffs, NJ: Prentiss-Hall.

Norris, P., \& Epstein, S. 2003a. Objective correlates of experiential processing. Working paper.

Norris, P., \& Epstein, S. 2003b. The investigation of some fundamental issues concerning rational-analytic and intuitive experiential thinking styles with a short form of the rational-experiential inventory. Working paper.

Novak, T.P., \& Hoffman, D.L. 2005. Consumer thinking style, task congruence and performance: New measures of task specific experimental and rational cognition. Unpublished paper.

O'Fallon, M.J. \& Butterfield, K.D. 2005. A review of the empirical ethical decisionmaking literature: 1996-2003. Journal of Business Ethics, 59: 375-413.

O'Reilly, C.A., \& Chatman, J. 1996. Culture and social control: Corporations, cults and commitment. In L.L. Cummings \& B.M. Staw (Eds.), Research in organizational behavior, vol. 18: 157-200. Greenwhich, CT: JAI Press.

Oz, E. 2001. Orgnizational commitment and ethical behavior: An empirical study of information system professions. Journal of Business Ethics, 34(2): 137-142.

Pabroteeah, K.P., Hoegl, M., \& Cullen, J.B. 2008. Ethics and religion: An empirical test of a multidimensional model. Journal of Business Ethics, 80: 387-398.

Pacini, R., \& Epstein, S. 1999. The interaction of three facets of concrete thinking in a game of chance. Thinking and Reasoning, 5(4): 303-325.

Paivio, A. 1986. Mental representations: A dual coding approach. Oxford: Oxford University Press.

Paivio, A. 1991. Images in mind: The evolution of a theory. New York: Harvester Wheatsheaf.

Paivio, A. 2007. Mind and its evolution: A dual coding theoretical approach. Manwah, NJ: Lawrence Erlbaum Associates.

Paolillo, J.G.P., \& Vitell, S.J. 2002. An empirical investigation of the influence of selected personal, organizational and moral intensity factors on ethical decision making. Journal of Business Ethics, 35: 65-74.

Parkinson, B. 1995. Ideas and realities of emotion. London: Routledge. 
Parks, C.D., Sanna. L.J., \& Posey, D.C. 2003. Retrospection in social dilemmas: How thinking about the past affects future cooperation. Journal of Personality and Social Psychology, 84: 988-966.

Payne, J.W. 1982. Contingent decision behavior. Psychological Bulletin, 92: 382-402.

Payne, J.W., Bettman, J.R., \& Johnson, E.J. 1988. Adaptive strategy selection in decision making. Journal of Experimental Psychology: Learning, Memory and Cognition, 14: $534-552$.

Peters, E., Vastfjall, D, Garling, T., \& Slovic, P. 2006. Affect and decision making: A "hot" topic. Journal of Behavioral Decision Making, 19: 79-85.

Peterson. D.K. 2002. The relationship between unethical behavior and the dimensions of the ethical climate questionnaire. Journal of Business Ethics, 4(4): 313-326.

Plessner, H., \& Czenna, S. 2008. The benefits of intuition. In H. Plessner, C. Betsch \& T. Betsch (Eds.), Intuition in judgment and decision making: 251-265. New York: Laurence Earlbaum Associates/Taylor \& Francis Group.

Plous, S. 1993. The psychology of judgment and decision making. New York: McGrawHill.

Priem, R.L., Rasheed, A.M.A., and Kotulic, A.G. 1995. Rationality in strategic decision processes, environmental dynamism and firm performance. Journal of Management, 21(5): 913-929.

Prietula, M.J., \& Simon, H.A. 1989. The experts in your midst. Harvard Business Review, 67(1): 120-124.

Parkinson, R. 1995. Ideas and realities of emotion. London: Routledge.

Potvin, P.J., \& Shutz, Statistical power for the two-factor repeated measures ANOVA. Behavior Research Methods, Instruments and Computers, 32(2): 347-356.

Pucetaite, R., \& Lamsa, A. 2008. Advancing organizational trust in a post-socialist context: Role of ethics management tools. Economics and Management, 13: 381388.

Raab, M, \& Johnson, J.G. 2008. Implicit learning as a means to intuitive decision making in sports. In H. Plessner, C. Betsch \& T. Betsch (Eds.), Intuition in judgment and decision making: 119-133. New York: Laurence Earlbaum Associates/Taylor \& Francis Group. 
Rallapalli, K.C., Vitell, S.J., \& Barnes, J.H. 1998. The influence of norms on ethical judgments and intentions: An empirical study of marketing professionals. Journal of Business Research, 43: 157-168.

Rayburn, J.M., \& Rayburn. L.G. 1996. Relationship between Machiavellianism and type A personality and ethical-orientation. Journal of Business Ethics, 15(11): 12091219.

Reber, A.S. 1993. Implicit learning and tacit knowledge: An essay on the cognitive unconscious. New York: Oxford University Press.

Reiss, M.C., \& Mitra, K. 1998. The effects of individual difference factors on the acceptability of ethical and unethical workplace behaviors. Journal of Business Ethics, 17(14): 1581-1593.

Rest, J.R. 1979. Development in judging moral issues. Minneapolis, MN: University of Minnesota Press.

Rest, J.R. 1986. Moral development: Advances in research and theory. New York: Praeger.

Reyes, R.M., Thompson, W.C., \& Bower, G.H. 1980. Judgmental biases resluting from differing availabilities of arguments. Journal of Personality and Social Psychology, 39: 2-12.

Reynolds, S.J. 2006. A neurocognitive model of the ethical decision-making process: Implications for study and practice. Journal of Applied Psychology, 91: 737-748.

Robertson, D.C., \& Rymon, T. 2001. Purchasing agents' descriptive behavior: A randomized response technique study. Business Ethics Quarterly, 11(3): 455-479.

Ross, L. 1989. Recognizing construal processes. In I. Rock (Ed.), The legacy of Solomon Asch: Essays in cognition and social psychology: 77-96. Hillsdale, NJ: Lawrence Erlbaum Associates.

Ross, L.D., \& Nisbett, R.E. 1991. The person and the situation. New York: McGrawHill.

Ross, W. T., \& Robertson, D.C. 2003. A typology of situational factors: Impact on salesperson decision-making about ethical issues. Journal of Business Ethics, 46(3): 213-234.

Russell, J.A. 2003. Core affect and the psychological construction of emotion. Psychological Review, 110: 145-172. 
Russell, S.V. 2008. Explaining workplace pro-environmental behaviors: The role of emotion, values and issue ownership. Academy of Management Proceedings: 1-6.

Sadler-Smith, E., Hodgkinson, G.P., \& Sinclair, M. 2008. A matter of feeling? The role of intuition in entrepreneurial decision-making and behavior. In W.J. Zerbe, C.E.J. Hartel \& N.M. Ashkanasy (Eds.), Emotion, ethics, and decision-making: Research on emotion in organizations: 35-51. Bingley, UK: Emerald Group.

Sadler-Smith, E., \& Sparrow, P.R. 2008. Intuition in organizational decision making. In G.P. Hodgkinson \& W.H. Starbuck (Eds.), The Oxford handbook of organizational decision making: 305-324. New York: Oxford University Press.

Sadoski, M. \& Paivio, A. 2001. Imagery and text: A dual coding theory of reading and writing. Mahwah, NJ: Lawrence Erlbaum Associates.

Salk, J. 1985. The anatomy of reality. New York: Praeger.

Sankaran, S., \& Bui, T. 2003. Ethical attitudes among accounting majors: An empirical study. Journal of American Academy of Business, Cambridge, 3(1/2), 71-77.

Sayegha. L., Anthony, W.P., \& Perrewe, P.L. 2004. Managerial decision-making under crisis: The role of emotion in an intuitive decision process. Human Resource Management Review, 14(2): 179-200.

Schneider, W., \& Shiffrin, R.M. 1977. Controlled and automatic human information processing: Detection, search, and attention. Psychological Review, 84: 1-66.

Schein, E. H. 2004. Organizational culture and leadership. San Francisco, CA: JosseyBass.

Schepers, D H. 2003. Machiavellianism, profit, and the dimensions of ethical judgment: A study of impact. Journal of Business Ethics, 42(4): 339-352.

Schoemaker, P.J.H. 1982. The expected utility model: Its variants, purposes, evidence and limitations. Journal of Economic Literature, 20: 529-563.

Schwarz, N. 1990 Feelings as information: Informational and motivational functions of affective states. In T. Higgins \& R.M. Sorrentino (Eds.), Handbook of motivation and cognition: Foundations of social behavior: 527-561. New York: Guilford Press.

Schwarz, N. \& Clore. G.L. 1988. How do I feel about it? Information functions of affective states. In K. Fiedler \& J.P. Forgas (Eds.), Affect, cognition, and social behavior: 44-62. Toronto: Hogrefe International. 
Schwarz, N. \& Clore. G.L. 2003. Mood as information: 20 years later. Psychological Inquiry, 14: 296-303.

Serwinek, P. J. 1992. Demographic and related differences in ethical views among small businesses. Journal of Business Ethics, 11: 555-566.

Shapeero, M., Koh, H.C., \& Killough, L.N. 2003. Underreporting and premature sign-off in public accounting. Managerial Auditing Journal, 18(6/7): 478-489.

Shapiro, S., \& Spence, M.T. 1997. Managerial intuition: A conceptual and operational framework. Business Horizons, 40(1): 63-68.

Sheidahl, T. K. 1986. Ethical dilemmas in managerial accounting. Management Accounting, 64: 34-41.

Simon, H.A. 1956. Rational choice and the structure of the environment. Psychological Review, 63: 129-138.

Simon, H.A. 1957. Administrative behavior. New York: Free Press.

Simon, H.A. 1986. Alternative visions of rationality. In H.R. ARkes \& H.K. Hammond (Eds.), Judgment and Decision Making: An Interdisciplinary Reader: 97-113. Cambridge: Cambridge University Press.

Simon, H.A. 1987. Making management decisions: The role of intuition and emotion. Academy of Management Executive, 1(1): 57-64.

Simon, H.A., \& Chase, W.G. 1973. Skill in chess. American Scientist, 61: 394-403.

Sinclair, M., Ashkanasy, N.M., Chattopadhyay, P., \& Boyle, M.V. 2002. Determinants of intuitive decision making in management: The moderating role of affect. In N.M. Ashkanasy, W.J. Zerbe \& C.E.J. Hartel (Eds.), Managing emotions in the workplace: 143-163. Armonk, New York: M.E. Sharpe.

Singh, J.J., Vitell, S.J., Al-Khatib, J., \& Clark, I. (2007). The role of moral intensity and personal moral philosophies in the ethical decision making of marketers: A crosscultural comparison of China and the United States. Journal of International Marketing, 15 (2): 86-112.

Singhapakdi, A. \& Vitell, S.J. 1990. Marketing ethics: Factors influencing perceptions of ethical problems and alternatives. Journal of Marcomarketing, 10(1): 47-65.

Singhapakdi, A., Vitell, S.J., \& Kraft, K.L. 1996. The perceived role of ethics and social responsibility. Journal of Business Ethics, 15: 1131-1140.

Singhapakdi, A. \& Marta, J.K. 2005. Comparing marketing students with practitioners on 
some key variables of ethical decisions. Marketing Education Review, 15(3): 1625 .

Singhapakdi, A., Gopinath, M., Marta, J.K., \& Carter, L.L. 2008. Antecedents and consequences of perceived importance of ethics in marketing situations: A study of Thai businesspeople. Journal of Business Ethics, 81: 887-904.

Sivadas, E., Kleiser, S.B., Kellaris, J.\& Dahlstrom, R. 2003. Moral philosophy, ethical evaluations, and sales manager hiring intentions. Journal of Personal Selling \& Sales Management, 23(1): 7-21.

Sloman, S.A. 1996. The empirical case for two systems of reasoning. Psychological Bulletin, 119: 3-22.

Slovic, P., \& Peters, E. 2006. Risk perception and affect. Current Directions in Psychological Science, 15(6): 322-325.

Smith, G.F. 2008. Teaching decision making. In G.P. Hodgkinson \& W.H. Starbuck (Eds.), The Oxford Handbook of Organizational Decision Making: 455-474. New York: Oxford University Press.

Somers, M.J., \& Casal, J.C. 1994. Organizational commitment and whistle blowing: A test of the reformer and the organization man hypothesis. Group \& Organization Management, 19(3): 270-284.

Sonenshein, S. 2005. Business ethics and internal social criticism. Business Ethics Quarterly, 15(3): 475-498.

Sonenshein, S. 2007. The role of construction, intuition, and justification in responding to ethical issues at work: The sensemaking-intuition model. Academy of Management Review, 32(4): 1022-1040.

Sprigge, T.L.S. 1988. The rational foundations of ethics. NY: Taylor and Francis Publishing.

Stanovich, K.E., \& West, R.F. 1998. Individual differences in rational thought. Journal of Experimental Psychology: General, 127: 161-188.

Stead, W. E., Worrell D. I,. \& Stead, J.G. 1990. An integrative model for understanding and managing ethical behavior in business organizations. Journal of Business Ethics, 9(3): 233-242.

Street, M., \& Street V.L. 2006. The effects of escalating commitment on ethical decisionmaking. Journal of Business Ethics, 64: 343-356. 
Stevens, B. 2008. Corporate ethical codes: Effective instruments for influencing behavior. Journal of Business Ethics, 78: 601-609.

Stevens, J.M., Steensma, H.K., Harrison, D.A., \& Cochran, P.L. 2005. Symbolic or substantive document? The influence of ethics codes on financial executives' decisions. Strategic Management Journal, 26: 181-195.

Stevens, J.P. 1980. Power of the multivariate analysis of variance test. Psychological Bulletin, 88(3): 728-737.

Tallent, S.H., \& Ryberg, R.A. 2008. Social work in the military: Ethical dilemmas and training implications. Unpublished paper available at: http://www.usafa.edu/isme/JSCOPE00/Tallant00.html

Tang, T., \& Chen, Y. 2008. Intelligence vs. wisdom: The love of money, Machiavellianism, and unethical behavior across college major and gender. Journal of Business Ethics, 82(1): 1-26.

Tang, T., Chen, Y., \& Sutarso, T. Bad apples in bad (business) barrels: The love of money, Machiavellianism, risk tolerance and unethical behavior. Management Decision, 46(2): 243-253.

Taylor, S.E. 1991. Asymmetrical effects of positive and negative events. The mobilization-minimalization hypothesis. Psychological Bulletin, 110: 67-85.

Tett, R.P., \& Burnett, D.D. 2003. A personality trait-based interactionist model of job performance. Journal of Applied Psychology, 88: 500-517.

Thoma, S.J., Narvaez, D., Rest, J., \& Derryberrry, P. 1999. Does moral judgment development reduce to political attitudes or verbal ability? Evidence using the defining issues test. Educational Psychology Review, 11: 325-341.

Trevino, L.K. 1986. Ethical decision making in organizations: A person-situation interactionist model. Academy of Management Review, 11(3): 601-617.

Trevino, L.K., Brown, M., \& Hartman, L.P. 2003k. A qualitative investigation of perceived executive ethical leadership: perceptions from inside and outside the executive suite. Human Relations, 56(1): 5-37.

Trevino, L.K. \& Youngblood, S.A. 1990. Bad apples in bad barrels: A causal analysis of ethical decision making behavior. Journal of Applied Psychology, 75(4): 378-385.

Trevino, L.K. \& Weaver, G.R. 2001. Organizational justice and ethics program 'followthrough': Influences on employees' harmful and helpful behavior. Business Ethics Quarterly, 11: 601-617. 
Trimprop, R.M. 1994. The psychology of risk taking behavior. St. Louis, MO: Elsevier Science and Technology Books.

Tsui, J. \& Windsor, C. 2001. Some cross-cultural evidence on ethical reasoning. Journal of Business Ethics, 31: 143-150.

Turner, J.H. 1997. The institutional order. New York: Addison-Wesley.

Tversky, A. 1969. Intransitivity of preferences. Psychological Review, 76: 31-48.

Tversky, A., \& Kahneman, D. 1971. Belief in the law of small numbers. Psychological Bulletin, 76: 105-110.

Tversky, A., \& Kahneman, D. 1973. Availability: A heuristic for judging frequency and probability. Cognitive Psychology, 5: 207-232.

Tversky, A., \& Kahneman, D. 1974. Judgment under uncertainty: Heuristics and biases. Science, 185: 1124-1131.

Tversky, A. \& Kahneman, D. 1981. The framing of decisions and the psychology of choice. Science, 211: 453-458.

Tversky, A \& Kahnaman, D. 1982. Judgments of and by reresentativness. In D. Kahneman \& A. Tversky (Eds.), Judgment Under Uncertainty: Heuristics and Biases. Cambridge, England: Cambridge University Press.

Valentine, S, \& Rittenburg, T. 2007. The ethical decision making of men and women: Executuves in international business situations. Journal of Business Ethics, 71(2): 125-134.

VanVoorhis, C.W., \& Morgan, B.L. Statistical rules of thumb: What we don't want to forget about sample sizes. Psi Chi Journal of Undergraduate Research, 6(4): 139141.

Volkema, R.J., \& Fleury, M.T.L. 2002. Alternative negotiating conditions and the choice of negotiating tactics: A cross-cultural comparison. Journal of Business Ethics, 36(4): 381-398.

Volz, K.G. \& Von Cramon, D.Y. 2008. Can neuroscience tell a story about intuition. In H. Plessner, C. Betsch \& T. Betsch (Eds.), Intuition in Judgment and Decision Making: 71-83. New York: Laurence Earlbaum Associates/Taylor \& Francis Group. 
von Neumann, J., \& Morgenstern, O. 1947. Theory of games and economic behavior. Princeton, NJ: Princeton University Press.

Wagner, S.C., \& Sanders, G.L. 2001. Considerations in ethical decision-making and software piracy. Journal of Business Ethics, 29(1/2): 161-167.

Weaver G., Trevino L., \& Cochran L. 1999b. Corporate ethics practices in the mid-1990's: an empirical study of the Fortune 1000. Journal of Business Ethics, 18: 283-294.

Weber, E.U., \& Lindemann, P.G. 2008. From intuition to analysis: Making decisions with your head, your heart, or by the book. In H. Plessner, C. Betsch \& T. Betsch (Eds.), Intuition in Judgment and Decision Making: 191-207. New York: Laurence Earlbaum Associates/Taylor \& Francis Group.

Weber, J. 1990. Managers' moral reasoning: Assessing their responses to three moral dilemmas. Human Relations, 43: 687-702.

Weber, J. \& Seger, J.E. 2002. Influences upon organizational ethical subclimates: A replication study of a single firm at two points in time. Journal of Business Ethics, 41(1/2): 69-84.

Watson, D., Clark, L.A., \& Tellegen, A. 1988. Development and validation of brief measures of positive and negative affect: The PANAS scale. Journal of Personality and Social Psychology, 54: 1063-1070.

Weick, K.E. 1995. Sensemaking in organizations. Thousand Oaks, CA: Sage.

Weiss, H.M., \& Cropanzano, R. 1996. Affective events theory: A theoretical discussion of the structure, causes and consequences of affective experiences at work. Research in Organizational Behavior, 18: 1-74.

Westermann, R., Spies, K., Stahl, G., \& Hesse, F.W. 1996. Relative effectiveness and validity of mood induction procedures: A meta analysis. European Journal of Social Psychology, 26: 557-580.

Whipple, T. W., \& Swords, D.F. 1992. Business ethics judgments: A cross-cultural comparison. Journal of Business Ethics, 11(9): 671-678.

White, K.D., Ashton, R., \& Brown, R.M.D. 1977. Imagery assessment: a survey of self report measures. Journal of Mental Imagery, 1: 145-170.

Wilson, D.S., Near, D., \& Miller, R.R. 1996. Machiavellianism: A synthesis of evolutionary and psychological literatures. Psychological Bulletin, 119: 285-299. 
World Values Study Group. 2000. World values surveys and European values surveys, 1981-1984; 1990-1993; 1995-1997; and 1999-2000. Ann Arbor, MI: InterUniversity Consortium for Political and Social Research.

Yanko, J. \& Epstein, S. 1999. Compromises between experiential and rational processing as a function of age-level. Unpublished raw data.

Zatorre, R. \& Halpern, A.R. 1993. Effect of unilateral temporal-lobe excision on perception and imagery of songs. Neuropsychologia, 21: 221-223. 


\section{BIOGRAPHICAL INFORMATION}

James R. Guzak received his Bachelor of Science in Business Administration from the University of Nebraska in 1974. He received his Master of Business Administration in 1975 from the University of Nebraska. He received a Master of Management from the University of Dallas in 2003. After school at Nebraska in 1976 he entered the United States Navy as an officer for three years then entered the private business sector with positions in the grocery, packaging, telecommunications and e-commerce industries. He entered the Doctorate program in Management at the University of Texas at Arlington in 2005 and received his $\mathrm{PhD}$ from that institution in 2009. 